\title{
Totum ex Parte
}

By

Patricia Salik, B.A.S.

A Thesis submitted to

The Faculty of Graduate Studies

In partial fulfillment for the degree of

Master of Architecture

Carleton University

Ottawa, Ontario

October 3, 2005

C) Copyright

2005, Patricia Salik 


\section{Abstract}

The chiasm is the reflection of the fantasy, the repetition which turns the game into a ritual, the sign into language and reality into the real. This mirror turns seeing into being seen. The original subject is contained by the reflected object through this superimposition without transparency. Therefore, the mirror makes the invisible visible.

The task of the architect is to "make visible that which is invisible." The architect makes the mirror in which man can view his body; can see his self. Architecture, therefore, is the body. For it is only through the body, that one can perceive it.

The fantastic body reflected by the chiasm (architecture) is infinite; like a set of mirrors opposite one another. The reflection is significant through the coincident moment it invents. Architecture stages the coincidence in which the original is contained by the copy. Therefore, architecture is an allegory for the universe; the whole is contained by the part.

\footnotetext{
${ }^{1}$ Marco Frascari, Monsters of Architecture: Anthropomorphism in Architectural Theory, (Savage, MD.: Rowman \& Littlefield, 1990) 4.
} 
Thanks to my parents for their lore and support. To Chiara

for questions and reassurances. To shaun for everything and nothing.

Finally, to Borges, who I saw in the mirror this morning.

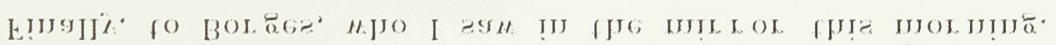

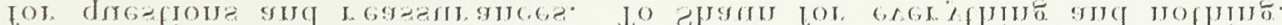

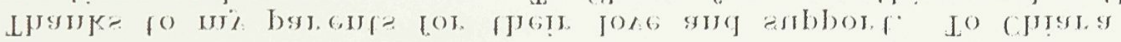




\section{Outline}

LIST OF ILLUSTRATIONS

LIST OF APPENDICES

$v i$

INTRODUCTION 1

CHAPTER 1: THE RHETORICAL FIGURE

1.1 Figures of Speech 6

$\begin{array}{ll}\text { 1.1.1 Figures of Repetition } & 7\end{array}$

$\begin{array}{ll}\text { 1.1.2 Figures of Omission and Emphasis } & 10\end{array}$

1.1.3 Semantic Inversion $\quad 12$

1.1.4 Figures of Resemblance or Relationship 13

CHAPTER 2: BORGES' METAPHYSICAL FICTIONS

2.1 Fictions of Time:

2.1.1 Borges: "The Garden of Forking Paths" 17

2.1.2 Borges: "The Immortals" 25

2.2 Fictions of Self:

2.2.1 Borges: "The Approach to al-Mu'tasim" 33

2.3 Fictions of Knowledge:

2.3.1 Borges: "Tlön, Uqbar, Orbis Tertius"

2.4 Fictions of the Universe:

The Kabbalah 48

2.4.1 Borges: "The Library of Babel" $\quad 49$

2.4.2 Borges: "The Aleph" 53

2.4.3 Borges: "The God's Script"

CHAPTER 3: THE EUROPEAN UNION

3.1.1 Program 66

3.2 Project: The Delegation for the Commission of the European Union 70

$\begin{array}{ll}3.2 .1 \text { Site } & 70 \\ 3.2 .2 \text { Process } & 71\end{array}$

$\begin{array}{ll}3.2 .2 \text { Process } & 76\end{array}$

CHAPTER 4: DEVIANTS

4.1 Thesis Intention 81

4.2 Four Deviant Characters:

$\begin{array}{ll}\text { 4.1.1 Time and Eternity: "The Chelephant" } & 82 \\ 4.1 .2 & 83\end{array}$

$\begin{array}{ll}\text { 4.1.2 The Twin Self: The Dioscuri and Gemini } & 83 \\ \text { 4.1.3 Knowledge: Medea } & 85\end{array}$

4.1.4 Space: Contiguity and Cannibalism $\quad 87$

4.3 Process

89 
$\begin{array}{ll}\text { Figure 1. Chi } & 8\end{array}$

$\begin{array}{ll}\text { Figure 2. Polyptoton } & 23\end{array}$

Figure 3. Ascending Descent 25

Figure 4. Paralypsis $\quad 38$

Figure 5. Paradox $\quad 45$

Figure 6. Site Montage $\quad 70$

Figure 7. Site Map $\quad 70$

$\begin{array}{ll}\text { Figure 8. Areal Photo } & 70\end{array}$

Figure 9. The chiasm 71

$\begin{array}{ll}\text { Figure 10. Paralypsis } & 72\end{array}$

$\begin{array}{ll}\text { Figure 11. Division } & 73\end{array}$

Figure 12. Map 74

$\begin{array}{ll}\text { Figure 13. Sequence } & 75\end{array}$

Figure 14. Interior Perspective $\quad 76$

Figure 15. Sequence: whole to part 76

Figure 16. Program Organization $\quad$ 77-79

Figure 17. Site Plan $\quad 80$

Figure 18. Site Perspective $\quad 80$

Figure 19. Paintings 90

Figure 20. Constructions and Collages 92 
Appendix-1. Entrance Pavilion $\quad 96$

$\begin{array}{ll}\text { Appendix-2. Security Pavilion } & 97\end{array}$

$\begin{array}{lr}\text { Appendix-3. Political and Public Affairs } & 98\end{array}$

$\begin{array}{ll}\text { Appendix-4. Gallery/Events } & 99\end{array}$

$\begin{array}{ll}\text { Appendix-5. Theatre/Conference Pavilion } & 100\end{array}$

$\begin{array}{ll}\text { Appendix-6. Economic Affairs } & 101\end{array}$

Appendix- 7. Research Pavilion 102

$\begin{array}{ll}\text { Appendix-8. Ambassadorial Pavilion } & 103\end{array}$

$\begin{array}{ll}\text { Appendix- 9. Matrix 104-105 } & \text { 105 }\end{array}$

Appendix- 10. Paralypsis 106

$\begin{array}{ll}\text { Appendix- 11. Chiasm } & 107\end{array}$

Appendix- 12. Cube Plans and Section 108

$\begin{array}{lr}\text { Appendix- 13.Process Work } & 109\end{array}$

$\begin{array}{ll}\text { Appendix- 14. Chelephant Construction } & 110\end{array}$

Appendix- 15. Chelephant Paninting 111

Appendix- 16. Gemini Construction 112

Appendix- 17. Gemini Painting 113

Appendix- 18. Medea Collage 114

Appendix- 19. Medea Painting 115

Appendix- 20. Cannibal Construction $\quad 116$

Appendix- 21. Cannibal Painting 117 


\section{Totum ex parte}

\section{$\underline{\text { Introduction }}$}

"This map, in such a case, should contain a map of the map, which should contain a map of the map of the map, and so on to infinity."

"Even the articulate or brutal sounds of the globe must be all so many languages and ciphers that somewhere have their corresponding keys-have their own grammar and syntax; and thus the least things in the universe must be secret mirrors to the greatest."

In literature the rhetorical figure shapes words. In architecture, the figure is an operation which shapes an object. ${ }^{3}$ This act of shaping leaves a mark. The mark, a trace of the process, signifies the figure and the object marked by the trace signifies the operation. The resultant is an object that contains its subject.

The reverberation between architecture as subject and architecture as object is an exchange which enfolds an imagined unity. The object which contains its subject links subjects to objects infinitely upward and downward until all is connected. The smallest thing imaginable is connected to the unimaginable. The particular is connected to the universal. As such, the particular architectural resultant of the exchange becomes an allegory for the universe. ${ }^{4}$

The term "universe" comes from the combination of the Latin terms unis, meaning "one," and versus, meaning "turning." The unity, the "oneness," of the universe

${ }^{1}$ Jorge Luis Borges, "Partial Magic in the Quixote," Labyrinths, Selected Stories and Other Writings, trans. James E. Irby, (New York: New Directions, 1964) 196.

2 Jorge Luis Borges, "Mirror of Enigmas," Labyrinths, Selected Stories and Other Writings, trans. James E. Irby, (New York: New Directions, 1964) 209.

${ }^{3}$ Judith Wolin, "The Rhetorical Question." VIA 8 (1986) : 29.

4 “...the history of the universe is an infinite sacred book that all men write and read and try to understand, and in which they are also written." Borges, "Partial Magic in the Quixote," Labyrinths, 196. 
is achieved by the action of one turn or rotation. The physical changes that take place in one rotation are unified by the cycle (time), not by any physical or visible attribute. Similarly, a turn in significance is called a "trope."

The term trope is a derivative of the Latin word tropus, meaning "turn." A trope is a figure of speech, an operation of language. The operation creates a change in meaning. The turn leaves a trace of the change on the operand.

While the trope is a change in significance, the scheme is a change in arrangement. These figures of speech can initiate self-referential actions of exchange that embed the object they disrupt with universal significance. The potential for particular objects to become signifiers of the universe will be explored in this thesis. Three tropes and one scheme will organize this exploration.

The scheme is a chiasmus, revealed by the actions of anaphora and polyptoton. The tropes are (1) paralypsis, also called preterition, (2) paradox, and (3) synecdoche. The tropes and schemes will be a vehicle by which to explore the unity inspired by changes or disruptions that link architecture to the universe.

The four figures of speech are the lens by which the thesis' architectural proposition will take shape. The chiasmus is defined as "a balancing pattern in which the second part of a line reverses and balances the words in the first part." ${ }^{, 5}$ A paralypsis is a pretended omission for emphasis. A paradox seems contradictory but is true. Lastly, synecdoche is a figure in which the part stands for the whole, and vice versa. The implications on architecture through the disruptions of these terms will be further explored through an analysis of their operation within the fictions of Jorge Luis Borges.

5 “Chiasmus," Dictionary of Literary Terms, (Toronto: Coles, 2005) 39. 
In Borges' fictions, grammar points to the trace of the action of the figure. The figure marked the fiction during its construction and is present in the syntax. The mark is the particular key which structures the reading of Borges' fictions. The key to the fictions has implications beyond its own limits. The key indicates the four questions of metaphysics that are at the core of Borges' intention. This intention will be transposed into an exploration of deviants.

Deviants, like rhetorical figures, are a disruption. "Deviant" shares the etymological origin of "deviate" in the Latin deviat and French deviare, meaning "depart from the way." "Turn" is a synonym for deviate. Therefore, the deviant, like the trope, is a figure which creates a change and signifies the action.

Deviants will embody the exploration of four metaphysical questions. They are: the problematical nature of time, the self, of knowledge and of the world. ${ }^{6}$ Correspondingly, four deviant characters were designed as avatars of this exploration, they are; "The Chelephant", Gemini, Medea and the Cannibal. Through their nature as "doubles," the deviants embody Borges' metaphysical question of the self.

"The Chelephant" is "a garment without seams." This character embodies the horizon through questioning the boundary between life and death. Gemini is the unity created by the dichotomy of presence and absence. Medea is a life-giver and a life-taker. She is the container of the natural and the unnatural, and an object which contains its subject. Lastly, the Cannibal is one and all.

\footnotetext{
${ }^{6}$ James E. Irby, Introduction Labyrinths, Selected Stories and Other Writings, (New York: New Directions, 1964) xviii.

${ }^{7}$ Warren Kenton, Adam and the Kabbalistic Tree, (London: Rider, 1974) 19.
} 
The deviant turns perspective; the subjective double is contained inside the objective union. The consequent union, in turn, re-interprets the deviant. The European Union is a political entity that embodies the turn created by the deviant because it too is contained by its creator; the member nation-states, because it becomes their maker.

The European Union is the intention of the nations of the European continent. The constitution is written by those members. The made, the E.U., contains the making; the writing of the constitution. However, the E.U. inverts the relationship between the made and the maker. It is made by the member states, yet the Union re-writes the notion of a nation. Therefore, the Union; the made, becomes the maker.

Through a speculative design proposal of an embassy for the European Union the potential for the E.U as a totem ex parte [whole in the part] will be explored. Specifically, how it becomes a part which contains its whole, how the made becomes the maker. The following chapters will construct the framework by which to view the Union. The framework is based in the structure of language, specifically in the figure of the chiasm. 


\section{The Rhetorical Figure}

\section{Introduction}

“... architecture as 'writing' as opposed to architecture as image.",

In literature, the rhetorical figure shapes words to communicate the excess of the evidence. $^{2}$ In architecture, the figure can inscribe the excess of the object; the act of making. It is possible to mark the architecture with the act because the figure is not a thing in itself, but an "operation." 3 Consequently, the work can be read as a process rather than an end, or as writing rather than an image. ${ }^{4}$

The value of the rhetorical figure in architecture is that the inscription of the act on the object creates a turn in perspective which inverts the relationship of the made to the maker. The made object which contains the subjective act of making becomes the reinterpretation of the figure. As such it is a figure in itself. It can convey a message and inspire another act, it is therefore simultaneously made and maker.

The reading of the figure in the work gives value to architecture itself, not in reference to something else. As such, it can communicate its own "truths," and

${ }^{1}$ Eisenman, Peter, "The End of the Classical: The End of the Beginning, the End of the End." Architecture Theory Since 1968. (Cambridge/London: MIT, 1998) 533.

${ }^{2}$ Wolin, 17.

3،... rather than see a figure as a thing, we should understand it to be an operation, a way of forming material, a process of assembling elements of language, without which only literal statements would be possible." Ibid, 29.

${ }^{4}$ Eisenman, 533.

5 "...Vico began a comparison of "study methods" that showed the "topical wisdom" of rhetoric to be uniquely capable of revealing humanistic wisdom." Donald Kunze and Wesley Wei. "The Vanity of Architecture: Topical Thinking and the Practice of Discontinuity." VIA 8 (1986) : 57. 
"humanistic truths." This clarity of the excess, or the figure, acts in the manner that myths do in primitive cultures. Just as a metaphor may link a culture to the cosmos, the figure links the particular to the universal.

\section{$\underline{1.1 \text { Figures of Speech }}$}

In her essay entitled "The Rhetorical Question," Judith Wolin argues that figures of speech are organized into five categories. ${ }^{6}$ They are: (1) Figures of Repetition and Regularity; (2) Figures of Resemblance or Relationship; (3) Figures of Emphasis or Understatement; (4) Figures of Overlay, Displacement, or Disruption; and (5) Intentional Errors. However, in the following argument, the fourth: Figures of Overlay, Displacement, or Disruption, is a subcategory of the first three. Furthermore, "Intentional Errors," can be added to this group.

The acts of disruption on the rhetorical figures, such as displacements and intentional errors, can be divided into two categories as outlined by Donald Kunze and Wesley Wei in "The Vanity of Architecture: Topical Thinking and the Practice of Discontinuity." These subcategories are Substitutions and Exchanges. ${ }^{7}$ The distinction between the two is integral in reference to architecture. The first type of disruption links two external bodies and transmits significance in a substitutive way. In contrast, the second type of disruption involves an imagined whole whose referent is itself. This is called an exchange.

\footnotetext{
${ }^{6}$ Wolin, 17.

${ }^{7}$ Donald Kunze and Wesley Wei, 61-62.
} 
An analysis of the four categories of figures and their division into types of disruptive acts is intended to differentiate between these figures of change. The first type of disruption is a figure of juxtaposition which points to meaning elsewhere. ${ }^{8}$ The second type of disruption inspires an architecture which is an allegory for the universe and is significant in itself. Furthermore, two types of figures of speech will be analyzed here; tropes and schemes. The trope is a "turn" in significance, whereas a scheme is a change in arrangement.

In the first category (figures of repetition) the schema chiasmus will be contrasted against schema anaphora. In the second (figures of omission and emphasis) the tropes preterition and meiosis will be analyzed. In the third the tropes paradox and oxymoron will emphasize the difference in the category of semantic inversions. Finally, relationships will be compared in the tropes synecdoche and simile.

\subsubsection{Figures of Repetition}

\section{Scheme: Chiamus and Anaphora}

The chiasmus is a figure of speech known as a scheme. A scheme is a change in arrangement. The chiasmus changes the "narrative direction... [as] in a palindrome." "Anna" is a palindrome. ${ }^{10}$

The most common form of the chiasm is in the transformation of the repetitive $\mathrm{ABAB}$ rhythm to ABBA. For example, "dark as night, night is dark" is a chiasm in the narrow sense. In the broader sense, John F. Kennedy's 1961 Inaugural Address contains

\footnotetext{
${ }^{8}$ Donald Kunze and Wesley Wei, 61.

${ }^{9}$ Wikipedia,1 Sept $(2005)<\mathrm{http} / / /$ en.wikipedia.org/wiki/Chi $>$

10 “Palindrome," Microsoft Encarta College Dictionary, 2001
} 
the chiasmic structure in the statement "...ask not what your country can do for you ask what you can do for your country." ${ }^{11}$ The scheme's action potential originates in the Greek letter from which it derives.

The chiasmus derives from the Greek letter chi which is represented by the shape $\mathrm{X}$. Each of the two lines crossed in the letter X are denoted by the letters $\mathrm{A}$ and $\mathrm{B}$, respectively. The ends or tips of each line crossed are labelled with the corresponding letter. The reading of the image of the labelled letter, from left to right and top to bottom as

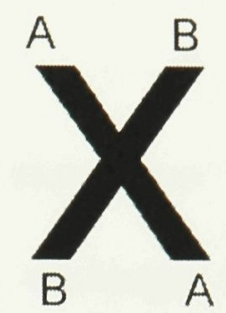

Figure 1. Chi in western tradition, presents the rhythm ABBA.

The change or reversal caused by the chiasmus to a chronology such as $\mathrm{AB}$, or $\mathrm{ABCD}$, creates an exchange that places the entire journey in a moment of crisis or climax. ABCD becomes ABCDCBA. This arrangement of the chiasmus is the mode of action for Italo Calvino's Invisible Cities [1.2.1.3.2.1.4.3.2.1.5.4.3.2.1... 5.4.3.2.5.4.3.5.4.5.]. ${ }^{12}$ The patter begins sequentlially, however it is rising as it falls. 1 , 2.1, 3.2.1...etc. The first term of each group is related to the others chronologically, however, each group represents a descent in itself. The significance of the chiasmus in this example is not in the act of inversion but in patterning the action of ascending descent, which "converts the unknown to the known." 13

${ }^{11}$ Wikipedia,1 Sept (2005) <http://en.wikipedia.org/wiki/Chi>

${ }^{12}$ David Sheridan, "The End of the World: Closure in the Fantasies of Borges, Calvino, and Millhauser. Contributions to the Study of World Literature. 118 (2003) : 17.

13 "The essence of the chi is expressed as a discontinuity leading to a collapse of space-extension reduced to a point, time to eternity. This $\mathrm{V}$ of ascent and descent, the katabasis, defines the chi, by converting the unknown to the know, going down to going up, losing with "seeing again,..." Kunze and Wei, 66. 
The chiasmatic action arranges the repetition of terms in such a way that places the entire journey in a constant moment of crisis. This moment is called kairos. ${ }^{14}$ In contrast, chronos, the chronological journey, progresses from beginning to end without significance or pattern. The chiasmus, through an inversion, creates significance in a vaired pattern of repetition.

The schema anaphora, a device of repetition where the same expression is repeated at the beginning of successive clauses, ${ }^{15}$ fails to create an exchange in significance. This scheme is a substitution. A substitution is an "indicative gesture" that points or grasps "at a distance." " The phrase "...I shall be No One, like Ulyssess; shortly, I shall be all men; I shall be dead" ${ }^{\prime 17}$ is ordered through the grammatical connection of the place holder. "I shall" acts as a place holder in the arrangement, which has no significance. Its reason for being is only to define a pattern that is linear and successive. It marks successive beginnings.

The two schemes defined here, the chiasmus and the anaphora, reveal the distinction between the two types of disruptive figures of speech. The chiasm is a disruption that creates an exchange between the terms. ${ }^{18}$ The inversion in the sequence of ascent in Calvino's chiasmus arranges the pattern in an ascending descent. The result,

${ }^{14}$ Sheridan, 13-19.

15 “Anaphora," Microsoft Encarta College Dictionary, 2001.

${ }^{16}$ Kunze and Wei, 57.

${ }^{17}$ Jorge Luis Borges, "The Immortal," Labyrinths, Selected Stories and Other Writings, trans. James E. Irby, (New York: New Directions, 1964) 118.

18 "A linear sequence "transcends itself" without departing from its narrative medium; the text works "mimetically" to produce spatial and semantic structures that enact the universal space it describes." Kunze and Wei 66. 
therefore, is a pattern that replaces order with significance and through coincident terms reveals the invisible.

The schema anaphora, however, is an organization of terms in a pattern; one that lacks significance. Therefore it must seek significance through an external referent. In a later analysis, it will be shown how Jorge Luis Borges uses the anaphora to reveal the structure of the chiasm within.

\subsubsection{Figures of Omission and Emphasis}

"In a riddle whose answer is chess, what is the only prohibited word?"19

"In aposiopesis, the meaning of the unspoken part of the speech must be supplied enthymemicly by the audience. This division of speech into spoken and silent parts... Castor and Pollux. "20

\section{Trope: Paralypsis and Meiosis}

A paralypsis is a rhetorical figure where one emphasises something by pretending not to mention it. Like ellipsis[...], paralypsis means "omission." However, the prefix para means "beside" in Greek. The paralypsis is an ommission which is grammatically present during the ommission. Paralypsis is the presence of an alternative.

The presence of the ellipsis is in the form of punctuation [...], whereas the presence of paralypsis is grammatical. For example, "not to mention" is a paralypsis. The statement communicates the omission semantically, yet it is present in grammatical terms. The paralypsis is the presence of an alternative grammatical term that communicates the omission for emphasis.

19 Jorge Luis Borges, "The Garden of Forking Paths," Labyrinths, Selected Stories and Other Writings, trans. Donald A. Yates, (New York: New Directions, 1964), 27.

20 Wikipedia,1 Sept (2005) < http://en.wikipedia.org/wiki/Praeteritio>. 
Likewise, this figure is also known as preterition. The prefix preter, meaning "beyond," comes from the Latin root prae, which means "before."21 The etymology of the term reveals its significance as a boundary between past and future tenses. Preterition refers to a past that was never present, like a reflection.

The trope; paeteritio, or preterition, is defined as the pretended omission for rhetorical effect. The notion that the omission is "pretended" is the distinction between preterition or paralypsis and ellipsis. The preterition draws attention to something while pretending to pass over it. This action is an exchange between the present term and the absent term. ${ }^{22}$

The exchange links the past and the future in an imagined whole. The whole is formed by the exchange in which both signifier and signified are altered. It "...involves a logic of poetic balance." ${ }^{23}$ The exchange is reciprocal.

In contrast to the imagined unity of the two internal terms of the self-referential preterition, meiosis is a disruption that refers to an external referent. The intention of this figure is to emphasize. ${ }^{24}$ However, unlike the balanced exchange of significance between the present and absent terms of the preterition, the meiotic trope substitutes meaning for rhetoric effect.

The meiotic trope is substitutive. The substitution of two terms draws on their relationship to transfer characteristics. For example, after having all his limbs amputated, the Black Knight in "Monty Python's Search for the Holy Grail" calls his wounds "just a

21 "Preterition," Microsoft Encarta College Dictionary, 2001

22 "The parasite becomes the hero and the pariah of the world." Kunze and Wei, 67.

${ }^{23}$ Kunze and Wei, 67.

24 “Meiosis," Dictionary of Literary Terms, (Toronto: Coles, 2005), 116. 
flesh wound." ${ }^{25}$ The scale of the wound is lowered by refering to something outside of it, a different type of wound. In meiosis, one term points to another, an external referent, to transfer meaning.

\subsubsection{Semantic Inversion}

Trope: Paradox and Oxymoron

"In my beginning is my end..." "In my end is my beginning. ",26

Russell's paradox: Does the set of all those sets that do not contain themselves contain itself?

Russell's paradox questions the boundary between the container and the contained. The container is the object which contains the subject. The object is the made result of the subjective act and is marked by the act. The made contains the making.

Through the mediator; making, the relationship between the made and the maker can be inverted. The made is a reinterpretation of the intention of the maker. Because the reinterpretation is an action (it contains the action) it too can inspire the making of another object. The object is simultaneously the made, and its inverse; the maker.

Paradox is a self-referential trope that has the potential for self-reversal. The inversion allows the two terms, in this case the container and the contained, to be seen as an imaginary whole. By questioning the boundary between object and subject this trope creates a turn in perspective.

${ }^{25}$ Meiosis," Dictionary of Literary Terms, (Toronto: Coles, 2005), 116.

26 T.S. Elliot, "East Coker-1940," Collected Poems 1909-1962, (London: Faber and Faber, 1963) 196-197. 
Similarly, an oxymoron is a contradiction of terms; however, those terms are juxtaposed. For example, "beggarly riches" is an oxymoron. ${ }^{27}$ This juxtaposition of the opposites; rich and poor, creates a substitution of meaning. The qualities of one term are applied to the other.

An oxymoron is a disruption that references an external term. The substitutive act has value only for that particular instance. This is a consequence of juxtaposing opposite terms; they refer only to one another. The act is substitutive.

The paradox, in contrast, is significant in a larger context. The imagined whole within the paradoxical contradiction allows for a transition from the realm of the particular to the universal. The transition is a consequence of the reciprocal exchange between terms. The paradox creates this self-reversing exchange.

\subsubsection{Figures of Resemblance or Relationship}

\section{Trope: Synecdoche and Simile}

Synecdoche is similar to metonymy and often referred to as a type of metonymy. They are distinct, however, in that synecdoche is a type of exchange relationship and metonymy is a relationship of substitution. Metonymy comes from the combination of the Greek prefix meta meaning "after/later" and onoma which means name. It is a substitution of associated terms.

The confusion between metonymy and synecdoche is presented in the following example. If Crown is substituted for the Kingdom and not specifically the King then it is an example of metonymy. Metonymy is the act of substituting a singular characteristic for

\footnotetext{
${ }^{27}$ Wikipedia,1 Sept (2005) <http://en.wikipedia.org/wiki/Oxymoron>.
} 
a sum. The substituted term is not necessarily a part of that sum, or whole. If it were, it would be an example of synecdoche.

Synecdoche acts through the relationship between a part and a whole. One can stand for the other because both belong to the same imagined whole. An example of synecdoche is the use of flame to communicate fire. This relationship is reciprocal because every flame is and contains fire and fire can also stand for the flame. ${ }^{28}$ Synecdoche creates an imagined unity around the terms because it is a figure of exchange that moves from the particular to the universal, and vice versa.

Likewise, a simile is a figure of association, a disruption that links terms based on a shared quality or characteristic. The simile juxtaposes two like terms. For example, the intention of the simile; love is like a rollercoaster, is to link the qualities of a rollercoaster to define love. It is indicative. ${ }^{29}$ This linking is unidirectional; it points to another and as such it lacks the potential to communicate more than the particulars of the case.

The inversion of the universal and the particular is the key aspect of reciprocal disruption. Reciprocity is a reverberation that creates a new space of significance. ${ }^{30}$ This space is lacking in figures of resemblance, such as a simile. In synecdoche, however, the imagined unity allows the reverberation between terms to reveal a connection between this imagined whole and the universal whole.

${ }^{28}$ Marcel Mauss, A General Theory of Magic, (London: Routledge, 1972) 80.

${ }^{29}$ Kunze and Wei, 58-60.

30 "..reversed antinomasia" had the ability of discovering humanistic truth by projecting a space-in this case a spiral form where each age "enclosed" the last by appropriating its forms for new uses-and by then threading that space "hypotactically," as a means of discovering humanistic truths through anthropological evidence." Kunze and Wei, 62. 


\section{$\underline{\text { Conclusion }}$}

The two types of disruptive actions of the figures are self-referential types and a juxtaposition that points to an external referent. The disruption of exchange is self contained in that its terms form an imagined union. The substitutive disruption lacks the necessary resonance between the terms to achieve unity. The unity, however, enables the self-referentail union of terms to have a significance; externally and universally. The reciprocity of the union inverts the particular and the universal.

The consequence of the disruption which inspires an exchange is an inversion of terms. The terms of the union are not only parts of the imagined whole, they are also wholes in themselves. This whole, an object which contains its subject (the parts of its making) inverts the perspective of the made object. This made becomes the maker.

The made is a reinterpretation or "copy" of the original intention and contains that intention; the subject. This intention has the potential to inspire another creation. The made, therefore, becomes the maker. The inversion which occurs between the made and the maker is a relationship of synecdoche. It will continue infinitely until the most minute part is connected to the vast cosmos, until the particular is an allegory for the universe.

This analysis of rhetorical figures will serve as the framework by which to read Jorge Luis Borges's work. Borges's fictions, however, do not explicitly communicate these figures in his texts. The fictions do, however, grammatically point to the trace left by the operation through their creation. The grammar and syntax are separate and distinct parts. The intention of the text is found in the information these terms exchange. 


\section{Borges' Metaphysical Fictions}

\section{$\underline{\text { Introduction }}$}

The four reoccurring themes of Jorge Luis Borges' fictions are the metaphysical questions of time, the self, knowledge and the universe. The fictions examine theories surrounding each question and then realize those theories in the context of fiction. The isolation of fiction, Borges maintains, allows the reader to be critical of assumed reality; guided by norms, givens and so called "truths." For example, Borges molds the planet Tlön around Bishop Berkeley's notion of Idealism in "Tlön, Uqbar, Orbis Tertius." These fantastic situations are not the product of Borges' wild imagination, but are rigorously constructed representations of the abstract notions of time, the self, religion, philosophy, and the universe.

Each fiction uses a rhetorical device to reveal the fictivness of reality, however, this device is not intended to order the grammatical structure of Borges' fictions. Its appearance grammatically reveals the constructive operation on the fictions' syntactical structure. The figure orders the creation of the fiction, therefore, its trace remains within the work. Like the "work of art [which] does not obliterate the traces of its own createdness," Borges' fictions reveal the constructing work on the work constructed.

In some cases, as a consequence of the translation of Borges' works from Spanish to English, the figure and the trace of its making have been lost. However, in those fictions translated by Norman Thomas de Giovanni, (who worked with Borges on the translations), the trace of the device is present. Moreover, in the following analysis, where the text was translated by someone other than di Giovanni, the device is revealed

${ }^{1}$ Véronique Fóti, "Turning at the Limits of Closure," Philosophy Today, Winter 1996: 309. 
grammatically. For example in "Tlön, Uqbar, Orbis Tertius," the figure is contained within the numerical terms of a paradox. In the case of "The Garden of Forking Paths," and "The Immortals," di Giovanni was not the translator. I would argue that because the device is contained within an anaphora; its grammatical significance is translatable. ${ }^{2}$ In reference to the pattern of the syntax, which would have to be intentionally structured, I have analysed multiple translations and a case could be made that the pattern revealed in these multiple translations are a coincidence. ${ }^{3}$ Borges would argue, however, that the coincidence reveals "a secret plan... a subtle kind of pattern..."4

The patterns revealed in the syntactical structures of Borges' fictions coincide with the intention of the plot. The harmonious exchange of information between the two levels creates a unity around each fiction. Each is a whole made of parts which are involved in an action of reciprocity. The part are wholes in themselves in that each present one of the four metaphysical questions.

\section{$\underline{2.1 \text { Fictions of Time }}$}

\subsubsection{Borges: "The Garden of Forking Paths"}

Borges" "The Garden of Forking Paths" is written as a detective story and professes to achieve bifurcated time. It is written as a linear sequence of events and contains a story that reveals all possibilities of time simultaneously. The chronos and

${ }^{2}$ A device of repetition in which the same expression is repeated at the beginning of successive clauses. "Anaphora," Microsoft Encarta College Dictionary, 2001.

3 "Two is a mere coincidence; three, a confirmation... a divine confirmation." Jorge Luis Borges, "Blindness," Jorge Luis Borges: Selected Non-Fictions, trans. Eliot Weinberger, (New York: Penguin, 2000) 476 .

${ }^{4}$ Richard Burgin, Conversations with Jorge Luis Borges, (New York: Avon, 1969) 125-126.

${ }^{6}$ Sheridan, 10 . 
chaos of "The Garden of Forking Paths" join to reveal the synchronous kairos. ${ }^{6}$ The opposites cancel each other out and at the same time create a significant and varied pattern in time.

The goal oriented assignment of $\mathrm{Yu}$ Tsun (the narrator and the protagonist of the story) and the illusion of a multi-verse presented by his great-grandfather Ts'ui Pen create the tension between the two versions of time. Yu Tsun recounts his journey during the war and includes within it Ts'ui Pen's story as interpreted by Albert, a signologist. Ts'ui Pen's fiction presents all possible outcomes. His intention is to represent the bifurcation of time. This intention, though alluded to, is not carried out.

Ts'ui Pen's story is structured sequentially, despite that it describes the opposite; bifurcating time. The multiple possibilities are divided into chapters so the events do not occur simultaneously. Borges' intention, therefore, is to reveal that the bifurcation of time is impossible, and linear time is an illusion. However, within the structure of this text which reverberates in tension between these two poles, a third notion of time is presented. A varied pattern links synchronous events in time. ${ }^{7}$ In this case, the pattern is structured by the disruption of the polyptoton. Like the chiasmus, the polyptoton is a disruptive figure of exchange. It structures time through links of significance, not through a linear sequence or simultaneity.

In a Borgesian fiction, a coincidence is the sign of a synchronous convergence of time. This event linked by meaning, rather than a chronological time line, reveals that time is cyclical. Time is cyclically infinite and its possibilities are finite, therefore, events are destined to repeat. The serendipitous convergence of two events that are

\footnotetext{
${ }^{7}$ Sheridan, 11.
} 
linked in significance, form a coincidence. This coincidence denies succession and coexistence.

The coincidence involving Albert and Yu's meeting is an example of this affirmation of time cyclically repeating. Yu went to Albert in order to signal to his German Chief the location of the British artillery park, by the name of the city; Albert. He found the corresponding name randomly; in a phone book. Coincidently, Albert was translating Yu's great-grandfathers' labyrinthine story and clearing the tarnished name of Yu's family.

In murdering Albert the sinologist, Yu would send a signal to his Chief. However, Yu would also be preventing Albert from publishing his research on Ts'ui Pen, Yu's great-grandfather. The meeting is significant because the coincidence made Yu's decision to murder Albert more difficult. The choice would prove Borges' notion of a varied pattern in time.

If $\mathrm{Yu}$ chose to kill Albert he would prove to his racist Chief that a "yellow man could save his armies." ${ }^{\prime 8}$ If he let Albert live, he would clear his families' tarnished reputation. ${ }^{9}$ Yu chose his species over his family. His choice of the universal, however, includes the particular.

Yu has remorse regarding the choice of his species, the "yellow race," over his familial lineage. However, he recognizes that his ancestors are not only his greatgrandfather, but his entire race. He says:

\footnotetext{
${ }^{8}$ Borges, "The Garden of Forking Paths," Labyrinths, 21.

${ }^{9}$ Chibka, Robert, L. "The Library of Forking Paths." Representations 56 (1996) : 115.
} 
"I did it because I sensed that the Chief somehow feared people of my race - for the innumerable ancestors who merge within me."

Yu's choice to use the term "innumerable" in the previous and following statements emphasises the significance of the choice of race over family. The previous statement occurs early on in the fiction. The repetition of the term links the first utterance to one spoken later in the fiction;

"He does not know (no one can know) my innumerable contrition and
weariness" The emphasis on the "innumerable" intends to reveal that $\mathrm{Yu}$ was aware that the whole, the species, is contained within the part; his family member, and vice versa. Therefore the decision to kill Albert was not ignorant of the reciprocal relationship of the part to the whole.

\section{Schemes: The Polyptoton in Borges" "The Garden of Forking Paths"}

"Patterns are formed through the travels in space rather than through the events unfolding on the time line..."

"The Garden of Forking Paths" denies both succession (linear time) and coexistence (bifurcating time). Borges maintains that the former is monotonous and the latter is chaos. The text's denial reveals that succession and coexistence are constructed

${ }^{10}$ Borges, "The Garden of Forking Paths," Labyrinths, 21.

${ }^{11}$ Ibid, 29.

${ }^{12}$ Sharon, Lynn Seiber, "Time, Simultaneity, and the Fantastic in the Narrative of Jorge Luis Borges.” Romance Quarterly 51.3 (2004) : 200. 
notions of time. The denial and the coincidence reveal that time is cyclical; a varied pattern of repetition. This rhythm can be found in the constructive aspect of the fiction, specifically the structure of its language. ${ }^{13}$

The rhythm of cyclically infinite time is presented in this fiction through the use of two schemes, polyptoton and anaphora. The schema polyptoton is hidden within a visible scheme anaphora. An anaphora is the repetition of a word, or group of words, at the beginning of successive phrases. The statement which precedes the narrators' reference to the "syllabic music" in "The Garden of Forking Paths" contains a schema anaphora. The statement is a meditation on the lost labyrinth of the narrators' greatgrandfather.

"Beneath English trees I meditated on that lost maze [14]: I imagined it inviolate and perfect at the secret crest of a mountain [21]; I imagined it erased by rice fields or beneath the water [16]; I imagined it infinite [8], no longer composed of octagonal kiosks and returning paths, but of rivers and provinces and kingdoms... I thought of a labyrinth of labyrinths [9], of one sinuous spreading labyrinth that would encompass the past and the future and in some way involve the stars. "14

Later in the text, the anaphora is repeated in the phrase: "I Imagined as well a Platonic $[10] \ldots, " 15$

Borges uses the anaphora, a substitutive change in arrangement, to continue his juxtaposition of chronos and chaos. However, the figure acts on the surface, in the semantic aspect of the text. It therefore, is meant to confuse the reader. It also, however,

13 "To always omit one word, to employ awkward metaphors and obvious circumlocutions, is perhaps the most emphatic way of calling attention to that world" Jorge Luis Borges, "The Garden of Forking Paths," Jorge Luis Borges: Collected Fictions. trans. Andrew Hurley, (New York: Putnam, 1998) 126.

\footnotetext{
${ }^{14}$ Borges, "The Garden of Forking Paths," Labyrinths, 23.

${ }^{15}$ Ibid, 25.
} 
places emphasis on that section. This is intentional because within this dully repetitive structure the varied pattern is hidden.

The anaphoric couple "I imagined" is repeated at the beginning of four of the phrases, while two others contain the synonyms "I meditated" and "I thought." Furthermore, the repetition of "I imagined" later in the text links it to the anaphora, structuring a pattern. It unifies the statements in which the schema polyptoton is contained.

The underlying significance of the anaphoric statement can be phonetically decoded in the manner of a polyptoton (Figure 2). The narrators' statement has a syllabic presence of $14: 21 ; 16,8,9 \ldots 10$ where punctuation creates the breaks. The schema polyptoton is an arrangement of repetition using words that derived from the same root. Therefore, it becomes apparent that the numbers are organized as $14: 21 ; 16 ; 8,9 \ldots 10$

$$
7(2: 3) ; 8(2 ; 1), 9 \ldots 10
$$

Sequence; 7,8 ,

Varied pattern; $2,3,2,1 \ldots$

Action pattern; +1 -1 -1

Sequence 9,10

Potential continued syllabic code; $9 ; 3 ; 10,5$,

$9(3 ; 1) ; 10(2 ; 1)$

Potential varied pattern; $3,1,2,1$

Potential action pattern; +2, $-2,+1,-1$

Figure 2. Polyptoton couples. They are related by derivatives. The rhythm, therefore, can be found in each component's relationship to its root. 
The first two couples are related mathematically as derivatives of the same root. The first pair derives from seven and the second from eight. The last two terms are separated in that they belong to different sentences, however they continue the ascension.

The pattern $2: 3 ; 2,1$ is revealed in the first two couples. The pattern derives from each couples' connection to the shared root. For example, fourteen and twenty-one share seven. The former term in the couple is twice seven and the latter is three times seven. Therefore, they can be represented as two and three respectively.

The varied pattern resulting from the action of the figure polyptoton has significance in meaning and not in order. The significance of this rhythm is an example of ascending descent. The roots, in order of appearance are seven, eight. The continuation of the rhythm is alluded to by the nine and later the ten. The ascension of terms is added to their alternate significance as the couples; two and three, two and one, respectively. Therefore, within what appears to be a pattern of chronological ascension, the rise and fall of terms is contained in an action pattern of ascending descent; $+1-1 \ldots$ and potentially in $+2-2+1-1$.

The varied pattern of ascending descent is contained within the successive ascent of $7,8,9$, and 10 . Unlike the sequence, the ascending descent of the action pattern is not consecutive. The pattern has the potential to continue infinitely, but its terms are not exactly the same. For example if the total potential action pattern $(+1,-1,+2,-2,+1,-1)$ is applied to the number 20, then the arrangement becomes; 20, 21, 20, 22, 20, 21, 20. This can be represented as ABACABA. The varied pattern is therefore a chiasm. It is an inversion of repeated terms which questions the notion of beginning and end. It is like a möbius in that the journey is the significant aspect of the action. 
In an alternate translation of "The Garden of Forking Paths" the pattern is the same but the terms are different. The translation is as follows:

"It was under English trees that I meditated on that lost labyrinth [28]: I pictured it perfect and inviolate on the secret summit of a mountain [21]; I pictured its outlines blurred by rice paddies [11], or underwater; I pictured it as infinite-a labyrinth not of octagonal pavilions and paths that turn back upon themselves [8], , but of rivers and provinces and kingdoms ... I imagined a labyrinth of labyrinths [10] ..."16

The terms in this case are 28:

$21 ; 11,8,10$. If the 11 is excluded for the moment, the first and last couples can be represented as $4: 3$, and 4,5 where the shared roots are 7 and 2 , respectively. Therefore the action pattern of the chiasm or
28: $21 ; 11,8,10$

$7(4: 3) ; 11,2(4,5)$

Roots; 7, 2,

Varied pattern; $4,3,4,5$

Action pattern; $-1+1+1$

ascending descent, where 11 is included, is; $-1,+1,11,+1$.

The disruption of the pattern by the number eleven is not a disruption at all. The term alludes to infinity. Eleven is a symbol of infinity in a Borgesian fiction, as will be presented in detail in the analysis of "Tlön, Uqbar, Orbis Tertius." Succinctly, the reasoning is that if the pattern of the number 11 continues to $11111 \ldots$ ad infinitum, it will never reach 12. Therefore it is sufficient, for now, to conclude that Borgess' intention is to communicate that the pattern of ascension and descent is infinite, as well as varied.

In both cases the terms of the patterns have meaning in relation to one another, and to an imagined whole that is infinite. This pattern is not a recurrence of identical 
terms but "it is, without similarities or repetitions, the same." $" 17$ It is a template for the pattern of ascending descent that gives significance to the relationship.

\section{Conclusion: Borges" "The Garden of Forking Paths"}

The Borgesian theme of the voyage in time questions the goal-oriented story and the notion of the multi-verse. Borges presents the concept of a significant journey within a constant moment of excitement or crisis by pointing out the structure of the chiasm. Significance is achieved in the synchronous relationship of a varied pattern of infinitely cyclical or repeating time.

The text is both signifier and signified. It is self-contained, self-referential and created by the action of its own process of making. That process leaves a trace of itself in the form of a chiasm. The trace is pointed out by an anaphora; a substitutive scheme. Within this scheme the polyptoton is contained; a disruptive figure of exchange that creates a chiasm within the text. Furthermore, the exchange that takes place in the particular action of the figures of exchange, has value as a "humanistic truth."18

\subsubsection{Borges: "The Immortals"}

Similar to "The Garden of Forking Paths," "The Immortals" is a fiction whose theme is "a voyage in time." 19 Both play on the tension between the themes of succession and coexistence, specifically in the dichotomy of mortality and immortality.

${ }^{17}$ Jorge Luis Borges, “A New Refutation of Time," Jorge Luis Borges: Selected Non-Fictions. trans. Suzanne Jill Levine, (New York: Putnam, 1999) 325.

${ }^{18}$ Kunze and Wei, 58.

${ }^{19}$ Irby, Introduction, Labyrinths, xviii. 
In "The Immortals," the schema anaphora is coupled with the action of the chiasmus to deny the two versions of time presented and reveal a third option. The fiction presents an infinite and varied pattern of time.

The fiction recounts the narrator's acquisition of immortality and reversion to mortality. He drinks the water of a particular river and loses both his mortality and individuality. The condition of immortality is that the immortal will experience all things, including the waters of the river which restores mortality. Time is infinite, but experiences are not. Consequently the immortal will become all men, and return to being one man.

The immortal man will be all men in life, while the mortal man will be all men in death. Death, like immortality, is "only another version of the identification of one man with all men." ${ }^{20}$ The mortal is unique and particular in life, and universal in his capacity for death. An exchange between the universal and the particular aspects of time are present in mans' mortality.

\section{Schemes: The Anaphora and The Chiasmus in Borges' "The Immortals"}

Borges' fiction reveals a disconnect between the image (significance of the word), and the phonetic and numerical terms of a scheme. ${ }^{21}$ The former presents the tension between chronos and chaos. In the latter the mortal connection is revealed. It exists within the structure of the fiction, not through our semantic reading of it. (1968) : 134 .

${ }^{20}$ Francis Wyers Weber, "Borges's Stories: Fiction and Philosophy." Hispanic Review 36.2

${ }^{21}$ Eliphas Levi, The History of Magic, (Boston: Weiser, 2001) 86. 
While a semantic reading of the text reveals one thing, the underlying structure reveals another. The universal connection of mortality is constructed schematically in the fiction and can be deciphered syllabically in a phonetic reading. The decoding reveals a pattern that is varied and infinite.

The anaphora, repetition in the beginning of a series of phrases, is used as a framing device in "The Immortals" as well as "The Garden of Forking Paths." In the case of "The Immortals" it is used to call attention to the phonetic structure of the schema chiasmus. In the chiasmus, as in the polyptoton above, the varied pattern of infinity will be revealed. Both are operations of exchange that through the act of making enable a significant pattern to emerge in the fiction.

The anaphoric repetition is present in the use of "I know," "I thought" and "I shall" at the beginning of certain phrases within the text. Their significance is that when they are spoken by an immortal they reveal the "truth" of recollection. ${ }^{22}$ The details of memory are not romanticised or personalised as they are for mortals. The immortal has no personal memory because he is not singular; he is not a person. The immortal cannot create false memories because they are common to all. ${ }^{23}$

In the anaphoric phrases the hidden significance of the fiction can be revealed. Firstly, in the phrases beginning with "I know" and "I thought," deconstructions of the anaphoric figure will reveal that there is no personal identity in immortality.

22 "After a year's time, I have inspected these pages. I am certain they reflect the truth, but in the first chapters, and even in certain paragraphs of others, I seem to perceive something false. This is perhaps produced by the abuse of circumstantial details, a procedure I learned from the poets and which contaminates everything with falsity, since those details can abound in the realities but not in their recollection..." Borges, "The Immortal," Labyrinths, 116-117.

${ }^{23}$ Borges maintains that in memory one creates a personal identity. For the mortal the personal identity is an illusion that is created by the self. In contrast, the personal identity is a truth for the immortal that has no personal identity. 
Furthermore, while their recollections may be called "truths," those "truths" have no validity in that immortality is a chaos of simultaneity. The anaphoric scheme in theses cases does not reveal a chiasmus or a varied pattern.

The scheme of the phrases beginning with "I thought" is revealed as 7, 6, 7, 20, $10,17,20,10,12,10$. The action path it reveals is $\mathbf{- 1},+\mathbf{1},+13,-10,+7,+3,-10,+2,-\mathbf{2}$. The anaphoric scheme of the phrases beginning with "I know" reveals the action path -7, $+7,-21,+21,+7$. Neither figure presents a chiasmic pattern. The first has an end and a beginning that are successive, but they are broken by an incoherent sequence. The second is unified in that all the terms are divisible by seven. However, the pattern is not varied in the form of a chiasm. Therefore, it can be concluded that there is no significance when the universal lacks a particular; such as in the case for immortality.

In contrast, the phrase "I shall" was spoken by the narrator after his reversion to mortality. In the last sentence of the fiction, the last three terms of the final pattern are contained. That final statement is as follows.

"I have been Homer; shortly, I shall be No One, Like Ulysses; shortly, I shall be all men; I shall be dead." 24

The scheme of the final anaphora is fitting, because it reveals the idea that the end, death in this case, is not the end. In mortality, one can achieve infinity. Death is man's immortality.

The pattern found in the phonetic deconstruction of phrases that begin with "I shall," is $4,5,5,4$. This scheme can be represented as ABBA. The infinite scheme in

${ }^{24}$ Borges, “The Immortal,” Labyrinths, 118. 
"The Immortals" is a variant on the ABAB rhythm. ${ }^{25}$ The scheme of the chiasmus transforms the $\mathrm{ABAB}$ rhythm into $\mathrm{ABBA}$ by inverting the latter couple.

The variation creates a break in the potential monotonous and repetitive reading and presents the sequence as an infinite one where the beginning is balanced by the end. The variation is grounded in the significance of the terminus that does not terminate the sequence, and in the potential for variation in the body. The body of the pattern between the terminuses/origins is different and significant.

The chiasmus is structurally present in the semantic anaphoric figure. The variant, the chiasm, alters the scheme of linear time. Consequently, time possesses a rhythm that gives significance to infinity; not order. The rhythm of the universal connection of mortality is infinite and cyclical.

\section{Conclusion: Fictions of Time}

Borges" fictions of time deny succession and coexistence. In "The Garden of Forking Paths" the linear detective search and the bifurcating time of the fiction within the fiction are denied by the chiasm. The chiasm structured the creative process and is revealed as a trace within the final form of the fiction. The fiction is a consequence of the process of making and communicates the process in its internal form.

The form of the chiasmus is revealed not only syntactically, but also on the surface, within the plot. "The Garden of Forking Paths" concludes with the notion that the universal is contained within the particular. Yu chose his species over his family.

\footnotetext{
${ }^{25}$ Sheridan, 12.
} 
However, his family is part of his species. Because his species can continue, Yu's lineage will also continue.

The chiasm; ABBA, is like a möbius. It is a " knot in the ...course ...of the simultaneous and the successive." ${ }^{26}$ The knot makes time infinite, yet the potential variations in time are finite. Therefore the terms are destined to repeat. Yu's greatgrandfather, "A," will repeat in general, not in particular. The first A and the last A in the pattern are the same, but different.

In mortality we are the same. As a consequence of that sameness, we are able to assert our difference. In "The Immortals," the notion of time is questioned by the tension between mortality and immortality. Immortality is revealed to be part of mortality; difference is created out of sameness.

In "The Immortals," Borges revealed that man is all men in death and one man in life. In other words, the universal aspect of immortality, sameness, is contained within the singular and mortal capacity for death. We are the same because we die and become immortal. Furthermore, we are different because we are the same, because something does die.

Death is both singular and universal. Death is the " $\mathrm{A}$ " in the chiasm ABBA. It is the beginning of the singular aspect of life and the universal aspect of death. In "A" man is different and the same. It is the beginning and the end.

\footnotetext{
${ }^{26}$ M. Taylor, "Carnality: Maurice Merleau-Ponty" Alterity, (Chicago: University of Chicago Press, 1987) 73.
} 


\subsection{Fictions of Self}

\subsubsection{Borges: "The Approach to al-Mu'tasim."}

$$
\begin{gathered}
\text { "Echoes echoing echoes...., } \\
\text { Mirrors mirroring mirrors... } \\
\text { "The sign, ...contains its past, present and future. }{ }^{, 28}
\end{gathered}
$$

"The infinite array of possible readings posits not the absence of a transcendent signifier, but the presence of a unity that enfolds in the plurality of readings. ${ }^{29}$

“...the proper essence of the visible is to have a layer of invisibility... which it makes present as a certain absence." 30

"The Approach to al-Mu'tasim" is structured as a book review. The reviewer narrates the plot of the book he is reviewing. He also reveals the context of the work in terms of variations in publication history and the major influences on the author. One of these major influences is a Persian writer of the twelfth-century; "Ferid Eddin Attar." The name of this author is an instance of variation that calls attention to a hidden significance. The name is later given as Farid ud-Din Attar. Neither is correct.

The "real" author of "Parliament of Birds,", that influenced the fictional novelist Mir Bahadur Ali, is Farid al-Din Abu Talib Mohammad ibn-Ibraham Attar. The

\footnotetext{
${ }^{27}$ Nora De Marval-McNair, "Of Echos and Clones: Mirror Images in Borges's "The Approach to Al-Mutasim." Contributions to the Study of World Literature 122 (2003) : 308.

${ }^{28}$ Thomas, L Cooksey, "The Labyrinth in the Monad: Possible Worlds in Borges and Leibniz." The Comparatist 17 (1993) : 54.

${ }^{29}$ Cooksey, 57.

${ }^{30}$ Maurice Merleau-Ponty, "Eye and Mind." The Primacy of Perception ed. James M. Eddie, (Evanston: Northwestern University Press, 1964) 187.
} 
difference of the two instances of reference in Borges' fiction is in spelling. Phonetically they are the same. These phonetic similarities establish the means of understanding the fiction. This phonetic decoding, as will be later shown, reveals the intention of "Parliament of Birds" and its copy, "The Approach to al-Mutasim." The intention is to present the idea of the preterition wherein the copy gives value to the original through a connection of the two to an otherwise unimaginable whole.

The binary relationship of copy and original finds its parallel in two relationships within the story. The relationship between the student "freethinker" and the religious extremists, as well as the student as a murderer in relation to a vile man, reveals the significance of the preterition to the later decoding of the message. The plot of the work begins when the student, who is an atheist, joins in a war between the Hindus and Muslims. He gets caught in the battle and kills one of the two opponents, not knowing which one. He then flees to the safety of a circular tower after encountering a few coincidences. There he meets a defiler of corpses.

The two encounters cause the character to question relationships of opposition. The student blurs the difference in the former relationship; between the atheist and the believer and between the two groups of religious extremists. ${ }^{32}$ He equates the orthodox

31 "The faraway king of all the birds, the Simurgh, lets fall a magnificent feather in the center of China: tired of their age-old anarchy, the birds resolve to go in search of him. They know that their king's name means thirty birds; they know his palace is located on the Kaf, the circular mountain that surrounds the earth. They embark upon the nearly infinite adventure. They pass through seven valleys or seas; the name of the penultimate is Vertigo; the last, Annihilation. Many pilgrims five up; others perish. Thirty, purified by their efforts, set foot on the mountain of the Simurgh. At last the gaze upon it: they perceive that they are the Simurgh and that the Simurgh is each one of them and all of them. In the Simurgh are the thirty birds and in each bird is the Simurgh." ${ }^{31}$ Jorge Luis Borges, "The Simurgh and the Eagle," Jorge Luis Borges: Selected Non-Fictions. trans. Esther Allen, (New York: Putnam, 1999) 296.

32 "He reflects that he has shown himself capable of killing an idolater, yet incapable of knowing with any certainty whether the Muslim possesses more of truth than the idolater does." Jorge Luis Borges, "The Approach to al-Mu'tasim," Borges: Collected Fictions, 83. 
and the atheist as two variations on the same theme. In reference to the latter connection, the student states that to be robbed by the man who he believes is "so thoroughly vile is in itself a kind of praise." ${ }^{33}$ This statement reveals that the ill-treatment by a defiler, a double negative, is a positive.

The double negative is a trope. The trope litotes is the denying of a negation. Literally litotes means "not X (but not necessarily Y)", yet it communicates "very much Y." ${ }^{33}$ Therefore, the potential for inversion of one pole into the opposite (X into $\mathrm{Y}$ ) reveals that both are prefigured in the same origin, as an imagined whole.

Likewise, "The Theologians" questions the notion of the self to emphasis the potential for inversion of opposites within the imagined whole. In the fiction the preterition is revealed by an inversion of terms in a phonetic reading. ${ }^{34}$ The reading reveals the terms $13 ; 31$. Therefore, like the opposite characters in the "Theologians," the extremist and atheist in "The Approach..." are parts of the same whole. This unity is revealed in their potential for inversion from $\mathrm{X}$ to $\mathrm{Y}$.

The conclusions to meditations on relationships of opposition present the notion that binary opposites are equal in their relationship to the whole. Each part of a binary couple is foretold by the preterit; the presence of one is accompanied by the absence of

33 "The law student reasons that the wrath and hatred of a man so thoroughly despicable is the equivalent of a hymn of praise." Ibid, 84.

${ }^{33}$ Wikipedia,1 Sept $(2005)<$ http://en.wikipedia.org/wiki/Litotes $>$.

34 "Like all those possessing a library, Aurelian was aware that he was guilty of not knowing his in its entirety; this controversy enabled him to fulfill his obligations with many books which seemed to reproach him for his neglect. Jorge Luis Borges, "The Theologians," Labyrinths, 120. 
the other. The imagined whole which unifies the presence and absence of the couple, creates the potential for inversion of that couple.

\section{Trope: Paralypsis or Praeteritio in Borges" "The Approach to al-Mu'tasim."}

In literature the presence of absence in a unity of inversion is called the preterit, or paralipsis. The preterition draws attention to something while pretending to pass over it. In "The Approach to al-Mu'tasim" this trope is utilized by Borges to affirm the completeness in the divided whole. The trope is revealed through a phonetic decoding of a list that summarizes the plot, and in the underling significance of the title of the fiction. The former, the code, is structured by the twenty-five orthographic symbols of language, and the latter is revealed to have been present all along. ${ }^{35}$

In a Borgesian fiction, linear listing or cataloguing is a mode that implies synchronicity through the clever variation of intervals. ${ }^{36}$ The elongated list contained in one sentence holds within it a pattern. ${ }^{37}$ This pattern is structured by commas, semicolons, and colons. In this case, the sentence is short and difficult to find, so the significance is foreshadowed in the previous sentence:

"It is hardly possible to outline here the involved adventures that befall him in the remaining nineteen. There is a baffling pullulation of dramatis personae, to say nothing

${ }^{35}$ It is note worthy to mention that Norman Thomas di Giovanni, who translated this "The Approach to Al-Mu'tasim," worked with Borges on the translation.

${ }^{36}$ Sheridan, 11-12

37 " The story begun in Bombay continues in the lowlands of Palanpur..." Jorge Luis Borges, "The Approach to Al-Mu'tasim," The Aleph and Other Stories. trans. Norman Thomas di Giovanni, (New York: E.P. Dutton, 1970) 48. 
of a biography that seems to exhaust the range of the human spirit (running from infamy to mathematical speculation) ....” 38

The tropic sentence follows the one above. The above sentence informs the reader of the trope structured within the text. The narrator (Borges) acknowledges that it is impossible to communicate the significance of the remaining adventures of the next nineteen chapters in this review. Therefore, he reveals that the significance can be found at the point of juncture between the characters' previous shameful actions and his new behaviour through "mathematical speculation."

This point is an inversion. For instance, where the character was previously a murderer, in the subsequent plot he is prayerful. This inversion reveals that the moment is significant because the preterit can be found when opposites, such as the infidel and the extremist, invert. The inversion is the moment of exchange where the opposites become part of the imagined whole.

At this point of inversion, the reader is called to speculate on the "dramatis personae," or listing of characters, which presents those characters in their absence. ${ }^{39}$ The previously mentioned phonetic similarity of the author that influenced Mir Bahadur Ali, reveals the significance of phonetics in this work. The pattern is revealed by counting the syllables of each phrase which describes the actions of the student in the sentence; "The

${ }^{38}$ Ibid, 48.

39 "Thus we begin to see the book's general scheme: The insatiable search for a soul by means of the delicate glimmerings or reflections this soul has left in others-at first, the faint trace of a smile or a word; toward the last, the varied and growing splendours of intelligence, imagination, and goodness." Borges, "The Approach to al-Mu'tasim," Borges: Collected Fictions, 84. 
story begun in Bombay continues in the lowlands of Palanpur..." ${ }^{40}$ The first three phrases in the sentence is not a listing of characters, therefore, they are not part of the pattern.

The process of deciphering the pattern is continued with the extraction of the numerical difference between those phrases. The inversion of terms from their positive to their negative value recalls the plot point where the student was robbed by the defiler of corpses. The character referred to this action as praise rather than a put down. The positive and negative were noted as two versions which originate in the same whole. ${ }^{4142}$

The process for the derivation of significance in the inverted code is revealed in the sentence following the metaphorical one. It is as follows:

${ }^{40}$ Borges, "The Approach to Al-Mu'tasim," The Aleph and Other Stories, 48. This sentence in the 1968 publication of Borges's "Ficciones" reveals the equation 42: 7. Forty-two is attained by adding the difference between the first seven phrases which contain a verb referring to the actions of the student, in the sentence. Seven is the syllabic count of the last such phrase. The last term, is a part contained in the whole, however, it is also a whole. It is the foreshadowed term. Jorge Luis Borges. Ficciones, (Buenos Aires, Emecé Editores, 1968) 38.

${ }^{41}$ In Andrew Hurley's translated version of "The Approach to Al-Mu'taism" in Jorge Luis Borges': Collected Fictions, the scheme is contained in the following statement. "There are distressing details: A black Jew from Cochin, describing Al-Mu'taism, says that his skin is dark; a Christina says that he stands upon a tower with his arms outspread; a red lama recalls him as seated "like that image which I carved from yak ghee and worshipped in the monastery at Tashilhumpo." This statement could be called a "dramatis personae," in which Borges call the reader to speculate. Furthermore, Borges reveals that this statement is an allegory. The equation which represents the syllabic rhythm of this sentence is 7:6, 7,6; 17, 34, or 7: 70. Borges, "The Approach to al-Mu'tasim," Borges: Collected Fictions, 85.

42 Similarly, on page forty-one of the 1968 publication of Borges's "Ficciones" the same statement reveals the pattern 8: 80. Jorge Luis Borges. Ficciones, (Buenos Aires, Emecé Editores, 1968) 41. 
"A mathematical analogy may be helpful here. Bahadur's populous novel is an ascendant progression whose last term is the foreshadowed "man called alMu'tasim.

The statement, the "...ascendant progression whose last term is the foreshadowed...." reveals the formula for the derivation of meaning. The sum of the difference between the fourth to seventh terms forms an ascending sequence with the last.

The last digit is in sequence with the inverted sum of the previous digits. ${ }^{44}$ The three highlighted terms, 1,6 , and 3 are equal to 10 . The sequence; 10,11 , reveals the progression toward unity. Therefore, the structural rhythm revealed in the text parallels the plot of the fiction in that both communicate the idea that all the characters encountered on the journey contain the attributes of the one sought. Furthermore, in the term 11 , the notion that God is infinite is revealed. ${ }^{45}$ Etymologically, Al-Mu'taism, or God, means "The Seeker after Help." ${ }^{46}$ Like the Simurgh in "Parliament of

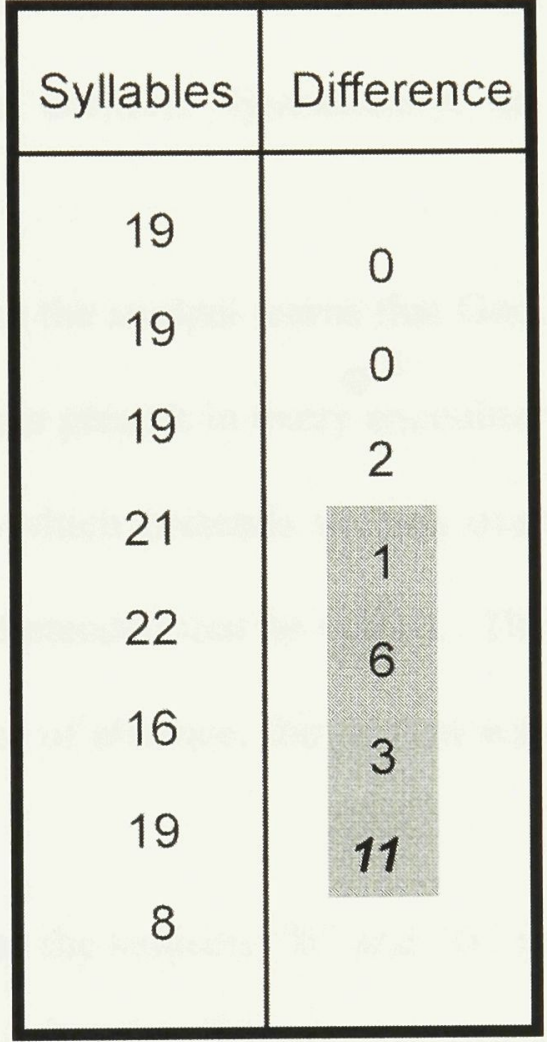

Figure 4. Paralypsis

${ }^{43} \mathrm{Ibid}, 48$.

44 "The insatiable search for a soul by means of the delicate glimmerings or reflections this soul has left in others..." Borges, "The Approach to al-Mu'tasim," Borges: Collected Fictions, 85.

${ }^{45}$ In a work by Borges the number 11 is a symbol of infinity. See the analysis of paradox in "Tlön, Uqbar, Orbis Tertius."

46 "Naming is always a concealed act of negation... It is a peculiar form of absence, arising from the presence of the word itself." Lisa Block De Behar, "Rereading Borges's "The Aleph." $\underline{\text { CR }} 4.1$ (2004) : 187.

${ }^{47}$ De Marval-McNair, 304. 
Birds," the sought one is the seeker. ${ }^{47}$ Therefore, God is also searching for God. The search is infinite. ${ }^{48}$

\section{Conclusion: Fictions of Self}

In Borges' fictions, which question the notion of the self, the operation of the figures of speech reveals the inversion of opposites. The potential for inversion is enabled by the whole, formed around the terms as a result of their exchange. The inversion of terms was revealed by the litotes in "The Approach to al-Mu"tasim" when the student encountered the extremists and the defiler of corpses. Syntactically, the inversion was revealed in the journey.

"The Approach to al-Mu'tasim" is a journey in which the student learns that God, for whom he is searching, is also the seeker of God. God was present in every encounter because the seeker was the sought. Like the preterition, which pretends to pass over something, God was present during a journey in which he pretended that he wasn't. The phrase "not to mention" is a literary example of the presence of absence; the student was the example of the preterition in Borges' fiction.

The student is the site of inverse relationship between the subjects " $\mathrm{B}$ " and " $\mathrm{B}$ " in the chiasm ABBA, which structures every fiction written by Borges. The student, like a deviant, is the unity of the double; a double negative which creates a positive. A deviant is "[n]ever reducible to the differences it simultaneously joins and separates, the body is

48 "Al-Mu'taism is an emblem of God, and the detailed itineraries of the hero are somehow the progress of the soul in its ascent to mystical plenitude." Borges, "The Approach to al-Mu'tasim," Borges: Collected Fictions, 85. 
forever entre-deux." ${ }^{49}$ The subject is both independently the seeker and the one sought; simultaneously $\mathrm{B}$ and the inverse 31 , and the unity this inversion inspires. Consequently, $\mathrm{ABBA}$ can be represented as $\mathrm{ABA}$, where "B" is the unity of the subjects "B" and "B."

\section{$\underline{2.3 \text { Fictions of Knowledge }}$}

\subsubsection{Borges: "Tlön, Uqbar, Orbis Tertius"}

In "Tlön, Uqbar, Orbis Tertius," chance plays a prominent role in the confusion of reality and fiction. Chance is the synchronous connection that gives significance to a situation. While the "causality principle asserts that the connection between cause and effect is a necessary one. The synchronicity principle asserts that the terms of a meaningful coincidence are connected by simultaneity and meaning." 50

There are five prominent coincidences or elements of chance that give significance to "Tlön, Uqbar, Orbis Tertius." The first significant coincidence is the purchase of a unique edition of a deviant cyclopaedia by Bioy Casares; a life long friend of Borges's. Secondly, Bioy happens to remember a quote from it during a conversation with the narrator, who is never revealed explicitly as Borges. Later, the narrator stumbles upon an edition of the First Encyclopaedia of Tlon, Vol. XI and then a letter that tells of Tlön's origin. Lastly, the narrator experiences the coincidental infiltration of objects

49 "As a result of this holey-ness or gappiness, the living body cannot be defined in terms of the binary opposites that structure conceptual reflection. The body is neither "subject nor object..." Ibid, 69 .

${ }^{50}$ Sharon, Lynn Seiber, "Time and the Fantastic: Simultaneity in Borges, Cortázar, Lezama Lima, and Paz." Contributions to the Study of Science Fiction and Fantasy 104 (2003) : 23. 
from Tlön into reality. ${ }^{51}$ While the plot of discovery proceeds in a linear detective search, chance contaminates the ordered reality.

The statement "copulation and mirrors are abominable" is the coincident incident which is the catalyst to the fiction. ${ }^{52}$ The quote found in the cyclopaedia refers to Uqbar. ${ }^{53}$ The borders of Uqbar are self-referential. The country is not included in any maps or atlases; the only source is the cyclopaedia. The cyclopaedia, furthermore, describes various aspects of the culture, including its literature. The country's literature is limited to the telling of fantasy, especially that of two imaginary regions; Meljnas and Tlön. The introduction of Tlön into reality is the reason for the cyclopaedia's existence.

The second episode described by Borges's fiction is the period after the infiltration of Tlön has begun. This infiltration was put into motion by the appearance of "A First Encyclopedia of Tlön. Vol. XI. Hlaer to Jangr." By chance, the narrator found this copy which belonged to a friend of his father who "suffered from unreality." 54 The book contained 1001 pages which describe the planet; it was stamped with the inscription: Orbis Tertius.

In the Eleventh volume, Borges presents philosophical theories as actual. Tlön, for example, is an isolated idealist archetype. ${ }^{55}$ Tlön presupposes that there are no nouns on this planet which are "successive and temporal, not spatial." The planet, furthermore,

${ }^{51}$ Wyers Weber, 128

52 Jorge Luis Borges, "Tlön, Uqbar, Orbis Tertius," Labyrinths, Selected Stories and Other Writings, trans. James E. Irby, (New York: New Directions, 1964) 3.

53 The "Anglo-American Cyclopaedia" is a delinquent reprint dated 1917, of the 1902 Encyclopaedia Britannica. The reprint contains four extra pages that describe Uqbar.

${ }^{54}$ Borges, "Tlön, Uqbar, Orbis Tertius," Labyrinths, 6.

55 "Hume noted for all time that Berkeley's arguments did not admit the slightest refutation nor did they cause the slightest conviction." Ibid, 8. 
presents the primacy of sensuous perception over the rationalism of necessary connection. The inhabitants of the planet Tlön do not believe in the materiality of the thing-in-itself. ${ }^{56}$ Tlön is an allegory for earth. Its fictive context allows the reader to be critical of accepted scholarship.

The third division in the chronology of Borges's fiction recalls the manner in which the hrönir infiltrated earth's reality, as centuries of idealism had influenced Tlön. The inhabitants of the planet are now able to combine the material with the immaterial. They are not only able to see what they think, but are now able to make those thoughts concrete. $^{57}$ These objects of thought and desire are called hrönir.

The first intrusion of hrönir into reality noticed by the narrator was on a compass which had traveled a great distance. The second intrusion was a coin, whose weight was said to be intolerable despite that it was "the size of a die." 58 This reference to dice reveals that the cone shaped coin is a symbol of chance and of "man's free will."59

The hrönir are elements of chance that have the potential to alter reality. One hrönir created "a rusty wheel of a period posterior to the experiment." 60 This "rusty

56 "Things become duplicated in Tlön; they also tend to become effaced and lose their details when they are forgotten. A classic example is the doorway which survived so long as it was visited by a beggar and disappeared at his death. At times some birds, a horse, have saved the ruins of an amphitheatre." Ibid, 14.

57 "In our dreams...images represent the sensations we think they cause; we do not feel horror because we are threatened by a sphinx; we dream of a sphinx in order to explain the horror we feel." Jorge Luis Borges, "Ragnarök," Labyrinths, Selected Stories and Other Writings, trans. James E. Irby, (New York: New Directions, 1964) 240.

${ }^{58}$ Borges, “Tlön, Uqbar, Orbis Tertius," Labyrinths, 16.

${ }^{59}$ Jorge Luis Borges, "The Zahir," Labyrinths, Selected Stories and Other Writings, trans. Dudley Fitts, (New York: New Directions, 1964) 159.

${ }^{60}$ Borges, “Tlön, Uqbar, Orbis Tertius,” Labyrinths, 13. 
wheel" from the future serves to collapse linear time through the synchronicity of the coincidence. This coincidence has the potential for self reversal.

The secret sect Orbis Tertius, which means Third Wheel, wrote the encyclopaedia of Tlön. However, in the text it is revealed that someone in Tlön imagined, and consequently created, the hrönir wheel. The synchronicity of these incidents questions the notion of a causal connection. Neither moment is a definitive beginning due to the overlap of the creation and the creator. The inhabitants of Tlön created the wheel, a metaphor for the secret sect, yet the secret sect wrote the "history" of Tlön. Therefore, the coincidence regarding the intrusion of Tlön into reality reveals that reality is an embraced hallucination.

For architecture, this is an important conclusion in that the connection between seeing and making is inverted. Making is prior to seeing. Making is "a seeing... which we do not make, it makes itself in us." ${ }^{, 61}$ This notion will be explored further in the fourth section through the connection of sound and sight. For now, the analysis will return to the deconstruction of the tropic figures in Borges works. The paradox, specifically, destabilizes the visible reality and allows the viewer to see the connection between the made and the making.

\section{Trope: Paradox in Borges's "Tlön, Uqbar, Orbis Tertius"}

"Borges holds the work and its subversion, reality and unreality, ideal and defeat, equally in view in one paradoxical vision... [that eludes] all rigid definitive formulations.

\footnotetext{
${ }^{61}$ Ibid, 167.

${ }^{62}$ Wyers Weber, 140.
} 
The attribute which reveals the tentative nature of reality is the potential for selfreversal. This paradoxical attribute confuses the boundary between the objective and subjective reality. Borges uses the paradox of the pure theories of Rationalism and Idealism in Tlön to reveal the hallucination of reality. This is achieved in the allegory of the nine copper coins.

During the second division of the fiction, the notion of materialism was introduced in Tlön, and it received great reaction. The theory was put forth through a paradox conceived of by a heresiarch of the eleventh century. The paradox is the "sophism of the nine copper coins.",63

The paradox of the nine coins allegorically questions the persistence of an idea in space. The idealists of Tlön maintain that "equality is one thing and identity another." They feel that the nine copper coins lost are not the same as the nine copper coins found, for they have only metaphorical value. Conversely, the rationalists and the heresiarch who wrote the question, maintain that the coins are materially the same.

It is noteworthy to also mention that the paradox presupposes the materialist perspective. The idea that the coins are objects existing through time is emphasised by their weathering in the rain. The narrative of the coins is as follows:

"On Tuesday, X crosses a deserted road and loses nine copper coins. On Thursday, $Y$ finds in the road four coins, somewhat rusted by Wednesday's rain. On Friday, Z discovers three coins in the road. On Friday morning, $X$ finds two coins in the corridor of his house. $" 65$

\footnotetext{
${ }^{63}$ Borges, "Tlön, Uqbar, Orbis Tertius," Labyrinths, 11.

${ }^{64} \mathrm{Ibid}, 11$

${ }^{65} \mathrm{Ibid}, 11$.
} 
The narrative reveals, what Borges believes to be, the paradox of the pure mental construct. It was written by a materialist and yet it contains within it the idealist theory. In the process of deciphering this sophistic message, it is beneficial to remind the reader of Zeno's paradox. Borges uses the example of Achilles and the tortoise to explain Zeno's paradox and the infinite subdivision of cyclical time.

The movement of Achilles is presented as the subdivision of space in a given amount of time: $10+1+0.1+0.01+0.001+\ldots$ ad infinitum. ${ }^{66}$ The total of this equation, $11.111111 \ldots . . a d$ infinitum, will never reach 12 . It will be revealed that the significance of this

$$
\begin{aligned}
& 9 x=\frac{4}{9}+\frac{3}{9}+\frac{2}{9} \\
& 9 x=0.99999999 \ldots \ldots . \text { ad infinitum } \\
& x=\frac{0.99999999 \ldots \ldots . . \text { ad infinitum }}{9} \\
& x=0.111111111 \ldots \ldots . \text { ad infinitum }
\end{aligned}
$$

Figure 5. Paradox

infinite number is that coincidence, not a chronology, is infinite. ${ }^{67}$ Therefore, the infinite number is a metaphor for chance.

Chance is a sign of significance in synchronous elements. This connection destabilizes linear time and the necessity of a causal connection. The infinite connection only exists as a subdivision, as is revealed in Zeno's paradox. Therefore, the narrative of the nine copper coins will be deciphered through the mathematical process of division.

${ }^{66}$ Jorge Luis Borges, "The Perpetual Race of Achilles," Jorge Luis Borges: Selected Non-Fictions. trans. Suzanne Jill Levine, (New York: Putnam, 1999) 44.

${ }^{67}$ Events linked by meaning, rather than a chronological time line, reveal that time is cyclical. Time is cyclically infinite while possibilities are finite, therefore, events are destined to repeat. The serendipitous convergence of two events which are linked in significance form a coincidence. 
The narrative can be explained through a mathematical division that presupposes the materialist theory in which it was written. There are nine copper coins on Tuesday. Furthermore, it can be inferred that 4 of the 9 are recovered on Thursday. On Friday, in two difference places, 3 of 9 and 2 of 9 are recovered. ${ }^{68}$ Therefore, the narrative can be represented by the following equation where $\mathrm{x}$ symbolises the coin.

The coin, which equals the number 0.11111111111 in the equation, is a symbol of the synchronous coincidence. The word coincidence comes from the root "coin." The two terms are related through synecdoche. Therefore, the numbers 11, 1001 and 0.1111111111...ad infinitum, are Borgesian metaphors for the significance of a coincidence.

The Eleventh volume of the Encyclopaedia of Tlön has 1001 pages. ${ }^{69}$ The Eleventh volume, like the coin, which is presupposed as an object by the materialists, is actually revealed to be immaterial by the fact that it is infinite. The immaterial coin within the materialist theory contradicts that theory.

The materialist perspective, which presupposed the persistence of the nine coins in space and time, is inverted internally. The assumption by the materialists, like all the books of philosophy in Tlön, contains its' antithesis. The coin, which appears to be the same object over time in the text of the narrative, is structurally revealed to be a subject.

\footnotetext{
${ }^{68}$ Similarly, in "The Lottery in Babylon" the same pattern is mentioned: "Let us imagine a first drawing, which decrees the death of a man. For its fulfillment one proceeds to another drawing, which proposes (let us say) nine possible executors. OF these executors, four can initiate a third drawing which will tell of name of the executioner, two can replace the adverse order with a fortunate one (finding treasure, let us say), another will intensify the death penalty (that is, will make it infamous or enrich it with tortures) others can refuse to fulfill it. This is the symbolic scheme....its is sufficient for time to be infinitely subdivisible, as the famous parable of the contest with the tortoise teaches." Jorge Luis Borges, "The Lottery in Babylon," Labyrinths, Selected Stories and Other Writings. trans. John M. Fein, (New York: New Directions, 1964) 34.

69 "Why does it disturb us that the map be included in the map and the thousand and one nights in the book of the Thousand and One Nights?" Borges, "Partial Magic in the Quixote," Labyrinths, 196.
} 
The self-reversal of the allegory reveals the paradox of pure theory. It is both material and immaterial; the object contains its subject. The "sophism of the nine copper coins" is "...true in what it denies and false in what it affirms..."70

\section{Conclusion: Fictions of Knowledge}

Borges' fictions of knowledge are not fantasies as much as they are studies of appearances. The intention of these fictions is to reveal the "hallucinatory nature of reality." Borges' "poetic language draws attention to its fictiveness..." like fiction, visible reality is a construct. Through the translation of reality into fiction he enables the reader to see according to "the imaginary texture of the real."

In Tlön, Borges reveals the overlap between the secret sect and the object of desire, between the making and the made. ${ }^{73}$ Grammatically, the stories blur the boundary between fiction and reality and through the syntactical operation they become an object which containes its subject. The surface fiction is sophistic. The structure is created in a manner which reveales it createdness.

The inversion created by the operation of the paradox links the subject to the object. The unified subject " $\mathrm{B}$ " is contained by the object " $\mathrm{A}$ " in the chiasm transformed

${ }^{70}$ Merleau-Ponty, 173.

${ }^{71}$ Véronique Fóti, "Turning at the Limits of Closure," Philosophy Today, Winter 1996: 310.

${ }^{72}$ Merleau-Ponty, 165.

73 "The subject thinks only by first thinking itself, then all knowledge is actually self-knowledge. When the knower becomes fully aware of what and how he knows, consciousness is necessarily transformed into self-consciousness. Transparent self consciousness despels the obscuirty of consciousness by effecting a perfect coincidence of subjectivity and objectivity." Taylor, 64-65. 
from $\mathrm{ABBA}$ into $\mathrm{ABA}$. Therefore it can now be represented by AA because the unified double subject is contained by the object A of the intention.

\subsection{Fictions of the Universe}

The origin of all words in Greek is the Alpha; in Hebrew it is the Aleph and in Hindi it is the Alif. All three mean "all," and all three are the first word which begot all others. Therefore, they are both the first, represented by number one, and the total.

The relationship between the one and the total is presented by the connection of the English word "alphabet" to its origin in "alpha." Alpha is the root of the word alphabet, and the first letter in the alphabet. It is both one and container for all. This notion, in which the part stands for the whole, is called synecdoche.

This figure of speech is the structure of not only the Greek, Hebrew and Hindu languages, but also the resulting religions. Christianity is based on the Latin language in which it was originally spoken. Judaism is defined by the Hebrew language and Hinduism by Hindi.

All three religions maintain that the world was created by the first sound which emanated from God. All three religions can be analysed in reference to their ability to communicate their origin in the relationship of the part and the whole. In the structure of language the "truth" of religion will be revealed.

Borges's short fictions "The Zahir," "The God's Script," "Death and the Compass," "The Library of Babel," and "The Aleph" are metaphors for the search for meaning in the universe. The fictions search within the limits of the three main world religions: Islam, Hinduism and Judaism. Borges limits his analysis to the language on 
which each religion is based. Specifically, his commentary is formed around the name each religion has for God. He then uses the structure of that language to reveal the veil of reality which is maintained by those religions.

\section{$\underline{\text { The Kabbalah }}$}

Yahweh, is one of the four Hebrew Names of the infinite God. Yahweh, or YHWH, is also called the Tetrgrammation or "four letters." The name was found through an interpretation of the Bible by the system designed by the Kabbalists. Therefore, the contradictions of that system will reveal the deception of this Name which means "all."

The Jewish mystical tradition of the Kabbalah is an interpretation of the Bible, specifically the Old Testament. The interpretation of the Hebrew text is structured by the aleph, the first letter (with a value of one) and the whole of the Hebrew alphabet. The system interprets the Bible by attributing a numerical value to each letter. Each word, then, is the sum of the letter values. The value of the sum is then reconstructed in an alternate way to reveal an alternate word. In this manner, the text has the potential to be interpreted infinitely.

The possibility for infinite interpretation contradicts the intention of the system, as it is based on the belief that the word of God is divine and every part is intentional. Nothing is the consequence of chance. However, the rigour of the system is such that it encourages the coincidental associations of words through the mediation of the number.

The contradiction internal to the system can be presented irrespective of the language in which it is interpreted. The following deconstruction will reveal the manner in which "I AM," one of the Judeo-Christian Names of God, could signify "evil." In the

\footnotetext{
${ }^{74}$ Levi, 99.
} 
Kabbalah, the letter a, or aleph, has a value of one. The letter i, called yod, has a value of 10. Mem, $\mathrm{m}$, has a value of forty. In reference to the above values, "I AM" has a value of fifty-one. The word "evil" shares that numerical value through the combination of the letters heh, vav, yod and lamed or 5, 6, 10 and 30.

The system of interpretation derived by the Kabbalists is contradictory. Borges reveals the contradiction of this, and the other major religions, through similar analysis of the languages in which they originate. ${ }^{75}$ Since these religions structure visible reality, the contradiction of the religion reveals the tentative nature of reality. Once the visible reality is questioned, Borges presents the conceptual origin of the religions (of reality) in the relationship that created language; synecdoche. He maintains that synecdoche is the only legitimate figure by which to create.

\subsubsection{Borges: "The Library of Babel"}

In the Genesis parable, "Babel" is the incoherent noise by which the Babylonians were condemned to communicate. This punishment is a consequence of their rebellion against God. The Babylonians attempted to build a ziggurat-like tower to reach heaven, so they could share it with God. God reacted to the rebellion by "confounding their tongue." Because they could no longer understand one another it became impossible to continue building. Therefore, the parable is an allegory for the relationship between sight and sound, or speaking and creating.

75 "[A] book which is a mechanism of infinite purposes, moved them to permute the scriptural words, add up the numerical value of the letters, consider their form, observe the small letters and capitals, seek acrostics and anagrams and perform other exegetical rigors which it is not difficult to ridicule. Their excuse is that nothing can be contingent in the work of an infinite mind." Borges, "Mirror of Enigmas," Labyrinths, 212. 
Borges's library of Babel is a container of an infinite number of books. Each is made up of twenty-five orthographic symbols; "Two signs, the space and the twenty-two letters of the [Hebrew] alphabet." ${ }^{, 76}$ As is consistent with the teaching of the Kabbalah, the infinite universe is believed to be contained in the library which contains the total of every possible variable. Borges, however, reveals that this infinite and total library is a contradiction. He maintains that the universe has meaning, not as the container of all possibilities, but through the universal relationship that structures the finite language of religion. Therefore, reality is an interpretation.

The Kabbalah attempts to recreate every possibility in the attempt to know the totality. The intention is that if all the combinations could be written, then the Library would be total. However, the contradiction of this approach is that if the library/universe contains every possible combination, it must contain its negation. ${ }^{77}$ Consequently, the visible reality created by the Kabbalah gives a false impression of the universe. The interpretation contradicts itself and has no value because the conclusions made are accidental. $^{78}$

The contradiction of the infinite and total library, which is ordered by the Kabbalah, is revealed in an example of its system of interpretation. The Kabbalah maintains that every combination of the twenty-five orthographic symbols must have value as one variation of the total. The total of these variations is the library. Borges

${ }^{76}$ Jorge Luis Borges, "The Library of Babel," Labyrinths, Selected Stories and Other Writings. trans. James E. Irby, (New York: New Directions, 1964) 51.

77 “...the searches did not remember that the possibility of a man's finding his Vindication or some treacherous variation thereof, can be computed as zero." Ibid,_55.

78 "They admit that the inventors of this writing imitated the twenty-five natural symbols, but maintain that this application is accidental and that the books signify nothing in themselves." Ibid, 53. 
gives the example of "dhcmrlchtdj" as one variation. He then calls the reader to decipher the riddle with the code of the Kabbalah in the following statement:

"[A]t first glance [the word is] incoherent, [but] can no doubt be justified in a cryptographical or allegorical manner." 79

The decoding of the combination of orthographic symbols consistent with the system of the Kabbalah reveals the contradiction of the system. The Kabbalah gives numerical values to letters, and in this manner, the above combination has a value of 311 . The system of the Kabbalah then re-arranges the sum to find the significance. The most obvious revision of this number is in the manner of 300-10-1. The values symbolize the letters shin, mem and aleph.

In the Sefer Yetsirah (Book of Creation) aleph, mem and shin are called mothers from which the other letters are formed. They are the symbolic figures for the 3 primordial elements. Shin is the hissing fire, Mem is the mute fish and Aleph is the airy air. They are symbolic of the sounds spoken by God in the creation of the earth. ${ }^{80}$

The letters the "mothers" denote are sh, $\mathrm{m}$ and a. When re-arranged they communicate the word "sham." fiction to reveal the self-contradictory or "terrible meaning." Borges communicates the hallucinatory nature of reality as created by religion and derived from language.

${ }^{79} \mathrm{Ibid}, 57$.

${ }^{80}$ Jamie Alazracki, Borges and the Kabbalah: And other essays on his fiction and poetry, (Cambridge: Cambridge University Press, 1998) 48-50.

${ }^{81}$ Similarly, in the fiction; "Death and the Compass" the tautology of a detective story it is revealed that the actor creates what he wants to see, or the hallucinatory nature of reality. His assistant knew all along the murderers were a sham. "It was, as Treviranus guessed, a mere sham." Jorge Luis Borges, "Death and the Compass," Labyrinths, Selected Stories and Other Writings. trans. Donald A. Yates, (New York: New Directions, 1964) 86. 


\section{Trope: Synecdoche in Borges's "The Library of Babel"}

In "The Library of Babel," the librarian reveals that the "universe" cannot be found in the total library that is a combination of all possibilities. He maintained that it is contained within the structure of language, by which both the library and the universe are built. This structure is synecdoche; the relationship of the part to the whole. This figure is present in the structure of "The Library of Babel."

The rhetorical figure which structures "The Library of Babel" is revealed by deciphering the phonetic structure of two sentences. They are the following:

"Within a century, the language was established: a Samoyedic Lithuanian dialect of Guarani, with classical Arabian inflections. The content was also deciphered: some notions of combinative analysis, illustrated with examples of variation with unlimited repetition. $" 82$

The passage calls the reader to decode it. ${ }^{83}$ The code is structured by the twentyfive orthographic symbols and can be decoded according to synecdoche. The comma and colon divide each phrase within the sentence, and the spaces between words divide groups of syllables. Therefore, the phonetic code of the first sentence can be mathematically represented as:

\section{$13: 26$ or $1: 2$}

and the latter as:

$8: 12,22$ or

$8: 24$ or

$1: 3$

${ }^{82}$ Borges, "The Library of Babel," Labyrinths, 54.

${ }^{83}$ In Borges's "Ficciones," the first passage reveals the code 28: 16, 12. 28:28, or 1:1. Jorge Luis Borges. Ficciones, (Buenos Aires, Emecé Editores, 1968) 89. 
Language is a means of communication and connection. The connection in which it is based is synecdoche. The terms of synecdoche share a past in the root; the origin of all variations. ${ }^{84}$ This root is revealed in Borges's fiction by the ratio.

The ratios 1:2 and 1:3 reveal the relationship between the whole and the part. The one is whole, and is also part of the two and the three. They are connected by an imagined unity that enables the terms to reach outside of the self-referential container to reveal a connection between this part and the universe. Like the letters that compose a book, each part is a derivative from the part that is both one and all; the aleph.

\subsubsection{Borges: "The Aleph"}

"The Aleph" is both the title of a fiction and a series of fictions written by Borges. It is both part and whole. In the fiction, the notion of the whole contained by the part is revealed in the memory of the relationship between the author and a woman whom he loved, Beatriz Vitterbo. It is in her that he sees "The Aleph."

The plot begins after Beatriz's death from cancer. To honour and remember her, every year on the anniversary of her birthday Borges goes to her old house and visits with her father and cousin who still live there. On one such occasion, her cousin recites one of his poems to Borges, Borges dislikes both the cousin and the poetry.

Borges's criticizes Carlos Argentio Daneri's poetry for its monotony and redundancy. ${ }^{85}$ A phonetic deconstruction of Carlos' poetry reveals that it lacks a figure

84 "All language is a set of symbols whose use among its speakers assumes a shared past." Jorge Luis Borges, "The Aleph," The Aleph and Other Stories. trans. Norman Thomas di Giovanni, (New York: E.P. Dutton, 1970) 26.

85 "Application, resignation, and chance had gone into the writing... real work lay not in the poetry but in his invention of reasons why the poetry should be admired.... drone of metric regularity tended to tone down and to dull that extravagance." Ibid, 18. 
of exchange. In one translation of the text, the poem reveals the continued recurrence of 12 syllables per stanza, which for Borges represents a monotony of order. ${ }^{86}$

Carlos' poetry is inspired by the "Aleph" in his cellar. His intention is "to set to verse the entire face of the planet." Therefore, like the Kabbalah which seeks the universal in the total, Carlos' Aleph is total, not universal. Despite Borges's affirmation that it is the "multum in parvo,"

Once he finds out that the house and the Aleph will be torn down, Carlos shares it with Borges. He, like Carlos, affirms that in the one-inch Aleph the whole world can be seen. Borges then describes what he saw, acknowledging that the description is limited by the successive nature of language. However, if the Aleph were a true Aleph, the structure of the description would reveal the metonymical relationship that structures both language and the Aleph; the universe.

Neither Carlos' poem, which was inspired by the Aleph, nor Borges description of the Aleph, present the relationship of synecdoche. However, the context of Borges' accusation of in-authenticity is a jealous rant regarding the publication and consequent rewards Carlos achieved for his poetry. ${ }^{88}$ As some critics have maintained, the statement seems to have no validity other than representing his jealousy.

In the context of a Borgesian fiction, this statement is sophistic. It intends to emphasise the question regarding the authenticity of the Aleph, as the question regarding

86 "Mine eyes, as did the Greek's, have known men's towns and fame...[12]" Ibid, 12.

87 "...the Aleph-the microcosm of the alchemists and Kabbalists, our true proverbial friend, the multum in parvo!" Borges, "The Aleph," The Aleph and Other Stories. 25.

88 "Incredible as it may seem, I believe that the aleph of Garay Street was a false Aleph." Ibid, 30. 
Carlos' Aleph leads the reader to find the true Aleph. On the surface Carlos' Aleph seems real. The eloquent and imaginative description, the jealousy of the narrator, and the "normal" cellar in which it was found, especially, add to the Aleph's authenticity. However, a true Aleph would reveal the "multum in parvo" it professes to contain. 89

\section{Trope: Synecdoche in Borges's "The Aleph"}

While the inch of space in Carlos Daneri's cellar is a fraudulent Aleph, there is one in the fiction. It is revealed in the relationship of the part to the whole. The figure synecdoche is present in Borges's description of the face of Beatriz. ${ }^{90}$ Beatriz is the Aleph.

The statement recalling his memory of Beatriz is the last in the fiction. It recalls a previous one regarding the fading memory of pillars of a mosque, which are said to hold the entire universe inside each one. These fading memories reveals that, like the pillars, Borges's memory of Beatriz is the relationship of the part to the whole.

In an early description of the photographs of Beatriz, the following pattern is revealed phonetically; the sentence is divided by the punctuation. ${ }^{91}$

$$
13,5,17: 13,6,12,8,17,8,8,17,17,2,6,2,4,5,4,15,14,6,3,8 \text {. }
$$

89 " [T] he aleph is the first letter of the Hebrew alphabet. Its use for the strange sphere in my story may not be accidental. For the Kabbala, that letter stands for the En Soph, the pure and boundless godhead; it is also said that it takes the shape of a man pointing to both heaven and earth, in order to show that the lower world is a map and mirror of the higher; for Cantor's Mengenlehre, it is the symbol of transfinite numbers, of which any part is as great as the whole." Ibid, 29. Ibid, 30 .

90 "I myself am distorting and losing, under the wearing away of the years, the face of Beatriz."

\footnotetext{
${ }^{91} \mathrm{Ibid}, 15-16$.
} 
The deconstruction reveals the ratio 35:210 or 1:6. Therefore in Borges's memory of Beatriz, the ratio of the part to the whole is found.

The relationship between Borges and Beatriz parallels Dante and Beatrice. "The Aleph" is Borges' homage to Dante's Canto XXXI. The fleeting memory of the woman is the focus of both works. The original, Canto XXXI of the Paradiso, was written to make the memory of Beatrice real. ${ }^{92}$

Both authors lost their unrequited loves to death. In the service of memory, both wrote about the ephemeral characteristics of their love. Borges recalled them in photographs. Dante did not have that luxury.

Dante's memory of Beatrice was metaphorical. He saw her image in the rose.

"The old man shows him one of the circles of the lofty Rose. There, in an aureole of reflected glory, is Beatrice; Beatrice, whose gaze used to suffuse him with intolerable beatitude; Beatrice, who used to dress in red...",93

Similarly, Borges uses the metaphor of the rose to reveal the parallels between Beatriz in "the Aleph" and Clementina in "The Zahir.

"The Zahir is the shadow of the Rose, and the Rending of the Veil.",94

92 "Forever absent from Beatrice, alone and perhaps humiliated, he imagined the scene in order to imagine he was with her." Jorge Luis Borges, "Beatrice's Last Smile," Jorge Luis Borges: Selected NonFictions. trans. Esther Allen, (New York: Putnam, 1999) 302, 304.

${ }^{93}$ Ibid, 304.

${ }^{94}$ Borges, "The Zahir,” Labyrinths, 163. 
"The Zahir" the Islamic variant on this theme of "multum in parvo." In this fiction the narrator is obsessed with a coin called the Zahir. The Zahir means "notorious," and "visible." In this sense, it is one of the ninety-nine Islamic names of God. The people (in Muslim territories) use it to signify "beings or thing which possess the terrible property of being unforgettable, and whose image finally drives one mad." ${ }^{95}$

The coin of obsession, the Zahir, is symbolically the translation of the ephemeral rose into an object. It is a "monstrous copy" for the purposes of faith in religion. The true rose is Clementina Villar. Similar to Beatriz, the relationship of the part to the whole is found in her fleeting image.

"Around 1930, her pictures were clogging the society magazines: perhaps it was the ubiquity that contributed to the legend that she was extremely pretty, although not every portrait bore out this hypothesis unconditionally. "96

The rose is in the description of Clementina's image. The text can be phonetically deconstructed as $7,13: 26,20$, or $6: 6,1: 1$. Clementina is both the root and the whole. Therefore, in "The Zahir" the woman, not the coin, is one and simultaneously all. Clementina is "notorious" and Beatriz is the aleph.

\subsubsection{Borges: "The God's Script"}

"The God's Script" is a Hindu variation on the theme of "multum in parvo." The plot is the search for truth by a priest who is locked in a dungeon and hopes to find the answer by the end of his life. He believes that the key to the universe can be found

\footnotetext{
${ }^{95} \mathrm{Ibid}, 161$.

${ }^{96}$ Ibid, 156.
} 
within the structure of religion. Specifically, the priest believes that god "ought to utter only a single word and in that word absolute fullness."97

The narrowness of his view prevents him from seeing what is right before him, the jaguar in the next cell. He hints that he may be able to find the secret in the spots of the "jaguar measuring with secret and even paces the time ands space of captivity." However, at the moment of his death he maintains that he has found the answer in the Wheel; the Hindu symbol of infinity and the Name of God. He misguidedly believes that the Name is a word and not a trope.

The priest refuses to utter the formula which he says is in the forty syllables and fourteen words that the Hindu religion believes created the world. The creation began with the "alif," the first sound which begot the rest. The resolve not to utter the sound reveals his ignorance. The key is not in the sound or the word "alif." It is in its significance as a trope.

\section{Trope: Synecdoche in Borges's "The God's Script"}

The narrator said himself that the "jaguar was one of the attributes of god." the use of the word tiger interchangeably with jaguar, Borges foreshadows that the "multum in parvo" is in their relationship. The Jaguar, like Beatriz and Clemintina, is symbolically the Name of God. It is the whole and the part.

${ }^{97}$ Jorge Luis Borges, "The God's Script," Labyrinths, Selected Stories and Other Writings. trans. L. A. Murillo, (New York: New Directions, 1964) 171.

${ }^{98}$ Ibid, 169, 171.

${ }^{99}$ Ibid, 170. 
The tiger and jaguar share the same lineage in the genus Panthera. They, however, are of different species. "Species" comes from the Latin specer which means "look" or "appearance." The two cats look different but are the same. Therefore, the interchangeable usage reveals that the animals are the embodiment of the relationship of the part to the whole; a relationship which the priest spoke about but could not see, for he was veiled by the appearance of truth in religion.

Synecdoche is revealed in a description of lineage which parallels that of language. The description is as follows:

"I considered that even in the human languages there is no proposition that does not imply the entire universe; to say the tiger is to say the tigers that begot it, the deer and turtles devoured by it, the grass on which the deer fed, the earth that was mother to the grass, the heaven that gave birth to the earth."100

The phonetic division of the sentence is as follows:

$$
32,15,10,7,8,9 \text {. }
$$

The case of "The God's Script" is unique in respect to the three examples of this theme presented previously. This example has no colon by which to divide the ratio of the part to the whole. The ratio is revealed by the relationship of the content to the structure of the sentence.

The sentence is anticlimactic in its implication of the whole universe. It is structured in reverse; the subject is composed of those before it. The subsequent feed the former and the end is actually the beginning. Therefore in the last digit nine, the origin of the rest is found. 
To achieve the totality which begins at the end, the equation must be read as $32+$ $15+10+7+8+9$. The sum of which is 81 . The root of 81 , the total of the universe, is nine, or the last digit in the equation. This inversion of sequence reveals that what appears to be the end is actually the beginning.

Borges has achieved, symbolically, the reciprocity of the universal and the particular. In his fictions the two are interchangeable in their imagined unity. For example, the use of species and genius interchangeably points to their unity. The space of significance has expanded through the exchange of the figure. Consequently, the particular fiction contains the universe.

\section{Conclusion:Fictions of the Universe}

Similar to his method in fictions of knowledge, Borges renders visible the nature of reality as a construct. In the fomer chapter he achieved this by questioning philosophy. In the fictions of the Universe, however, he makes the invisible structure of the universe, which has its origin in language, visible through its mediation in religion.

The religions of the world are questioned using their origin in language. The deviation from that structure is presented and the religions' contradiction is revealed. Once the invisible is made visible, Borges, syntactically reveals that the structure of the universe originates in language; seeing is speaking. The fiction's are semantically structured around religion because the intention of these fictions are in the connection between sight and sound.

Every religion presented in the above analysis of Borges' work maintained that the world was created when God spoke it into existence. Similarly, the creation of the 
Babylonians' tower in the Biblical parable is rooted in sound. When the Babylonians lost their ability to communicate they were unable to create the vertical bridge to heaven. The Babylonians ceased to be architects when they lost their language.

Grammatically and syntactically Borges reveals the origin of the universe, of the visible. It is in the synecdochical relationship of the part to the whole. Grammatically, the aleph is both the first and all. Furthermore, syntactically, Beatriz is the aleph. She is the origin of creation, and is both the architect and the architecture, the maker and the made.

The operation of the trope synecdoche places the object of intention within the object of the fiction. The first "A" the chiasm "AA" is contained within the second "A." Therefore, the chiasm is reduced to "A." "A" contains the union created by the cancelled subjects of its operation and the object which contains that subject. Furthermore, "A" is the part which contains the whole, it is totem ex parte.

\section{Conclusion: Borges' Metaphysical Fictions}

Borges' metaphysical fictions question the notions of time, the self, knowledge and the universe. The scope of these questions is far reaching. They pertain to ideas about mortality, personal identity and difference, creation, creating and the creator. They do so in a manner that is consitent with their questioning. The implications of these questions are revealed in a trace contained within the structures of the fictions; is a consequence of the process of making.

Borges' process of constructing his fictions is formed around a disruption, caused by a figural operation that structures the work and is later revealed by the work. Those 
figures are the chiasmus, paralypsis, paradox and synecdoche. Each is a figure of exchange. The tranfer of significance between their terms is a consequence of the imagined unity which their reciprocity creates.

The transference that occurs between the terms of the union transgresses a boundary. The flow across the boundary opens a space; a place where the operation leaves its trace. The trace in Borges' works is in the form of the operations which created it.

The trace left by the figural operations employed by Borges in his fictions have implications beyond their own limts. The implications are revealed in an analysis of the following quote.

"Are the enthusiasts who devote themselves to a line of Shakespeare not literally Shakespeare?"101

This quote, like his fictions, is structured by the chiasm. It can be represented by the chiasm: intention/reading/writing/result or object/subject/subject/object.

The connection between reading and writing is of particular importance to Borges. His works intentionally transgress the boundary between the two realms. Borges constructs overlaps in the space of actor and reader, and reader and writer. Typically, in Borges' fictions, he is also the protagonist; he is both the writer and actor of the story. This overlap is pushed futher in Borges' "The Approach to al-Mu'tasim" where the protagonist's identity is never revealed except to say that he is studding to be a barrister. 
Borges' "The Approach to al-Mu'tasim" is a book review of Mir Bahadur Ali's "The Approach to al-Mu'tasim." The reviewer reveals that Ali is a barrister. This coincidence alludes that the fiction is an auto-biography, and implies the fact that the reviewer reads Ali's and writes Borges' fiction, which is of the same name. In this way, the reviewer is both reader and writer.

The double role of the reviewer as both reader and writer links the actor and the writer in the series. ${ }^{102}$ In a chiasmatic way, the connections between the pairs; actor and reviewer (as reader), reviewer (as writer) and writer, lead to the connection of the first to the last, throught the repetition of the middle term and the chiasmatic inversion. In this link the whole intention of Borges four types of metaphysical fictions are found.

Firstly, the scheme of the inversion is a chiasm. Secondly, the set of pairs (the middle subjects of the chiasm) creates a mirror-like inversion. The inversion creates a unity which presents the absence of the pair. Thirdly, the overlap of the reviewer's role as both reader and writer paradoxically reveals that the fiction is an object that contains its subject. The reviewer is both created and creating. Lastly, the chiasmatic inversion is contained within the synecdocal relationship. The schema links the actor; the created subject and first in the series, to the writer; the creator and the last term of the series. This connection is infinite in that the creator is potentially created by another creator.

The four figural operations employed by Borges; the chiasmus, paralypsis, paradox and synecdoche, leave a trace that has implications beyond their own limts. The trace is the subject, contained by the object of its making. This inverted relationship is

\footnotetext{
102 "...these inversions suggest that if the characters of a fictional work can be readers or spectators, we, its readers or spectators, can be fictitious." Borges, "'Partial Magic in the Quixote," Labyrinths, 196.
} 
analogous to the paradoxial situation of the reviewer in "The Approach to al-Mu'tasim." The trace contains another trace. The relationship is therefore infinite.

The mirror and infinity are re-occurring topics in Borges' fictions. The mirror is a means of expressing the relationships that are at the heart of his literary investigations. Borges exploration of the four metaphysical questions is driven by an intention to explore mans' connectedness. Specifically, mortality, the role of the personal identity, the relationship between the process of making and the made, and the made and the maker, drive his work.

These four questions bring his fictions closer to his concern than an outright or obvious concentration would. They point to an embodied connectedness. During an interview Borges responded to a question regarding the type of enjoyment his literature inspires with the following statement.

"The individual is getting away from his personal circumstances and finding his way into another world, but at the same time, perhaps that other world interests him because it's nearer his inner self than his circumstances. "103

It appears as though Borges' work is distanced from the body. His ommission of human experiences; pleasure and pain, may appear to be a critique on what is suitable for scholarly attention. However, like the riddle whose answer is chess, ${ }^{104}$ Borges omits to

${ }^{103}$ Burgin, 139.

104 "In a riddle whose answer is chess, what is the only prohibited word?" The answer is chess. Jorge Luis Borges, "The Garden of Forking Paths," Labyrinths, Selected Stories and Other Writings, trans. Donald A. Yates, (New York: New Directions, 1964), 27. 
give emphasis. The distance of his work from the body- from suffering and pain- is an acknowledgment of its promenance. ${ }^{105}$

${ }^{105}$ "What you yourself can suffer is the utmost that can be suffered on earth. If you starve to death, you experience all the starvation that ever has been or ever can be. If ten thousand other women starve to death with you, their suffering is not increased by a single pang: their share in your fate does not make you ten thousand times as hungry, nor prolong your suffering ten thousand times. Therefore do not be oppressed by "the frightful sum of human suffering": there is no sum...Poverty and pain are not cumulative." Jorge Luis Borges, "A New Refutation of Time," Jorge Luis Borges: Selected Non-Fictions, trans. Eliot Weinberger, (New York: Penguin, 2000) 323. 


\section{The European Union}

\subsection{Program: The European Union}

Shortly after the Second World War, philosopher Alexander Kojève, a Russian immigrant, worked for the French Ministry of foreign economic relations. He corresponded with General de Gaulle about a theory for France's future. France, like much of Europe, was weak after the war, and was fearful that a potential Third World War between America and Russia would be fought on the European continent. In response, Kojeve designed an allied "Latin Empire."”

The empire was thought of as a balance in response to the two existing powers. The empire was to be a neutral actor in the prevention of war on the continent, and the occupation and appropriation of France by the Anglo-Saxon or Slavo-Soviet Empires. Kojève saw the alliance as the mediating step between the current reign of the sovereign state and the Universal and Homogenous State he envisioned for the future. ${ }^{2}$ The alliance of nations with Latin-based languages and a Catholic Church would serve as the common thread for the alliance.

Kojève maintained that the Union was necessary because of the advancement of military technology. Improvements in technology made it impossible for a single nation to maintain the militaristic resources needed to protect its sovereignty. To "sustain a modern war," the Germans had to exploit other countries, importing ten million foreign

${ }^{1}$ Alexandre Kojève, "Outline of a Doctrine of French Policy (August 27, 1945)," Policy Review 126 (2004) : 1.3. 7 May $2005<$ http://www.policyreview.org/aug04/kojeve.html>.

${ }^{2}$ Ibid, 2.1 .

${ }^{3}$ Robert Howse, “Kojeve's Latin Empire.” Policy Review 126 (2004). 7 May 2005 $<$ http://www.policyreview.org/aug04/howse.html>. 
workers. ${ }^{3}$ However, Germany, still wanted to win a as nation-state. Their exclusivity and dependence on external resources marked their eventual downfall. ${ }^{4}$

Similarly, the failure of the all inclusive socialist State was their perspective. The Internationalism of the Soviet empire was utopian in that it saw "nothing politically viable short of Humanity." To achieve the vast undertaking of this inclusion, socialism had to turn the idea of all of humanity into an abstraction. It compromised its ideal to be the best for all, by lowering its own standards of what "best" meant. Best became a question of quantity not quality.

Germany's failure was based on the perspective of exclusivity and Socialist Russia's failure was based on its excessive inclusion. The focus of the former was on the microcosm and the focus of the latter on the macrocosm. The perspective of the Latin Empire relates both micro and macro through synecdoche. The macro is contained within the micro. In this way the micro is a whole in itself.

Kojève's "empire" would be created out of a Latin "general will" to autonomy. ${ }^{6}$ The economy, not the military would give the union its strength through the abolition of economic barriers. Furthermore, a political elite, which would govern independent of the electoral process, would stabilize the system. The governing body would function "above the municipal conflict of the Left and of the Right."

\footnotetext{
${ }^{4}$ Robert Howse, "Kojeve's Latin Empire.” Policy Review 126 (2004). 7 May 2005 $<\mathrm{http}$ //www.policyreview.org/aug04/howse.html $>$.

${ }^{5}$ Kojève, 1.2.

${ }^{6}$ Ibid, 3.3 .

${ }^{7}$ Ibid, 4.2 .
} 
The E.U. recognizes that the conflict between the political positions is stagnant to the political progress. Consequently, it is structured in three tiers. Two tiers have the power to accept or deny policy; they include the Parliament and Council. However, they do not have the ability to write it; instead a hired workforce writes and implements policy. The resultant "democracy deficit" threatens the current world order. ${ }^{8}$

Today's European Union finds its origin in Kojève's "Latin Empire." Its ideals were implemented in the creation of the European Coal and Steel Community. This community attempts to prevent material shortage established by the alliance of purchasing power and colonial exploitation. The origin of the community is revealed in the "Outline of a Doctrine of French Policy," written by Alexander Kojève and presented to the French government on August 27, $1945 .^{9}$

The Union has the potential to be more than intended and its success depends on the people. The people, who are accustomed to electing local officials, may find the transfer of sovereignty to the Union difficult. However, globalization is re-defining boundaries and Europe has to follow suit. Consequently, the scale of the nation-state will soon be out of date. The union is in the best interests of the state.

This shift in scale will lead the European Union to re-connect governance with the primary concerns of man as Municipalities replace nation-states. Consequently, the particularities of geography and culture will gain new emphasis. The re-connection of

\footnotetext{
${ }^{8}$ Lee A. Casey and David B. Rivkin Jr. "Europe in the Balance," Policy Review Magazine 107
} (2001). 7 May $2005<$ http://www.policyreview.org/jun01/casey.html $>$.

${ }^{9}$ Alexandre Kojève, "Outline of a Doctrine of French Policy (August 27, 1945)," Policy Review 126 (2004) : 1.3. 7 May $2005<\mathrm{http}: / /$ www.policyreview.org/aug04/kojeve.html $>$. 
the political macro and microcosm will encourage the idea that the union is contained within, and is only as strong as, each individual who participates within it.

The European Union, like Borges' fictions can be analyzed through the structure of the chiasm. The chiasm, in this case, can be represented by the schema; European Union/writing the constitution/reading the constitution/Nation-state. The E.U. is the intention of the nations of the European continent. The constitution is written by those members. The made, the E.U., is formed by the making; the writing of the constitution. It contains the trace of that process.

The E.U., furthermore, inverts the relationship between the made and the maker. It is made by the member states, yet the Union re-writes the notion of a nation. Therefore, the Union; the made, becomes the maker. This connection is infinite. It links all creation. 


\subsection{Project: The Delegation for the Commission of the European Union in Ottawa}

\section{$\underline{\text { 3.2.1 Site: Sussex }}$}
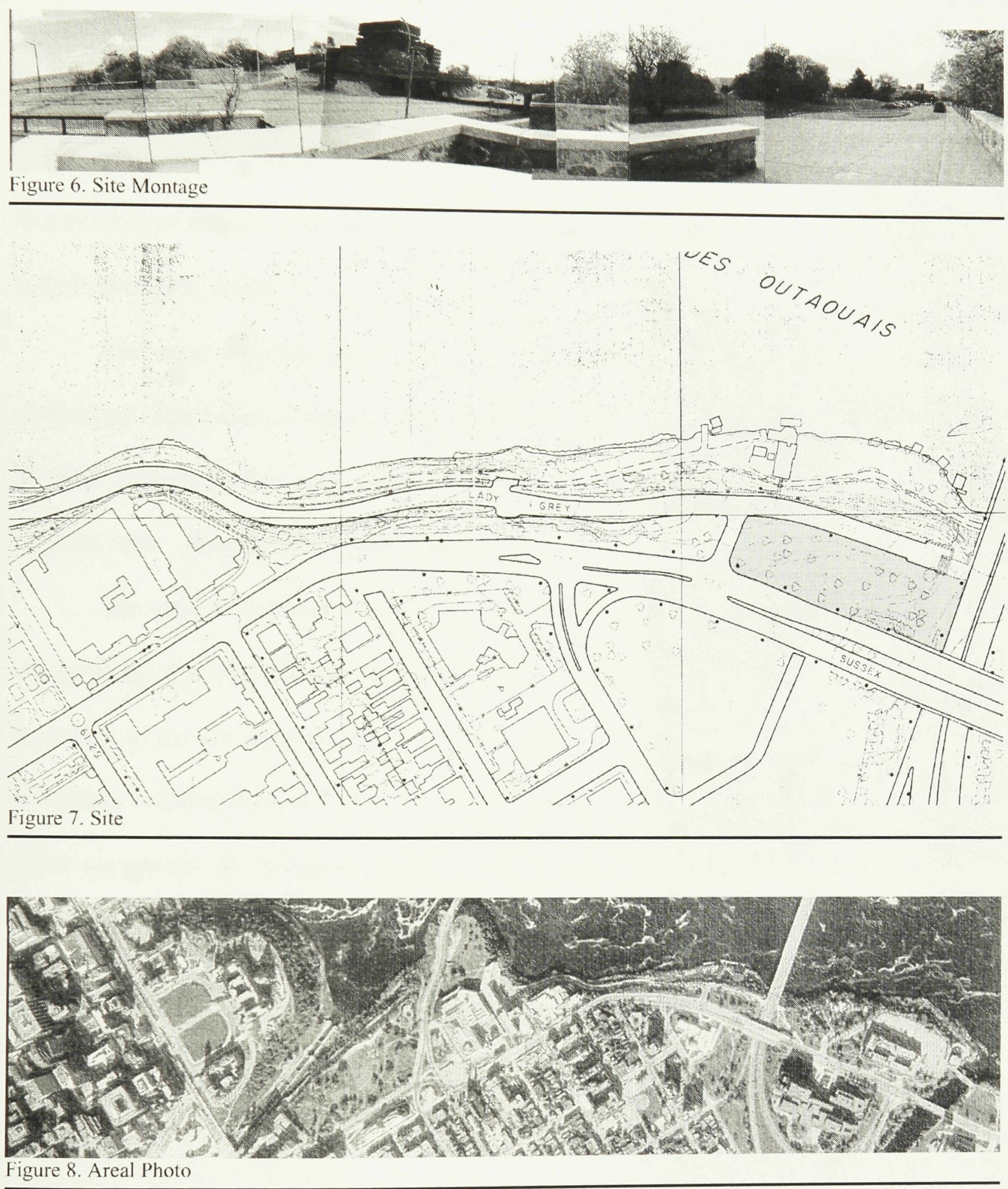


\subsubsection{Process:}

\section{A. The Cube}

The etymological origin of the word cube comes from the Latin cubus and the Greek kybos, which means "die" or "solid figure of six equal sides." The die is a numbered cube used in games. It is a symbol of chance. Similarly, the ancient unit of length, the cubit, comes from the same origin.

The cube was the framework for the process of making. The process began with its division. The division is made by the insertion of continuous planes into the cube. The planes are möbius-like.

The games' rules are; (1) the planes can turn at angles but they must be continuous and (2) touch at least two of the six external sides. The continuity of the planes ensures the division of the cube into parts. After separation the resultant parts are then rotated. The rotation must result with one plane parallel to the ground plane. It cannot end on a point.
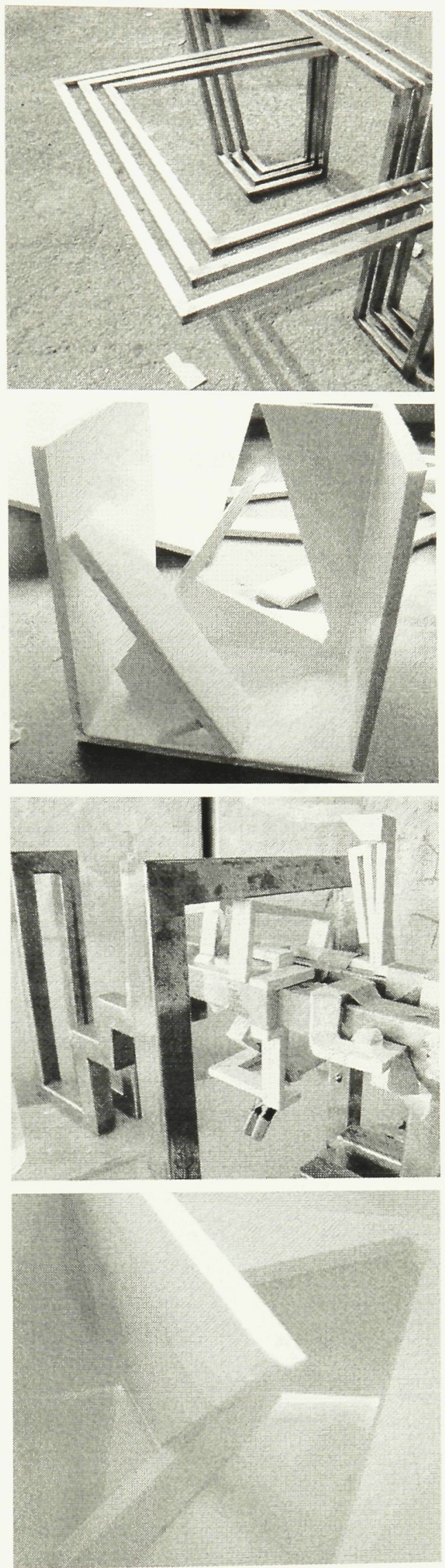

Figure 9. The chiasm 
Salik 72
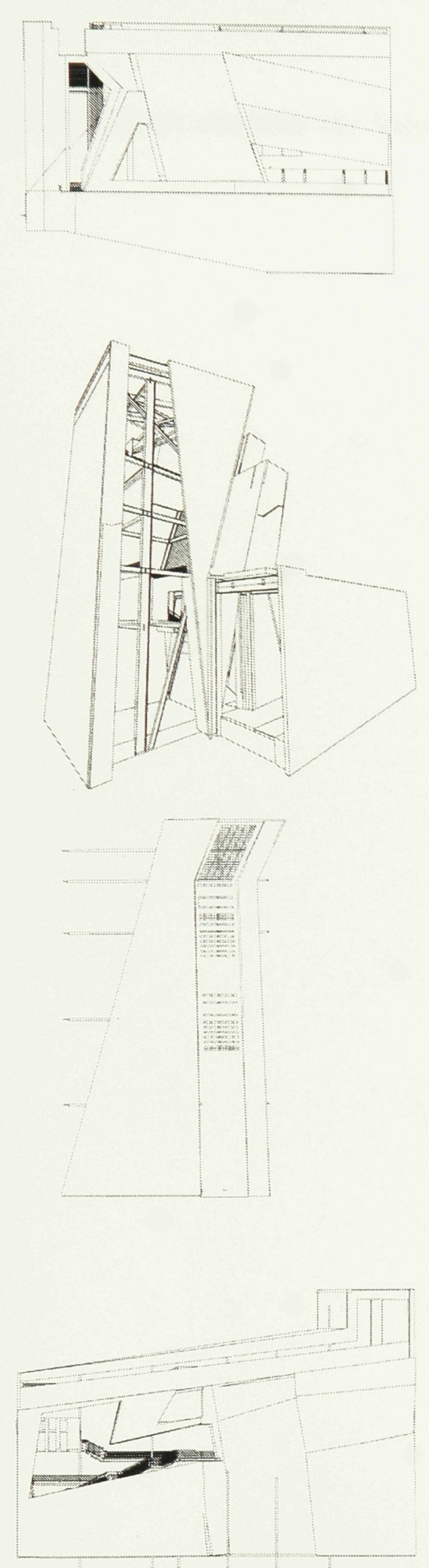

Figure 10. Paralypsis
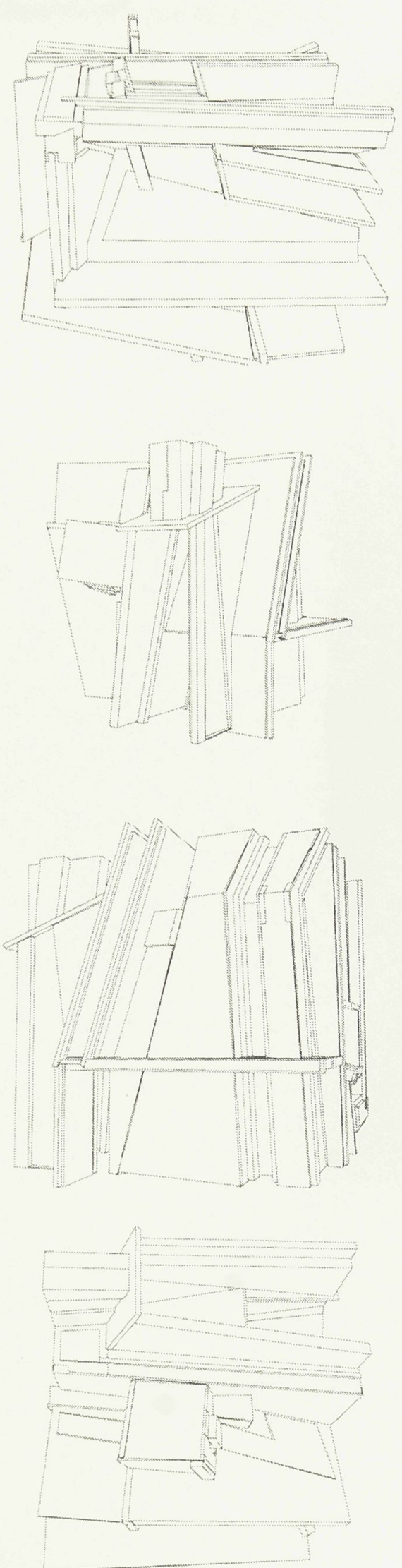

B. Difference and Inverse

The

process of dividing and separating parts from the cube reveals visible connections. Planes on either side of the dividing plane are related. The relationship is one of inversion. Furthermore, each part of the couple refers to the plane which divided them. While it is no longer physically present, it is emphasized 
by its absence. The relationship is therefore a paralypsis.

B. The Object contains the Subject
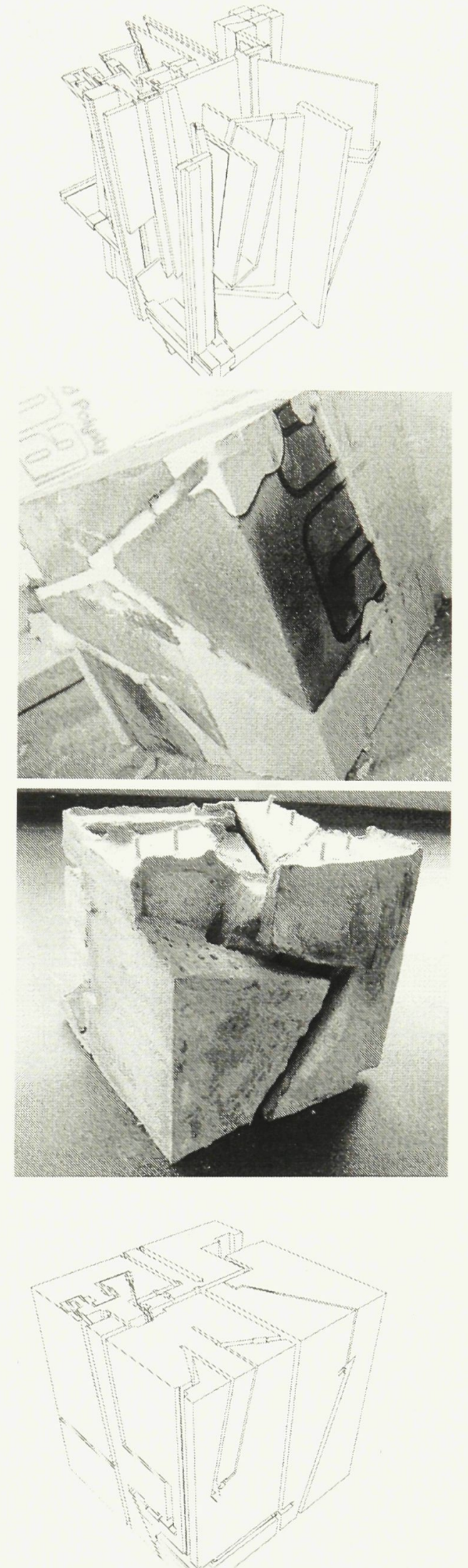

Figure 11. Division 
Salik 74

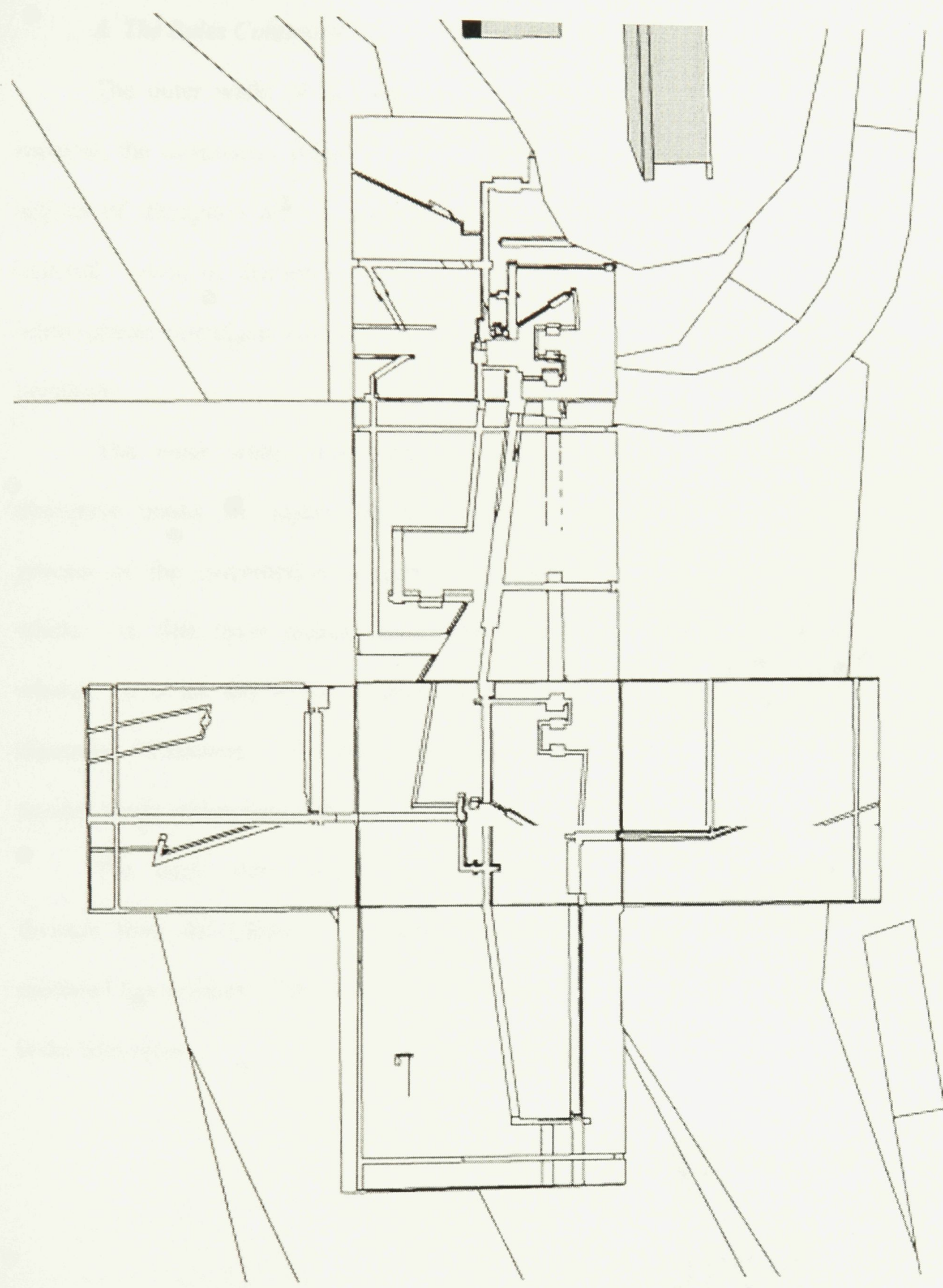

Figur IO Map 


\section{A. The Rules Continued}

The outer walls of the cube are of one material, the continuous planes of another. The actions of disruption are of a third and fourth material. Acts of disruption include moments where planes extend and cut into another space of continuity.

The outer walls, inner walls and the disruptive marks are layers which reveal the process of the construction of parts from the whole. A fifth layer makes those parts into wholes. It is the key to the reading. It is the chiasmic "formwork" for the generation of another world within this one.

The parts were formed through their division from the whole. A continuous plane mediated that division. This möbius-like structure is the fifth-layer.
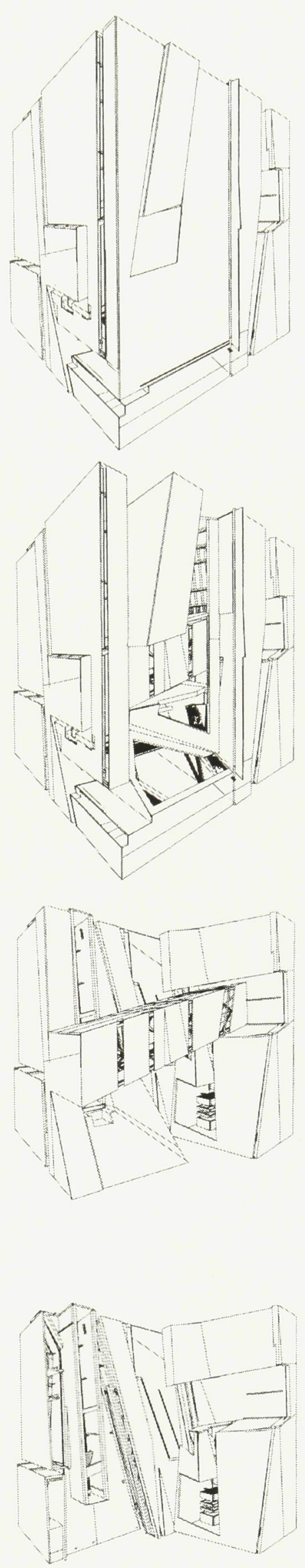

Figure 1:3: Sequenee 
Salik 76
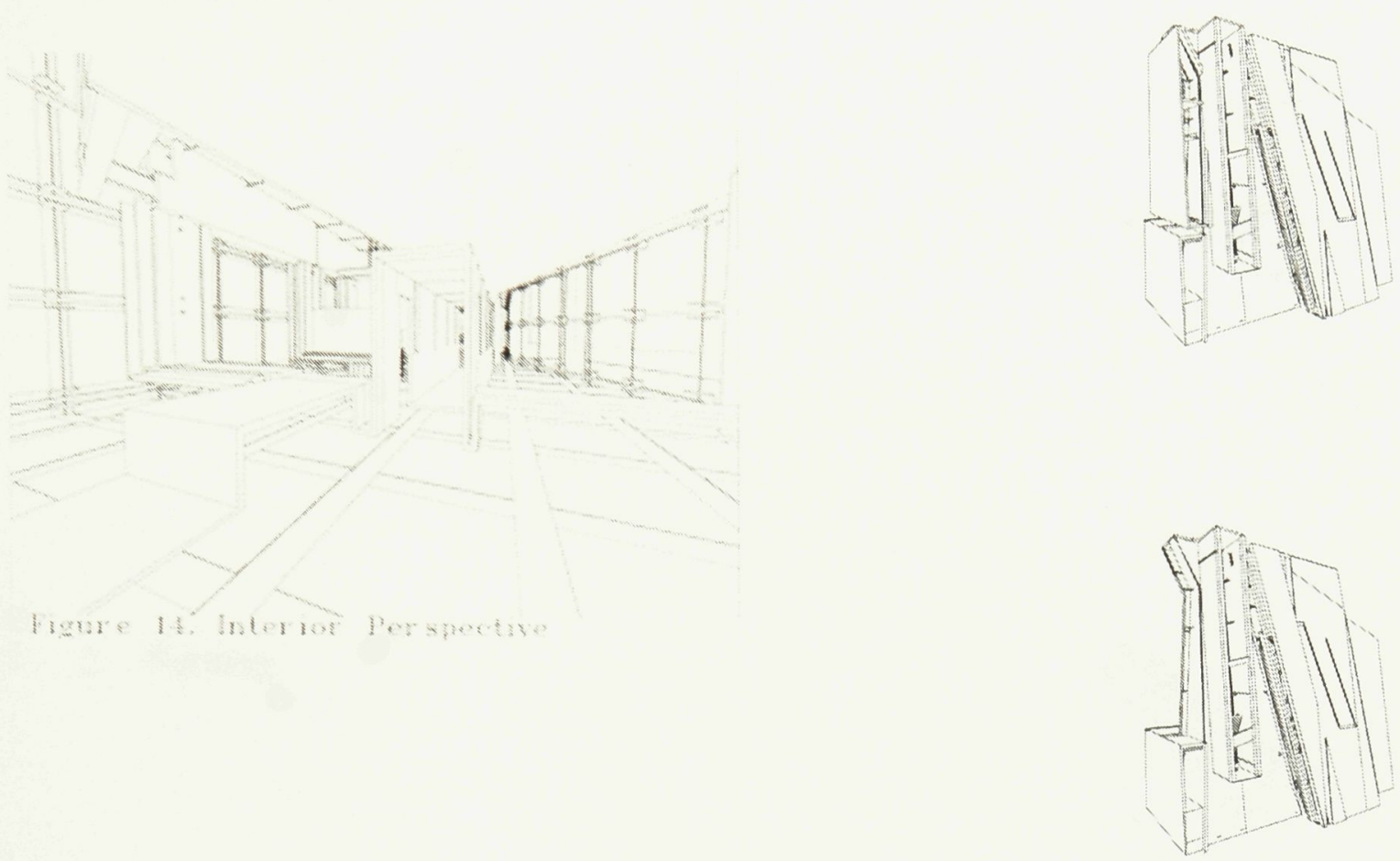

\section{Proposal:}

Each puzzle part contains one aspect of the program, of which there are eight. The components are divided

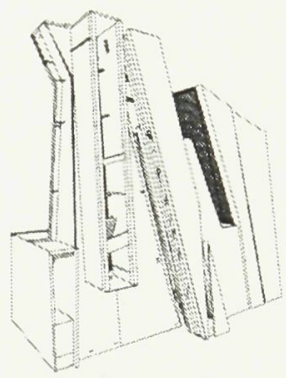
into the following categories.

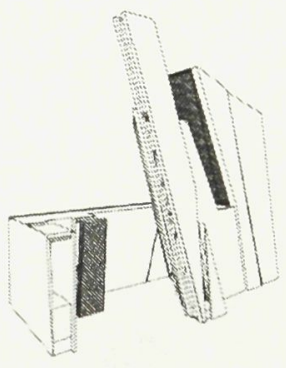

Figure 15. Whole to parl 
1. Security/Entrance

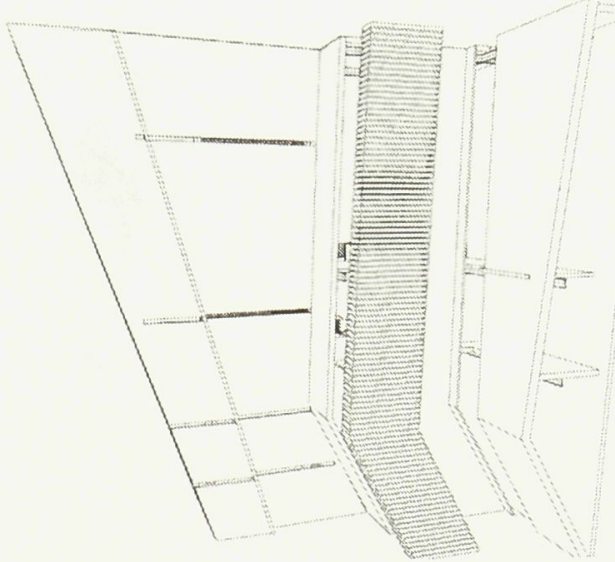

2. Parking

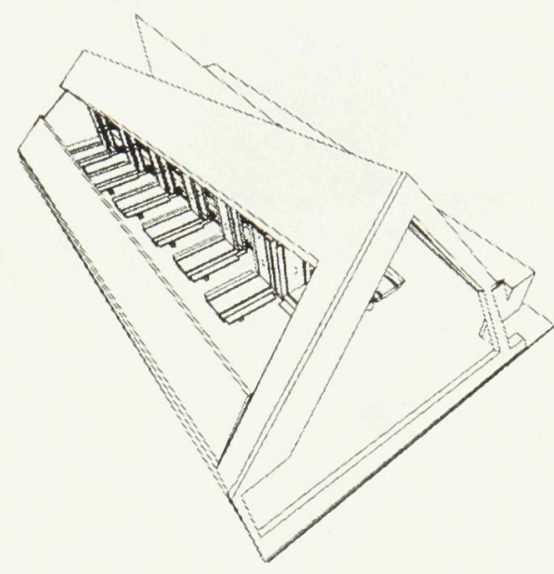

3. Political and Public Affairs

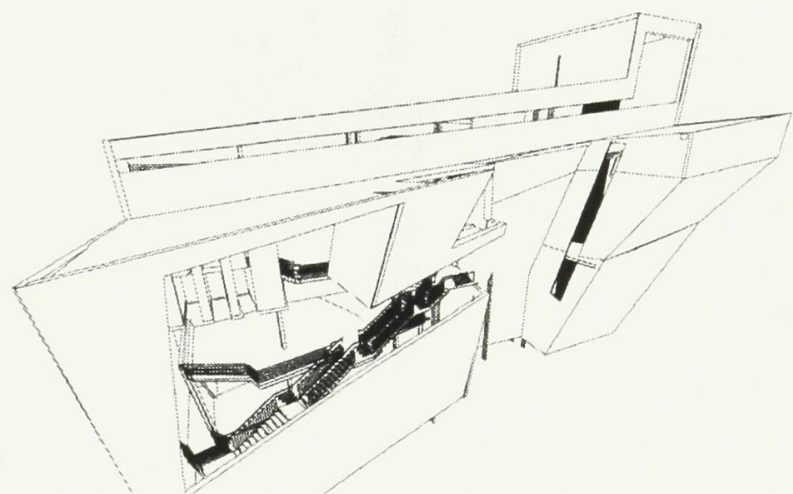

4. Gallery and Events Space

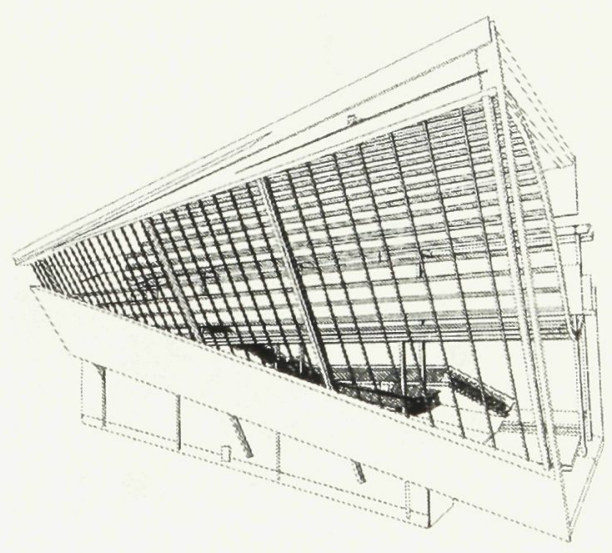


5. Theater/Conference Center

6. Economic Affairs

7. Research

8. Ambassadors' Residence, Office and Commissioners Suite
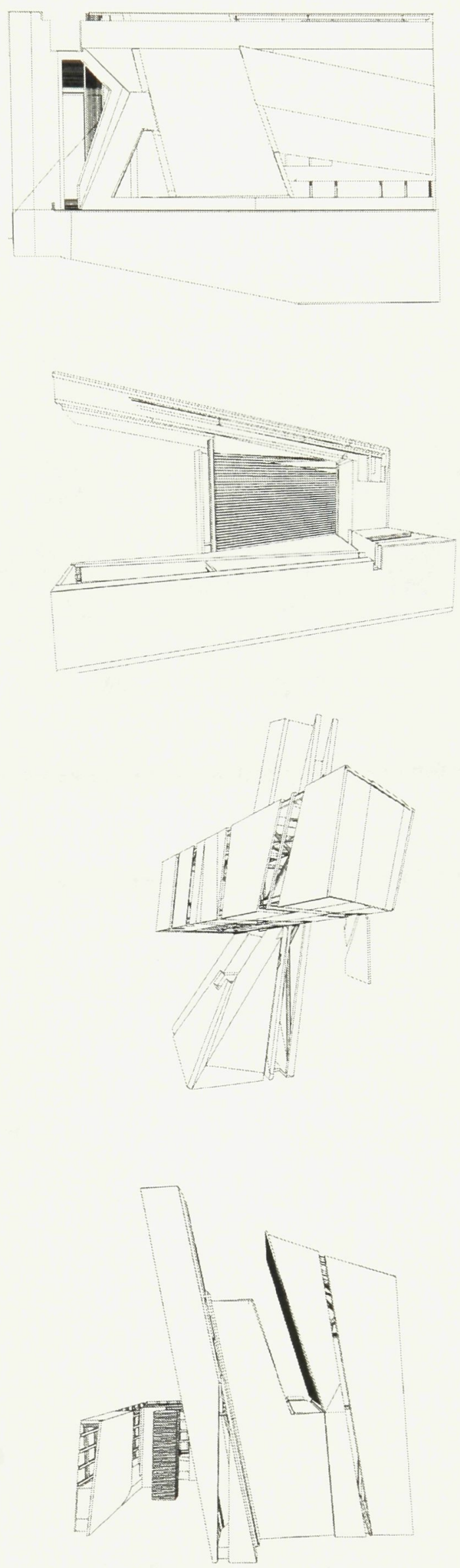
Site Plan:

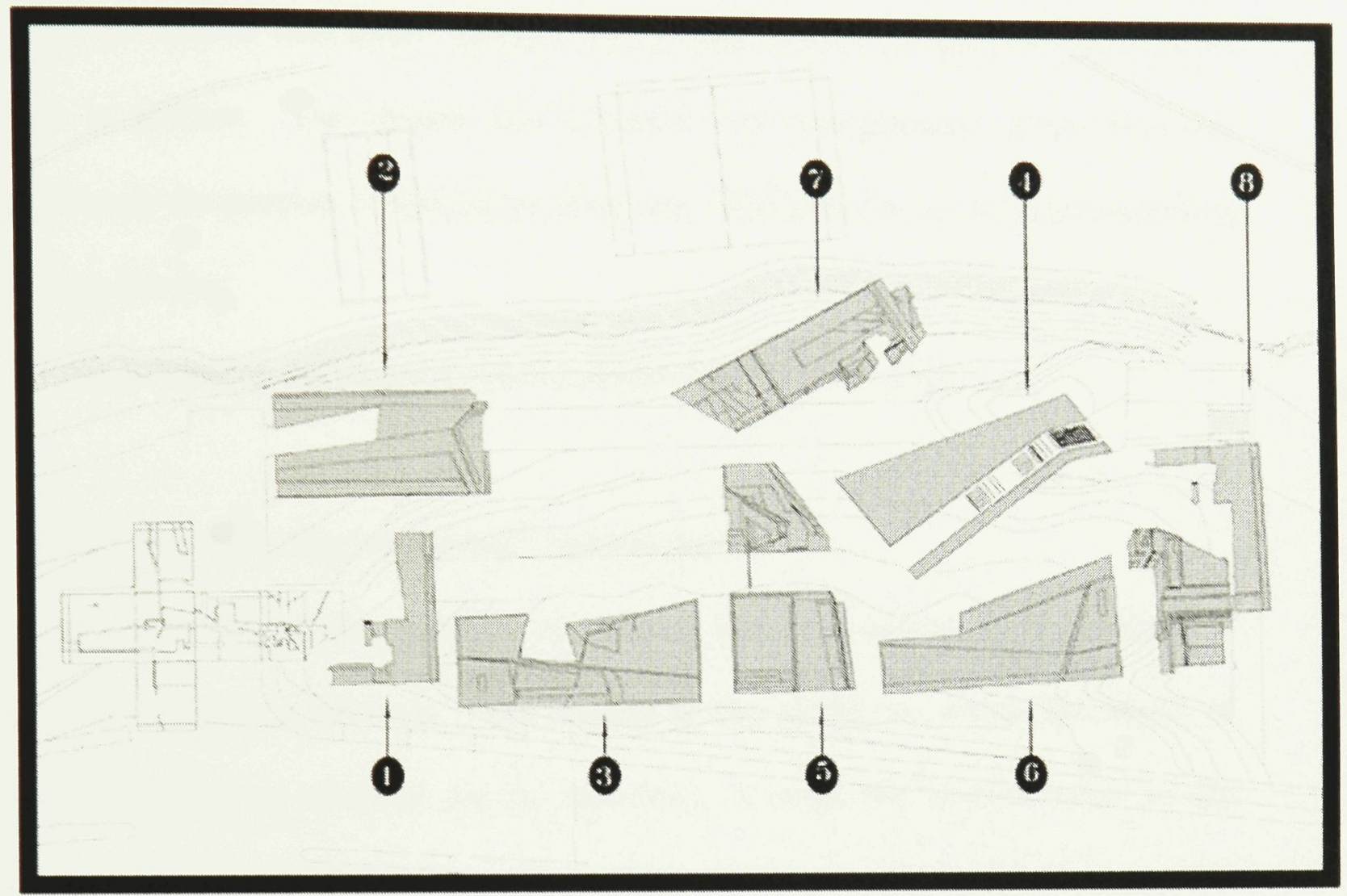

Pagerto di. Site Mati

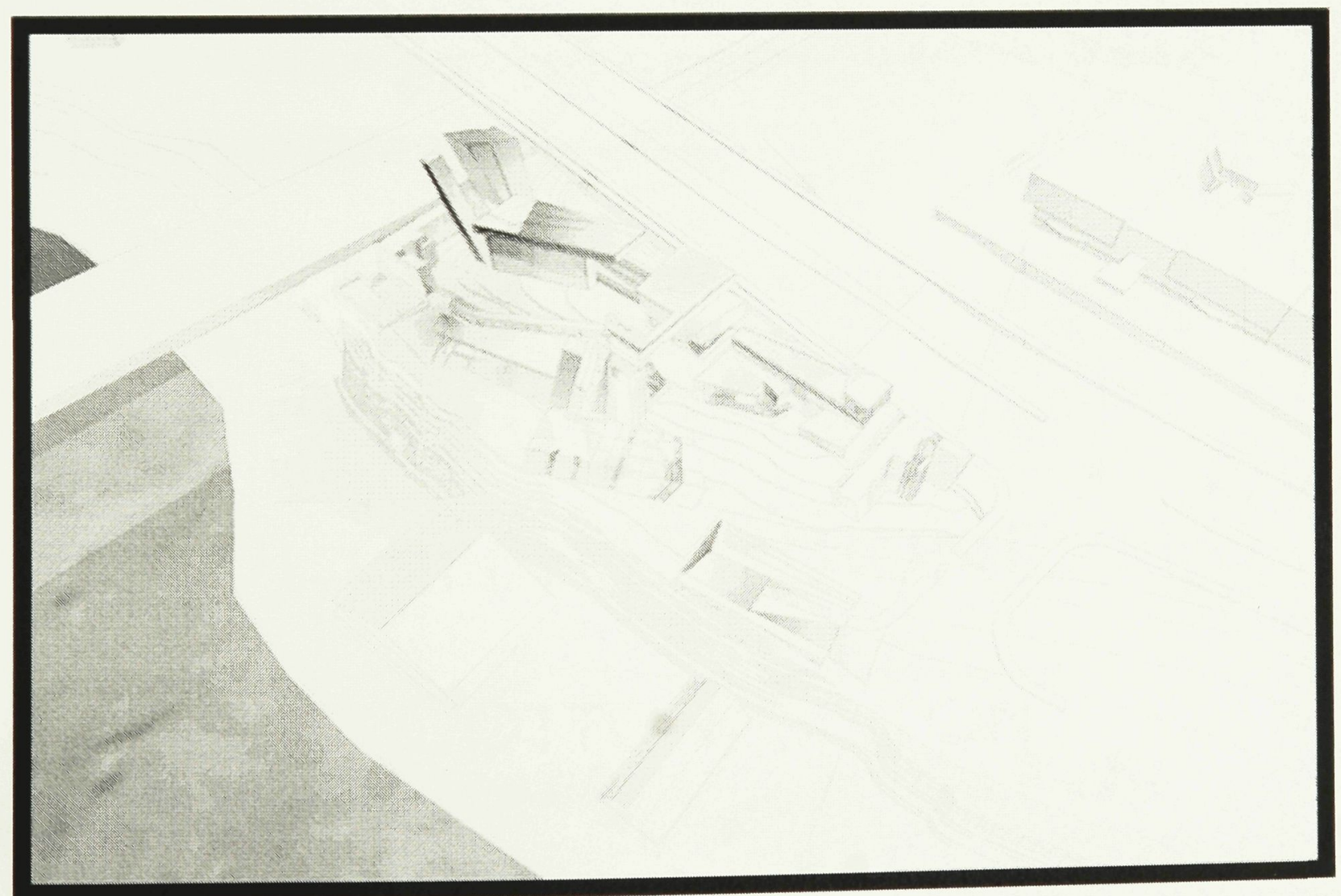

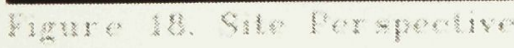




\section{$\underline{5.5 \text { Conclusion }}$}

The chiasm, which questions the notion of time, structured the metaphysical question of the self in this thesis through the deviant characters and the question of knowledge in politics. The chiasm also structured the metaphysical question of the universe through the process of making architecture. This process can be represented by the following chiasm:

Intention/writing architecture/reading architecture/Architecture

or

Intention/constructing/construing ${ }^{11} /$ Architecture

The connection of the subjects of making and the objects of architecture is revealed in the chiasmic structure. The chiasm is the mirror by which the object of architecture becomes an allegory for the universe. It links the inverse terms of the subjects constructing and construing as the making. Then the chiasmic inversion turns this unified subject inside of the object of its making. Finally, the intention which contains its subject is contained by the result. In this manner architecture embodies the chiasm. It reflects the invisible so as to make it visible.

${ }^{11}$ Marco Frascari, Monsters of Architecture: Anthropomorphism in Architectural Theory, (Savage, MD.: Rowman \& Littlefield, 1990) 18. 


\section{Deviants}

\subsection{Intention}

"The faithful who come to the Amr mosque in Cairo, know very well that the universe lies inside one of the stone columns that surround the central courtyard...No one, of course, can see it, but those who put their ear to the surface claim to hear, within a short time, the bustling rumor of it... The mosque dates to the seventh century; the columns were taken from other, pre-Islamic, temples, for as ibn-Khaldun has written: In the republics founded by nomads, the attendance of foreigners is essential for all those things that bear upon masonry."

The allegory above symbolizes synecdoche; the reciprocal relationship of the part to the whole. Specifically, it reveals architecture as the microcosm of the universe. The connection is made through a link between the column and the nomad. Through the personification of the column as a foreigner, the parallel is revealed. Consequently, in man, like the column, the whole of the universe is heard.

The intention of this thesis is to create an architectural allegory for the universe; where the whole exists within the part. This connection is an exchange called synecdoche in literature. The fantastic body reflected by the chiasm creates synecdoche.

The reflection of the chiasm is infinite, like a set of mirrors opposite one another. The infinite reflection is significant through a coincident moment that it invents; the subject is contained by the reflected object. The invisible is thereby made visible.

The task of the architect is to "make visible that which is invisible." the mirror, in which man can view his body; can see his self, is to create architecture. Architecture, therefore, is the body. For it is only through the body, that one can perceive the body. Through the inversion of the double subject into the object (seeing in to being

${ }^{1}$ Borges, "The Aleph," Jorge Luis Borges: Collected Fictions, 285-286.

${ }^{2}$ Marco Frascari, Monsters of Architecture: Anthropomorphism in Architectural Theory, (Rowman \& Littlefield, 1990) 4. 
seen), the intention is written on the architectural body. That body is an allegory for the universe.

\section{$\underline{4.2}$ Four Deviant Characters}

The deviant subject is the embodiment of the constructive operation which reveals the illusions of personal identity. The deviant character is the site of exchange between two terms, terms which are considered opposites. The exchange is a reverberation which confuses "the edges [bordes] of the container with the overflows [desbordes] of the contained." ${ }^{\prime 3}$ The confusion opens the boundary of significance between signifier and signified and makes visible the invisible.

The deviant is the personification of the signs which reveals that we have dreamt the world. ${ }^{4}$ The characters' confusion of the boundary of significance allows it to be transgressed. Four characters will be explored for their capacity for transgression. They transgress the boundaries between the temporal and eternal, presence and absence, passion and reason, and life and death.

\subsubsection{Time and Eternity: The" Chelephant"}

The elephant, like time, is a moving image of eternity." 5 The animal's physical attributes, or image, inspired its comparison to two of the four elements. The grey color and round shape linked the animal symbolically to clouds and mountains; air and earth.

\footnotetext{
${ }^{3}$ Block De Behar, 173.
}

${ }^{4}$ Jorge Luis Borges, "Circular Ruins," Labyrinths, Selected Stories and Other Writings, trans. James E. Irby, (New York: New Directions, 1964) 50.

5 Jorge Luis Borges, "A History of Eternity," Jorge Luis Borges: Selected Non-Fictions, (New York: Putnam, 1999) 123. 
As the mediator between the realms of the earth and the sky, the elephant came to represent the horizontal axis of the universe. ${ }^{6}$ Due to this threshold condition, the elephant became the symbol of eternity. ${ }^{7}$

\subsubsection{The Twin Self: The Dioscuri and Gemini}

"absolute completeness in the division of a given whole." 8

The synchronous relationship of the Greek mythological characters Castor and Pollux seen through the legend of the Dioscuri reveal the significant completeness of their division. The characters are twins whose relationship of perpetual inversion is significant in that each is predicted in the whole. This relationship questions the notion of origin and the self. Each part is defined by its connection to the original whole.

The legend of the Dioscuri has origin in the third race or Bronze Age of Greek myth. The third race was androgynous. They produced their young by exuding drops of vital fluid, which formed an egg shaped ball. It is in this manner that Leda produced the twins Castor and Pollux (aka. Polydeuces- "multiple double"). ${ }^{9}$

The Dioscuri are fraternal twins; they came from two different eggs. From one came Pollux and Helen and the other Castor and Clytemnestra. Zeus fathered the former, and Leda's husband, Tyndareus, mortal king of Sparta, fathered the latter.

Elephant.

\footnotetext{
${ }^{6}$ As a chiasm, "The Chelephant" can be represented as: Chelephant/mortality/immortality/
}

${ }^{7}$ J.E Cirlot, A Dictionary of Symbols. 2nd ed. (London: Routledge, 1993) 96.

${ }^{8}$ Immanuel Kant, Critique of Pure Reason, (London: Everyman, 1993) 312.

9 "Pollux, " Microsoft Encarta College Dictionary, 2001. 
Castor's title, Dioscuri, is not etymologically accurate. He is not a "son of Zeus" or Dioskouroi in the biological sense. He came to be known as Dioscuri due to the actions of his immortal brother, which caused the title to be shared. The title is shared through the perpetual inversion. ${ }^{10}$

The legend has it that Castor was killed in battle and Pollux was not. Zeus had given the latter immortality. Pollux, however, would not accept the gift which demanded the eternal division of the twins; Castor in the underworld, and Pollux with the Gods. As a compromise, Zeus allowed each to spend one of every two days among the Gods and the other in the Underworld. ${ }^{11}$ This compromise is one of perpetual inversion and exchange (return).

The infinite exchange of the two between the realm of the gods and the Underworld represents the true character of the Dioscuri. It is a totality rather than a dichotomy. The relationships of Pollux and Helen, and Castor and Clytemnestra, respectively, are dichotomous. Such is the relationship of the masculine to the feminine. However, the Dioscuri are not contradictory but plenary. ${ }^{12}$

The Dioscuri is a whole, whose division in space and time is deceptive. The division between the realms, initiated by the sacrifice of Pollux, reveals the "absolute completeness" 13 of the twins, not their independence. The division requires a daily inversion of the situation which joins the two in a synchronous significance. The presence of each symbolizes the absence of the other and the future inversion.

\footnotetext{
${ }^{10}$ Pierre Grimal, The Dictionary of Classical Mythology, (Oxford: Blackwell, 1996) 141,107, 254.

${ }^{11}$ Grimal, 141,107, 254.

${ }^{12}$ Ibid, 141,107, 254.

${ }^{13}$ Kant, 312.
} 
Gemini, like the Dioscuri, is the symbol of inversion. Gemini is a zodiacal constellation whose most prominent features are two bright stars; Castor and Pollux. Castor is alpha Geminorum, a spectroscopic binary, the two components of which revolve around each other. Pollux is beta Geminorum, a star of the $1^{\text {st }}$ magnitude.

The connection between Gemini and the Dioscuri is as a copy of the original. As a chiasm this relationship can be represented as:

\section{Dioscuri/pollux/castor/Gemini}

The subjects Pollux and Castor cancel each other out. The consequence is an imagined unity. This relationship of perpetual inversion labels them "Dioscuri." "Dioscuri" signifies the process. Lastly, the unity of the Dioscuri is contained within Gemini. Gemini is an interpretation of the original that contains a trace of the process of its own creation.

\subsubsection{Knowledge: Medea}

Sorcery is a symbol of chance. "The word 'sorcerer' clearly designates victims of chance and, so to speak, the poisonous mushrooms of fatality."14 The sorceress Medea, for example, is an avatar of chance. As a practitioner of Goëtic, or Black Magic, Medea possesses alchemic knowledge and is able to harness and manipulate the tentative nature of knowledge. ${ }^{15}$

The legend of Medea is one which manipulates the staples of reality. Medea commits the greatest atrocities: patricide, fratricide, and infanticide. The latter of which

\footnotetext{
${ }^{14}$ Levi, 90 .

${ }^{15}$ Levi, 90 .
} 
holds the most force in destabilizing the image of reality. Her ability to mediate reality is revealed in her passion; the characteristic which makes her difficult to control.

The event which is catalyst to her subsequent crimes is the atrocity of patricide. Medea reveals to Jason how to win the Golden Fleece - an allegory of alchemy - from its guardian, her father. In doing so, Medea commits patricide. The law is such that the guardian of the fleece will suffer death in the event that it is lost. ${ }^{16}$

Medea chooses to be faithful to her husband over her family. During her and Jason's escape, Medea kills and dismembers the body of her younger brother and throws him off of Jason's ship, The Argo. This action delays the pursuers who seek to avenge the death of her father. Consequently, the couple are able to escape because the pursuers are forced to collect his body for burial.

The couple later settles in Corinth, where Jason leaves her and the two sons she bore him to marry the princess. Medea vows revenge. Under the guise of a gift, she has her sons deliver poison to the princess and the king. Then she murders her sons to prevent the king's family from taking vengeance on her through them. The guilt she feels for this action against nature is relieved in knowing that she has made Jason suffer. ${ }^{17}$

Euripides' interpretation of this myth ends with a statement on the gods and destiny, revealing that her actions are a test of fate. ${ }^{18}$ Through her choices against nature, she altered her own destiny. Her passion is the element of chance which fate could neither predict nor control. While nature demands that a mother nurture her children,

\footnotetext{
${ }^{16}$ Ibid, 86-91.

${ }^{17}$ Ibid, 91 .

18 Philip Vellacott, tr. Euripides: Medea and Other Plays, (London: Penguin, 1963) 61
} 
Medea selfishly killed them. Medea is life-giver and life-taker. Therefore, she is pejoratively viewed as unnatural or evil, and especially not "normal."

The norm is a condition which comforts individual decisions. When one acts in the norm, there is a sense of security in visible reality. However, when an action presents itself as unnatural or not normal, this action has the capacity to reveal the illusion and malleability of the real. Therefore, the selfish passion of Medea is the mediator which reveals the tentative nature of reality; it confuses the normal.

Medea is life-giver and life-taker. She can be represented by the chiasm:

Medea /murderer/mother/Child

In Medea the simultaneity of being a murderer and mother cancel one another out. The result is written on her. While physically the child was once contained within her, the chiasmic inversion places her inside her children. Medea is the trace of the action which created and murdered her children.

\subsubsection{Space: Contiguity and Cannibalism}

"...the law of sympathy... assumes that 'things act on each other at a distance” through a secret sympathy, either because their form is similar (imitative or homeopathic magic) or because of ...contagious magic." 19

${ }^{19}$ Jorge Luis Borges, "Narrative Art and Magic," Jorge Luis Borges: Selected Non-Fictions, (New York: Putnam, 1999) 80. 
The magical rite is preformed by the laws of similarity and contiguity. The former law affects objects with physical similarities and the latter through the connections of its parts to the whole. Contagion connects two physically separate objects through their meaning and the significance of their relationship. Cannibalism is an example of the rite which acts in the law of contagion.

The practice of cannibalism is an example of the ideologically causal relationship of contagion. There are two main types of cannibalism, endo and exo-cannibalism. Endo-cannibalism, which occurs between loved ones, is practiced to unite the spirit of the deceased with their living relative. It links subjects through a physical operation of synecdoche. Spiritually, the action is reciprocal.

The practice of exo-cannibalism is intended for the acquisition of traits the victim possessed in life. The crossing of the trait through the figure links the two actors in a substitution. Exo-cannibalism is an example of metonymy. There are few contemporary examples of endo-cannibalism, therefore an example of exo-cannibalism will be used to reveal the crossing of contagion in the deviant.

In 2001, a German by the name of Armin Meiwes performed exo-cannibalism. Meiwes had posted a request for a good-looking volunteer on the internet. ${ }^{20}$ The act, which was not hostile, was shared by the two participants. ${ }^{21}$ Mr. Meiwes believed

${ }^{20}$ Clare Murphy, “Cannibalism: A modern taboo,” BBC News 2 Dec 2003. 11 May 2005 $<$ http://news.bbc.co.uk/1/hi/world/europe/3254074.stm>.

${ }^{21}$ During the trial Meiwes revealed a fantasy of having a good looking younger brother, to whom he would bind to himself through consumption. Clare Murphy, "Cannibalism: A modern taboo," BBC News 2 Dec 2003. 11 May 2005 <http://news.bbc.co.uk/1/hi/world/europe/3254074.stm>. 
physical attributes would be transmitted metonymically. He chose specifically which part he wanted to consume.

The practice of cannibalism for Mr. Meiwes was based on the belief in the law of contiguity. Furthermore, the connection between the part and the whole was believed to enable the continuation of life. Through consumption, traits and spirits would be transmitted. These transmissions in contiguity revealed that life did not end with death. Therefore, the deviant cannibal embodies the boundary between life and death, between personal mortality and universal immortality. ${ }^{22}$

\subsection{Process}

The process of my investigation mirrors my intention. I began my investigation with characters which embody the notion of the plural within the singular. Four "deviant" characters were chosen as sites. The site is a boundary between worlds. The characters which embody the boundaries are "The Chelephant," Gemini, Medea and the Cannibal.

"The Chelephant" is an elephant. The animal transgresses the boundary between the eternal and the temporal and symbolically represents the horizon; the boundary between earth and sky. Gemini is simultaneously present and absent. Medea embodies the boundary between reason and passion where the object contains its subject. Lastly, the Cannibal is both life and death, both one and all.

\footnotetext{
${ }^{22}$ Cannibal is the deviant represented by the chiasm: Victim/eaten/eating/Cannibal.
} 

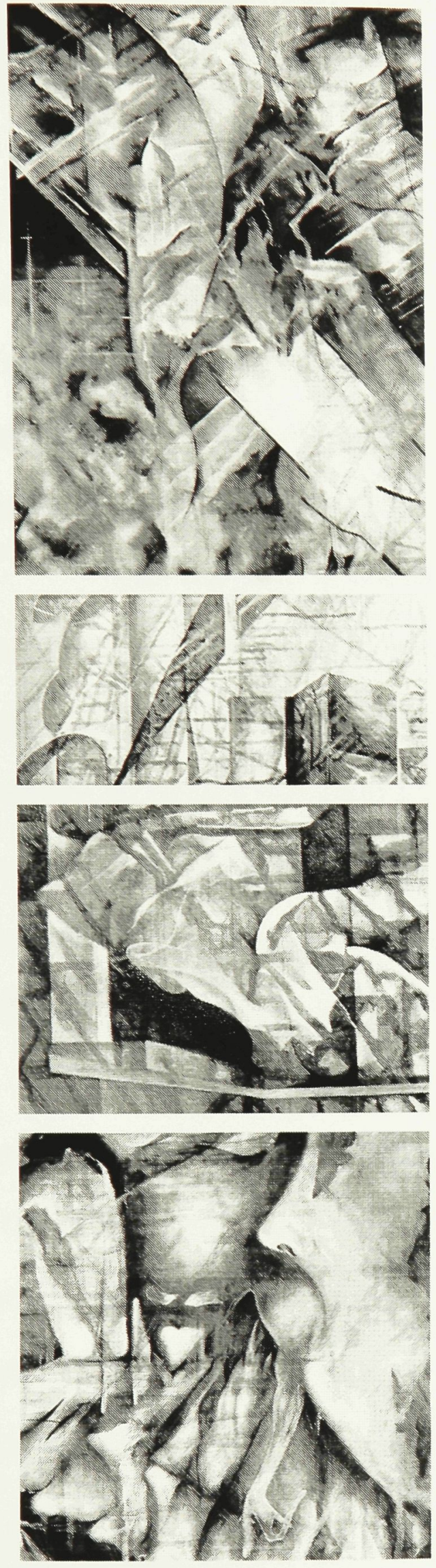

Figure 19. Paintings
The deviant characters embody multiple qualifiers. The multiple characteristics enable a making which is a self-referential exchange. Consequently, the process of making embodies the imagined whole of the character. The characters' multiplicity is a sign of their singularity. The singular whole, in turn, has value as part to the universal whole. The embodiment the qualities of the characters are present in a series of four paintings, and a series of two constructions and two collages.

The former employs gravity as the rule. Between the layers of the operation, in which the three primary colors are applied in succession, a depth of field emerges. That depth unifies the process and gives significance to the outcome.

The constructions utilize other operations. "The Chelephant" is an exercise in the inversion of the chiasm. Gemini is an exercise in balance between the two terms; Pollux and Castor. The terms invert is in the form of a paralypsis.

The 1:1 construction called "The Chelephant" is a möbius-like structure. The construction is composed of three continuous bands 
of a one-inch cold-rolled hollow-core steel section. Mitre joints are the rule of connection. Furthermore, with two exceptions, the planes turn in ninety degree intervals.

Three parallel paths run the entirety of the structure. Due to the inversions, which result from the turns, the first string becomes the third. They are intertwined. "At this intersection, opposites fold into each other in such a way that everything seems to be "completely reversed or turned inside out [retourné]."23 The process of the chiasm or intertwining is infinite. If there were a fourth string, the same would occur between it and the second, and so on to infinity.

"[T]he two maps are complete, and yet they do not merge into one. The two parts are total parts and yet are not superposable." ${ }^{24}$ The functional aspect of the rule of the turns is that it allows the parts of the planes to be used in different manners. At one moment the plane is horizontal and can be used as a bench, and in the next moment it can act as a table. Then the plane turns to a vertical position. It supports the bench and table, and encloses the structure. Potentially, it could continue and the plane would become the floor and the ceiling of the structure.

The structure is one continuous whole whose parts are useful for different purposes. The parts, furthermore, are wholes in themselves, in a functional sense. Therefore, the reciprocal exchange between the realms of the universal and particular is present in "The Chelephant." Similarly, the 1:1 construction entitled "Gemini" represents the connection of synecdoche, in this case, through the inversion of the paralypsis.

${ }^{23}$ Taylor, 71 .

${ }^{24}$ Maurice Merleau-Ponty, "The Chiasm” The Visible and Invisible. Ed. Alphonso Lingis. (Evanston: Northwester University Press, 1968) 134. 
"Gemini" is composed of two contrasting parts; the solid singular component and the multiple reverberating components. The former is the concrete "base" which supports a combination of wood and steel. The composite component is dependant on the stability of the solid component; this dependence creates an imaginary whole around the structure.

The vibrating component was designed as a chair. Its materiality and curvilinear form were designed to house the human body. However, this component lacks the quality of stability necessary to hold the body's weight in gravity. Therefore, the solid component below, whose angle mirrors that of the above, brings the missing attribute of stability to the union. The whole, known as Gemini, is therefore made of parts which are wholes in themselves.

Lastly, the process of making two collages reveals a plural term within a singular. Medea is the object which contains its subject. Medea's layers blur the boundary between passion and
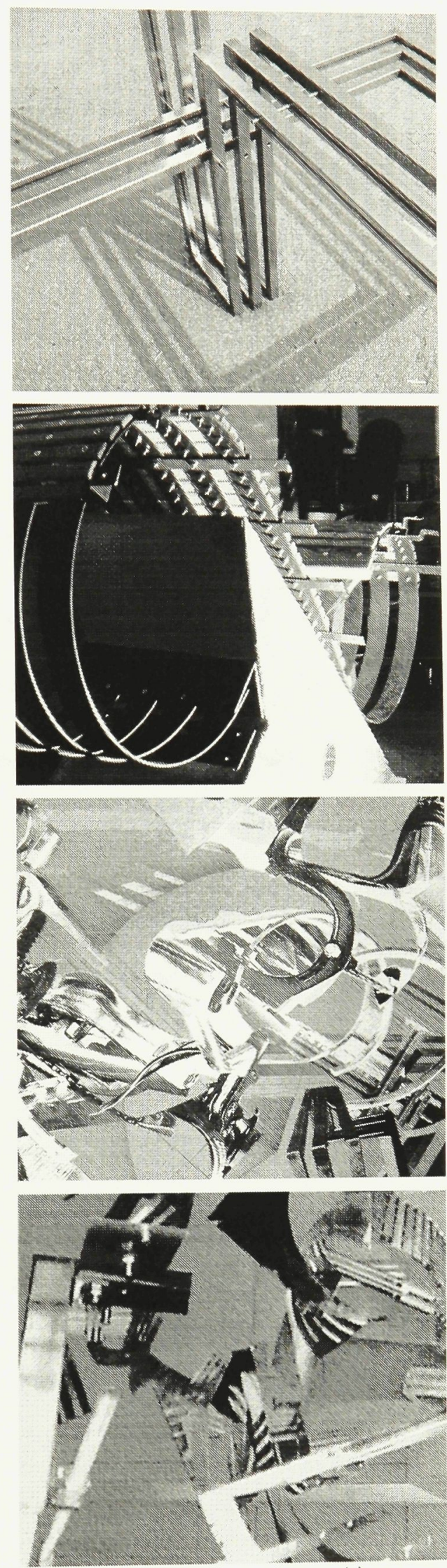

figure 20 . Constructions and Collages

reason, between curvilinear and orthogonal forms, 
and between man and machine. The collage is limited to images of Gemini, "The Chelephant," and an anthropomorphic machine. The made object contains the making.

The Cannibal's layers, in contrast, blur the boundary between realms. The blurring is revealed in the overlap of scale. The material palette is limited to the above mentioned constructions only. The overlap links the parts as a whole.

\section{Conclusion}

The value of the rhetorical figure in architecture is in the communication of the act of making. The mark of the act is possible because the figure is not a thing in itself, but an "operation." 25 Consequently, the work can be read as a process rather than an end, or as writing rather than an image. ${ }^{26}$ In literature, the rhetorical figure shapes words to communicate beyond a literal reading; as such it can be seen as the excess. ${ }^{27}$ In architecture, the figure can inscribe the act of making on the building.

As a container of the subjective act of making, the made object; the architecture, can alter its own "createdness." 28 The architecture contains its intention, as well as the process of making itself. It is therefore the made object which has the intention to make another. It is both made and maker. As such has to potential to link all creations through their "createdness." 29 In this manner it is an allegory for the universe.

25 "....rather than see a figure as a thing, we should understand it to be an operation, a way of forming material, a process of assembling elements of language, without which only literal statements would be possible." Ibid, 29.

${ }^{26}$ Eisenman, 533.

${ }^{27}$ Wolin, 17.

${ }^{28}$ Véronique Fóti, "Turning at the Limits of Closure," Philosophy Today, Winter 1996: 309.

${ }^{29}$ Ibid, 309. 
Appendices 


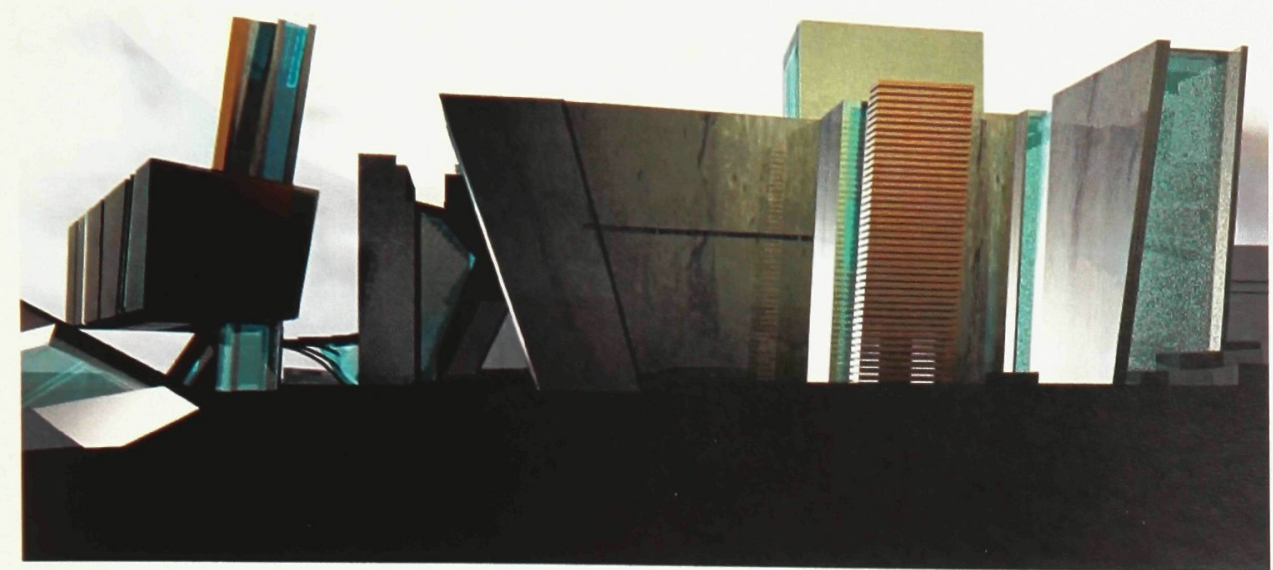

Figure 1. Exterior Perspective

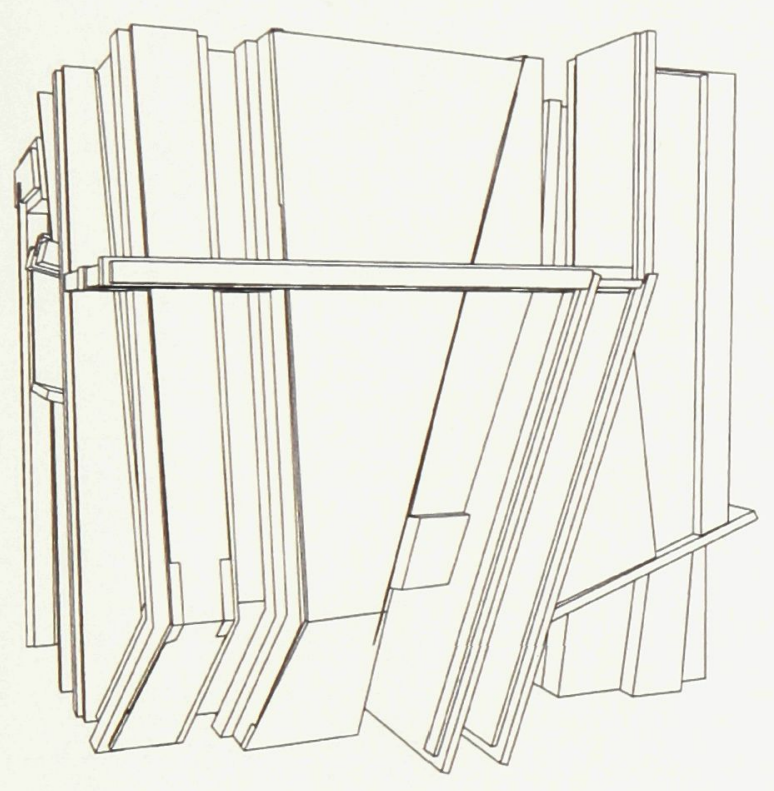

Figure 3. Process of Subdivision

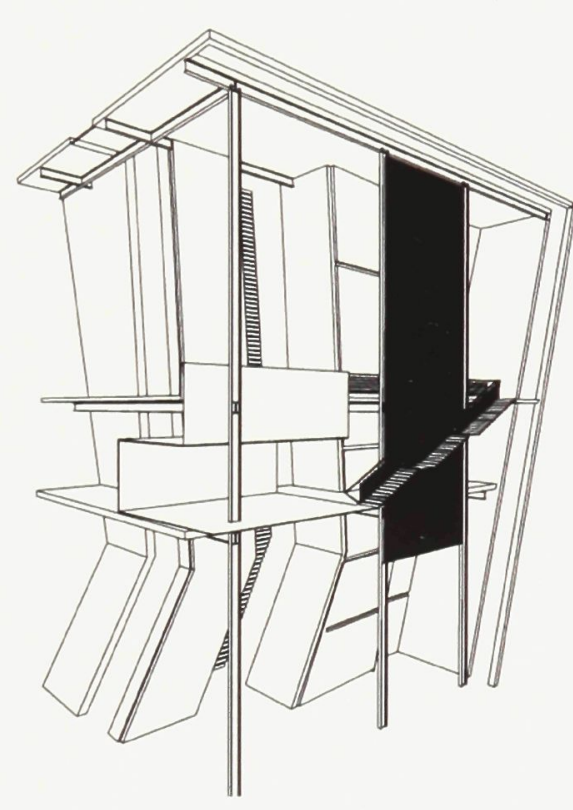

Figure 4. Axonometric

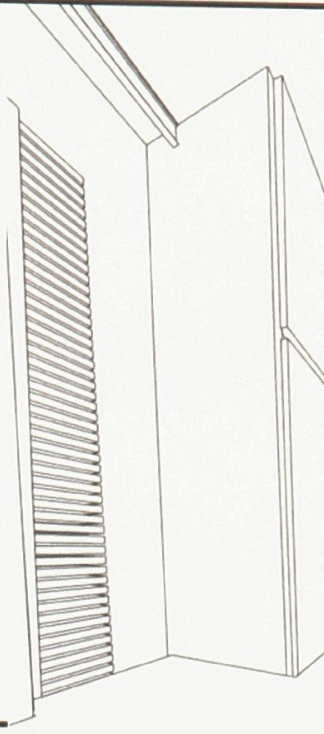

Figure 2. Interior Perspective
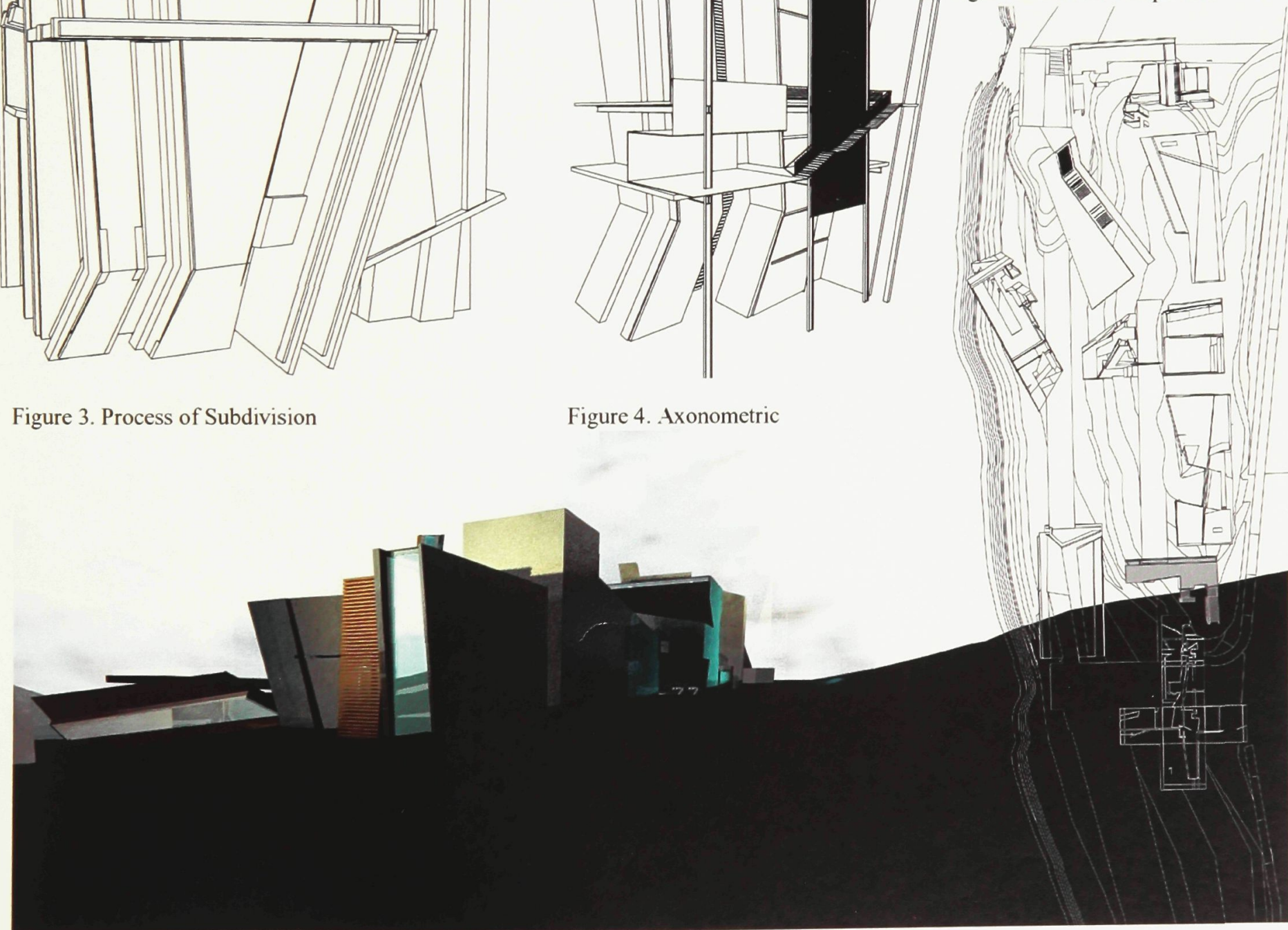


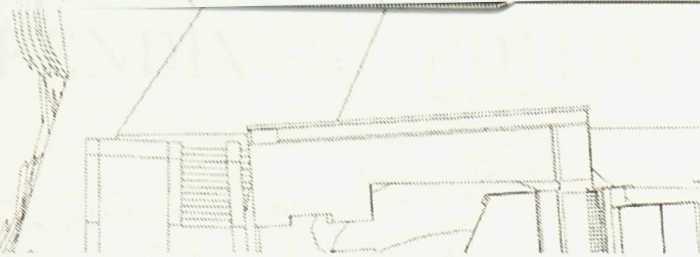

\section{PPENDIN-2. SECURITY PAVILLION (y)}

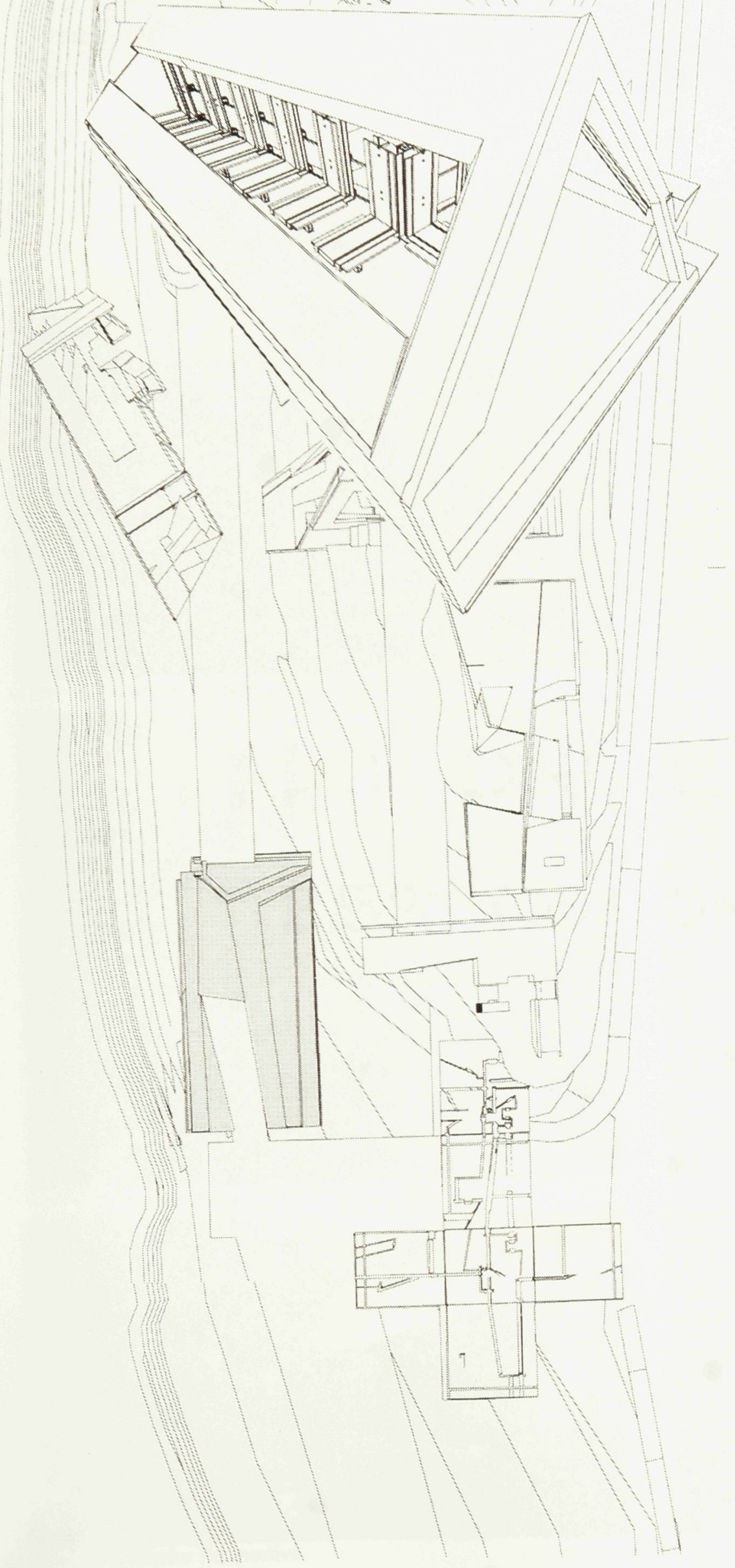

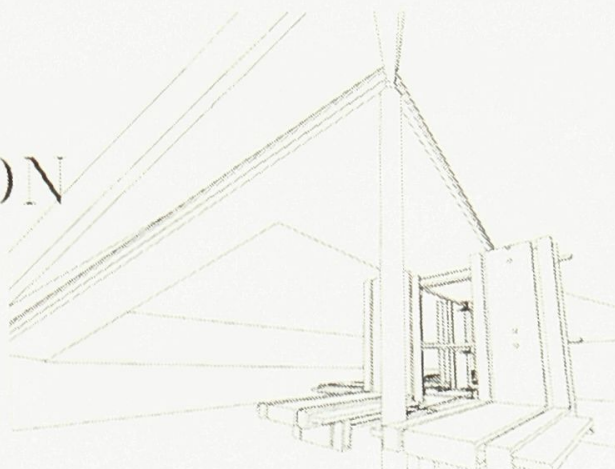

Figure 7. Interior Perspective

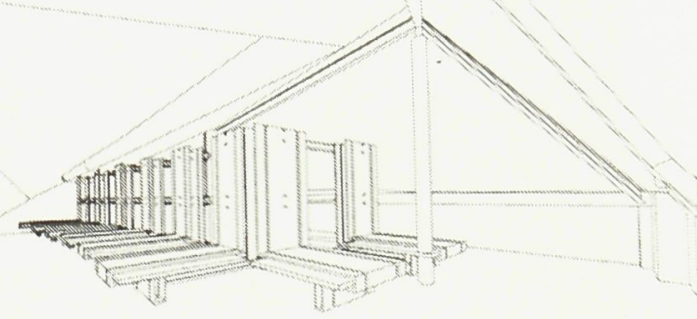

Figure 8. Interior Perspective

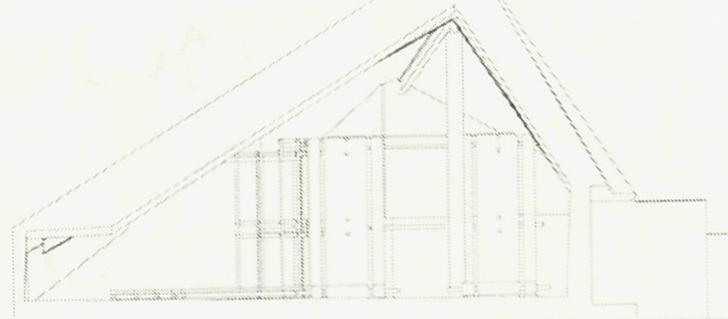

Figure 9. Interior Perspective

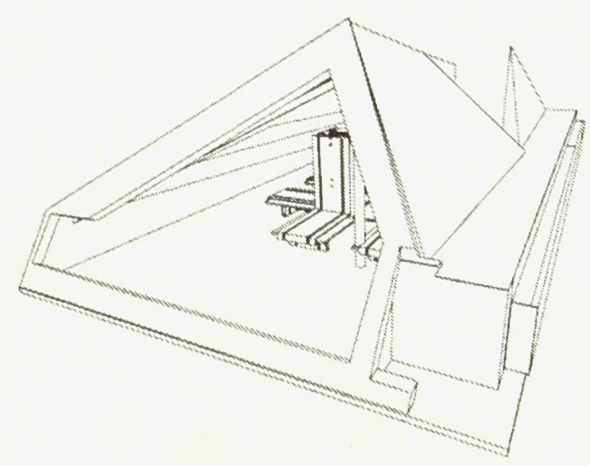

Figure 10. Exterior Perspective 
APPENDIX-3. POLITICAL AND PUBLIC AFFAIRS

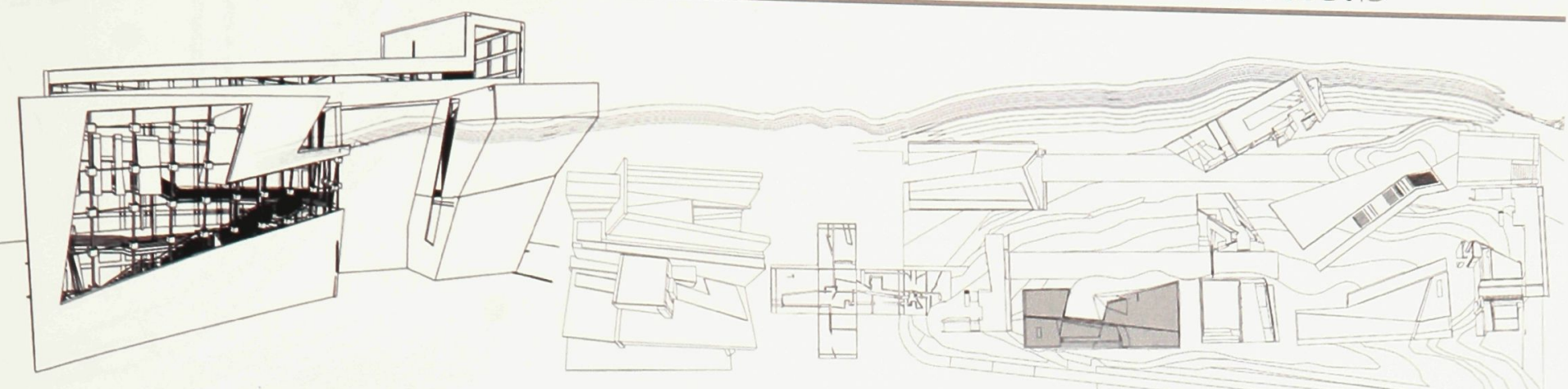

Figure 12. Exterior axonometric, puzzel subdivision, map and site plan
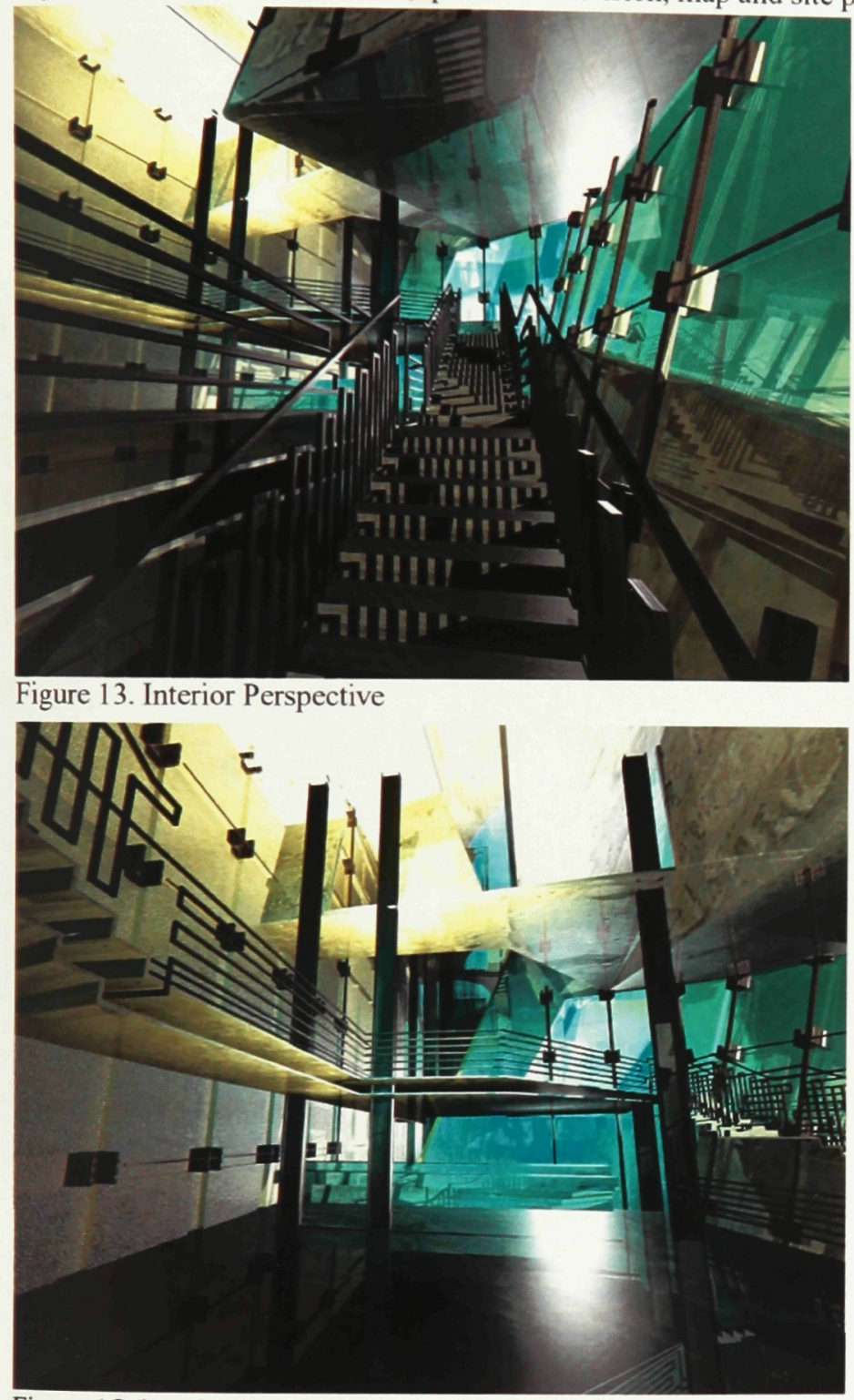

Figure 15. Interior Perspective

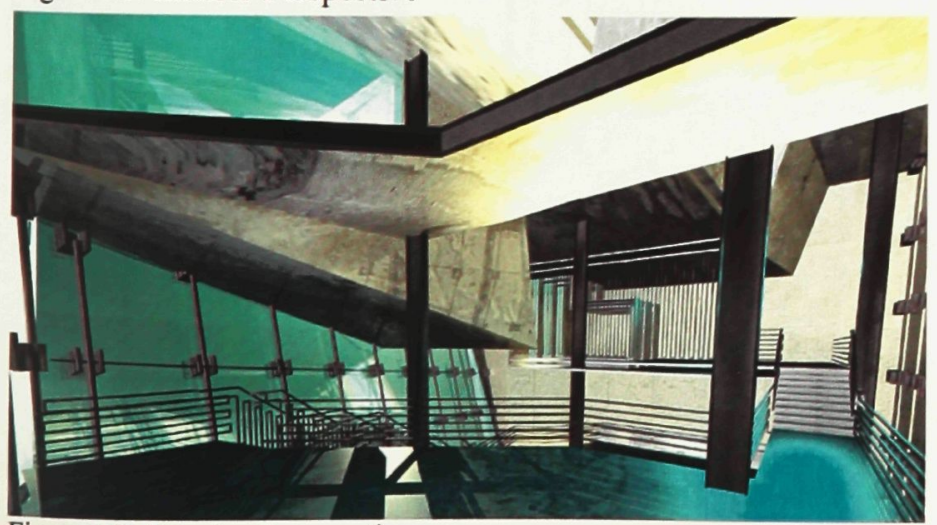

Figure 17. Interior Perspective

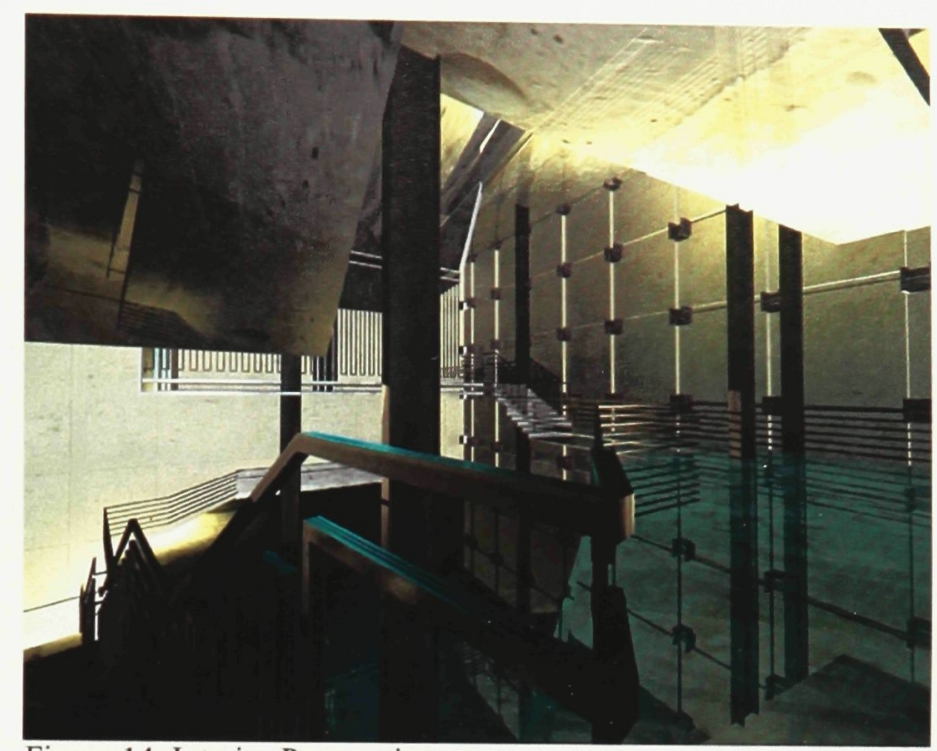

Figure 14. Interior Perspective

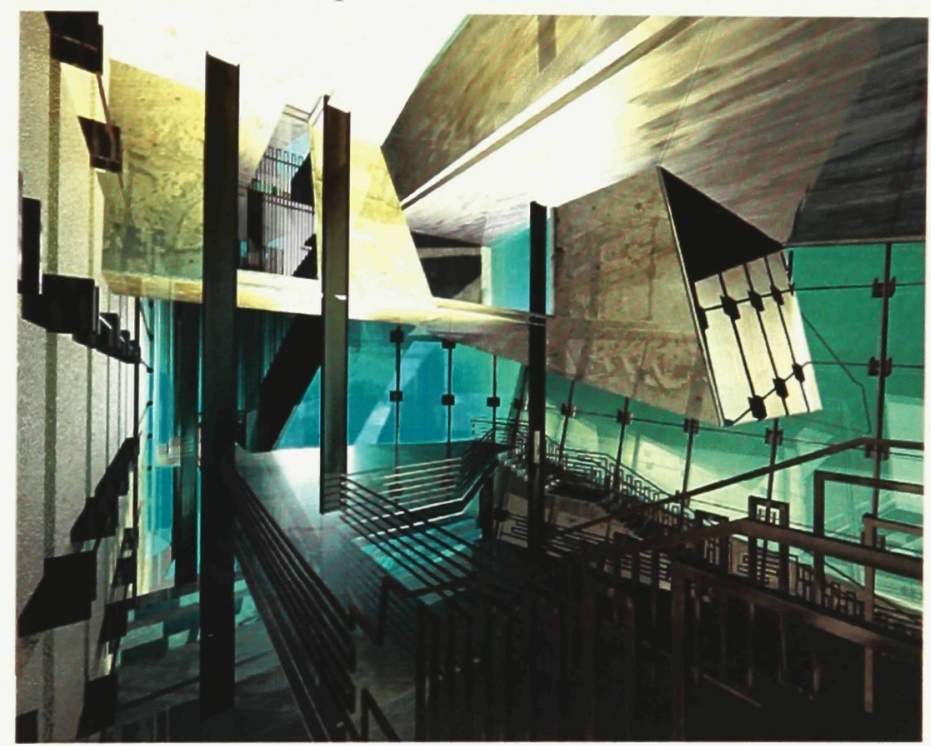

Figure 16. Interior Perspective

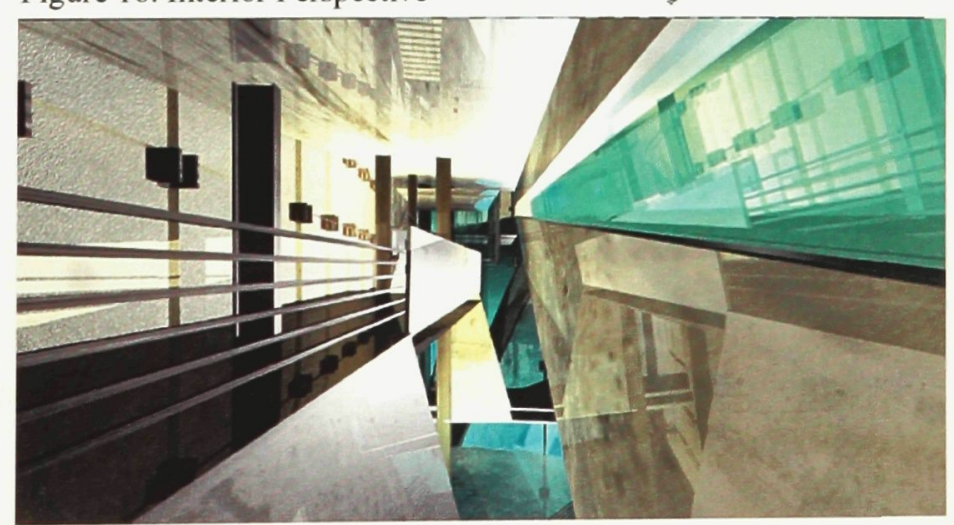

Figure 18. Interior Perspective 

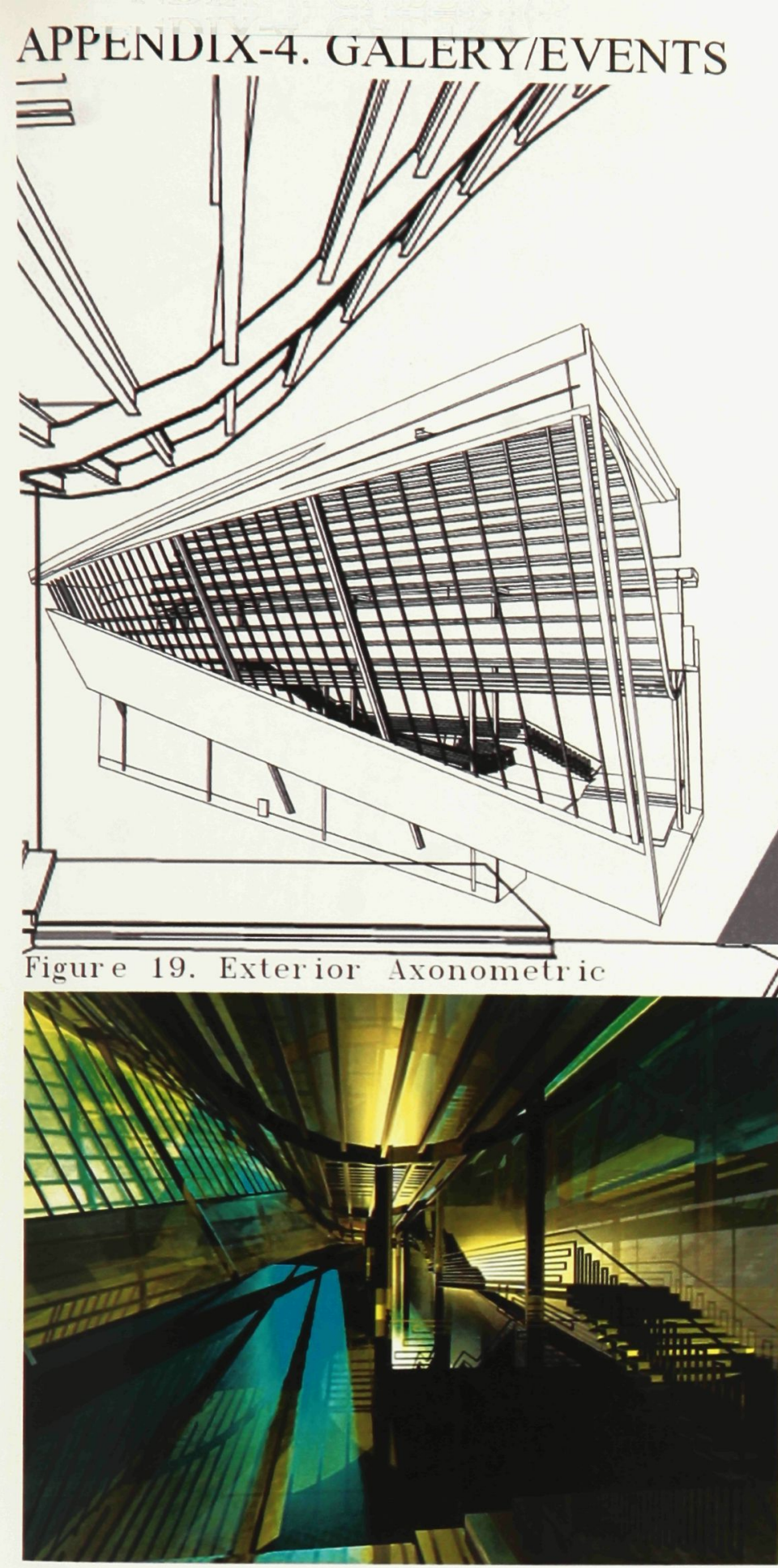

Figure 21. Interior Perspective

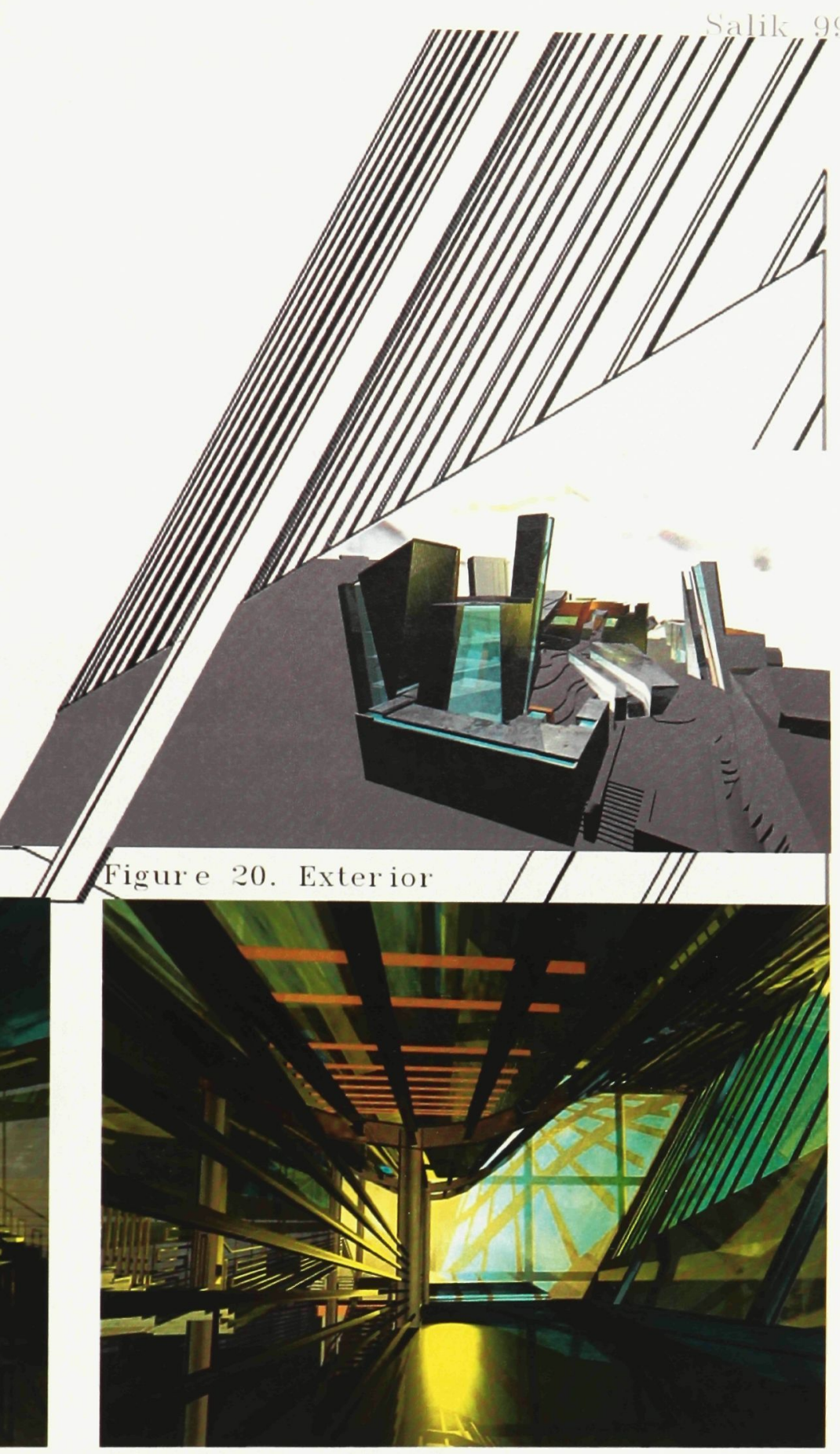

Figure 22. Interior Perspective

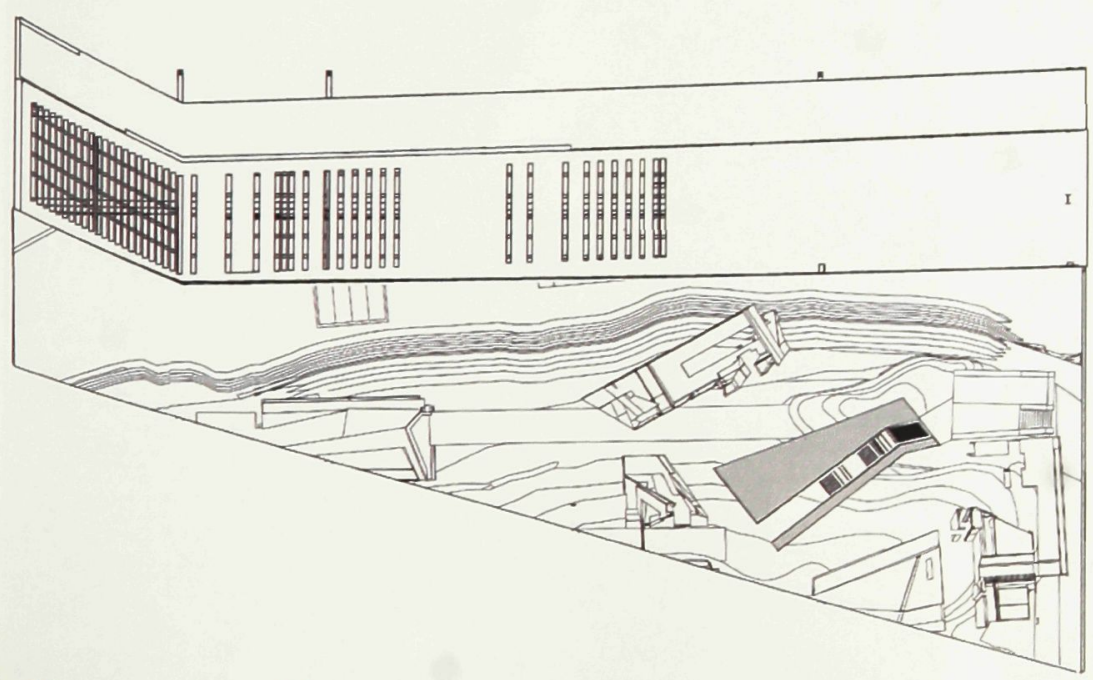

Figure 2:3. Plan

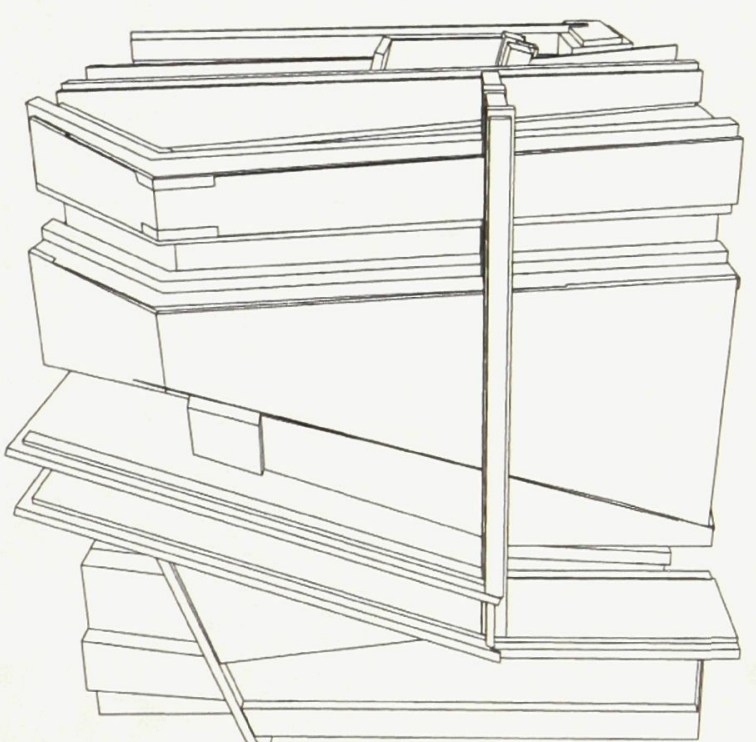

Figure 24. Puzzel Division 
APPENDIX-5.THEATRE/CONFERENCE PAVILLION
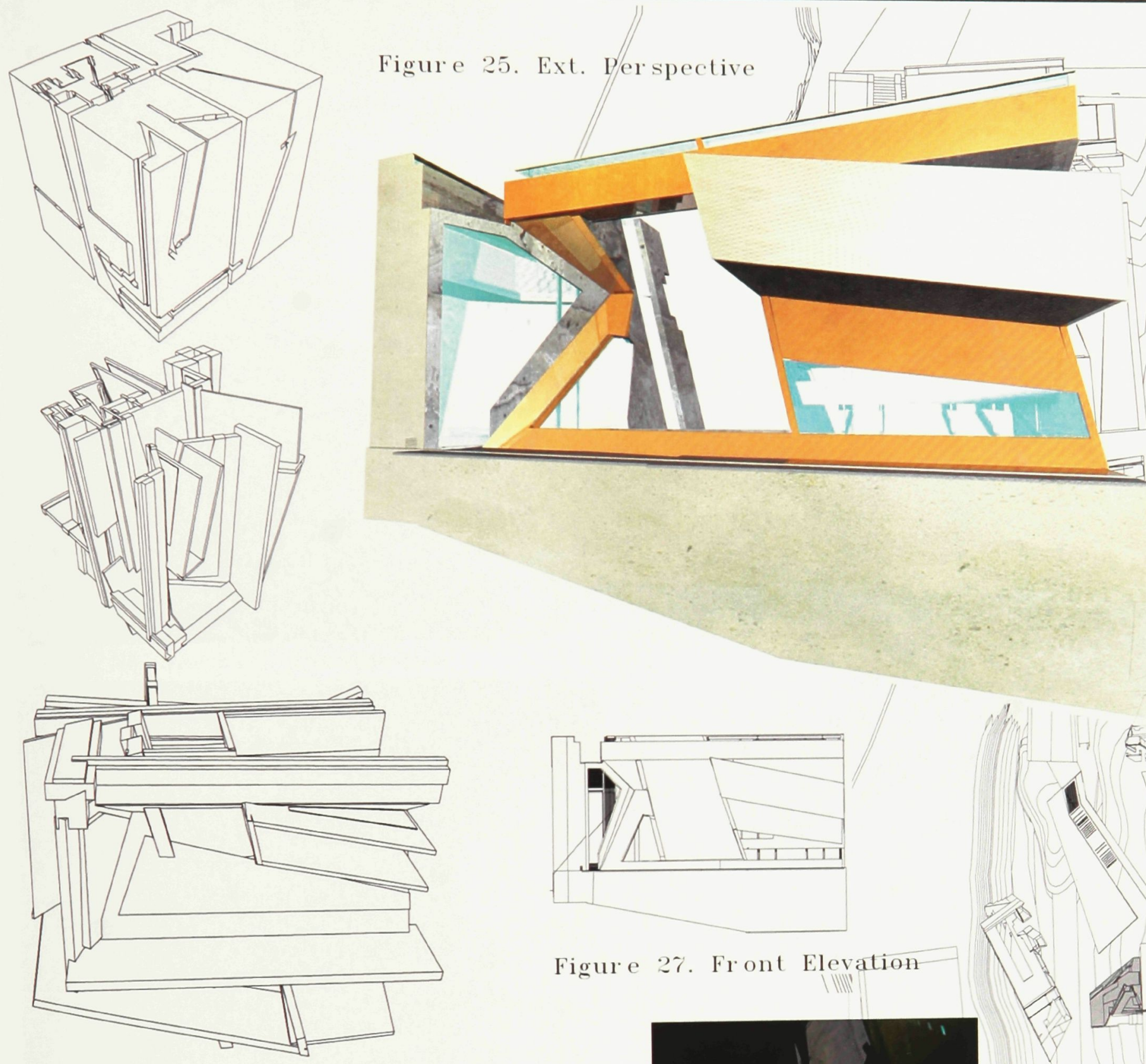

Figure 26. Puzzel Division

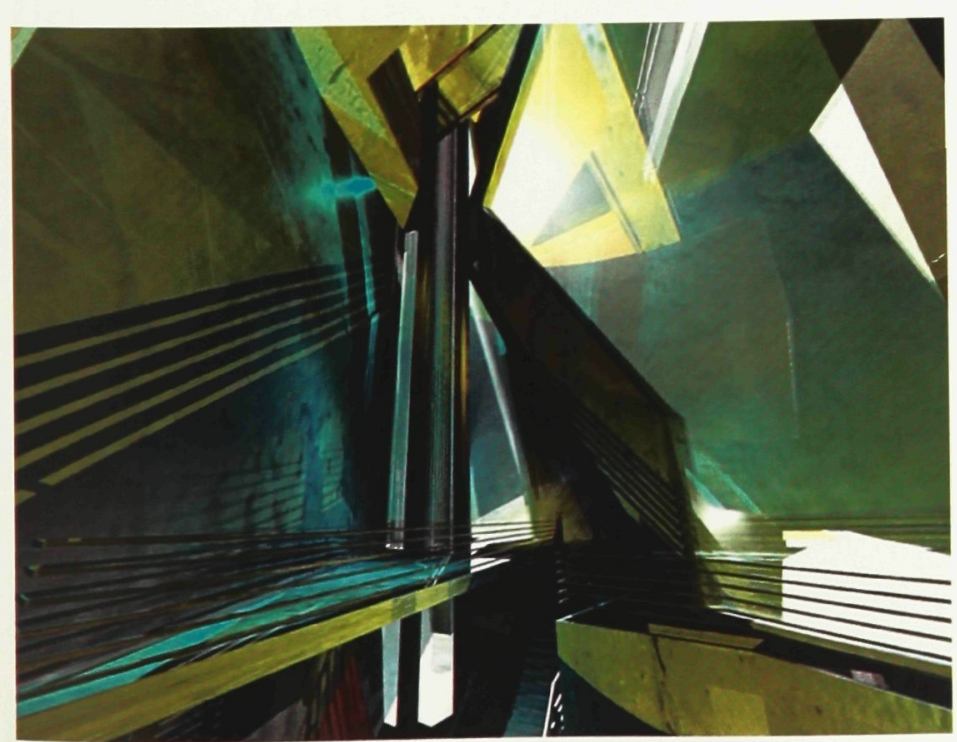

Figure 28. Interior Per spective

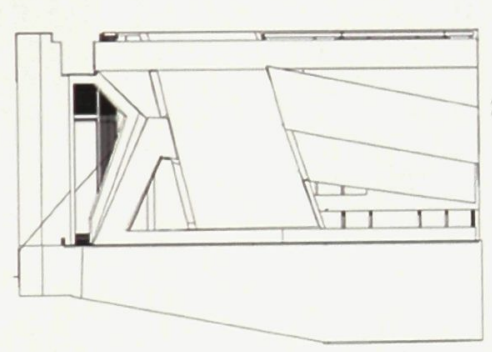

Figure 2\%. Front Elevation
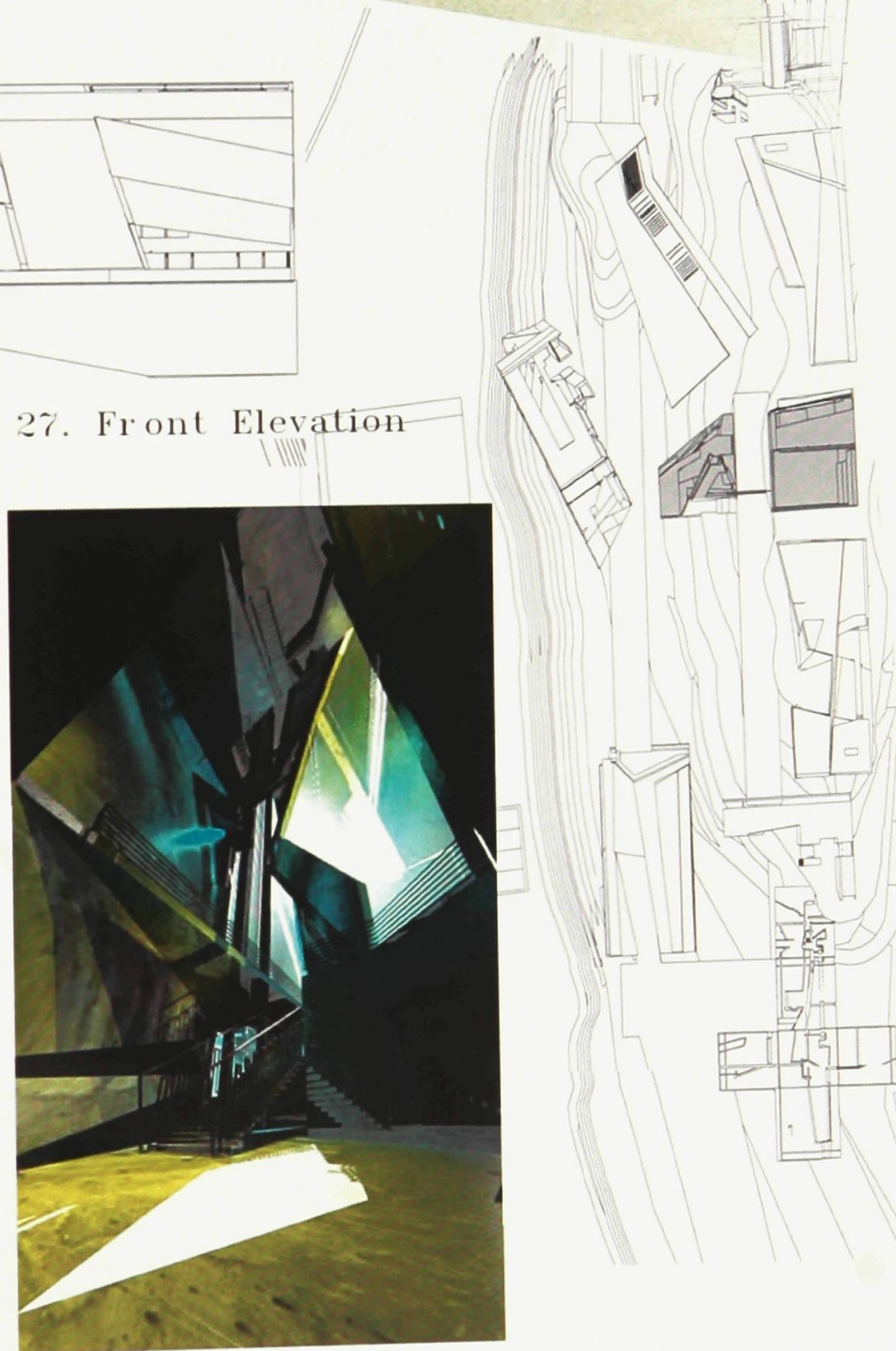

Figure 29. Int. Perspective and site Plan 


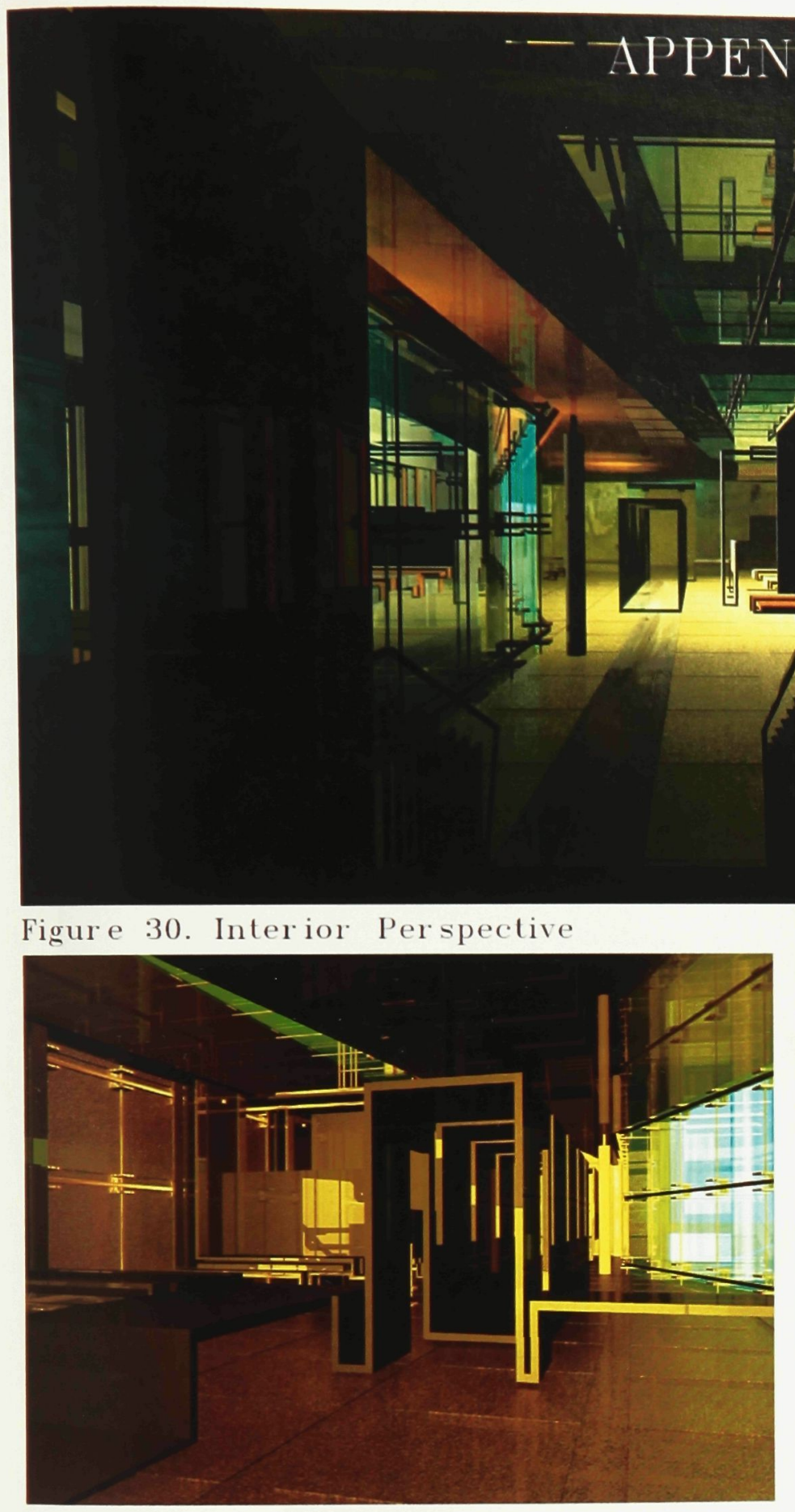

Figure 31. Interior Per spective

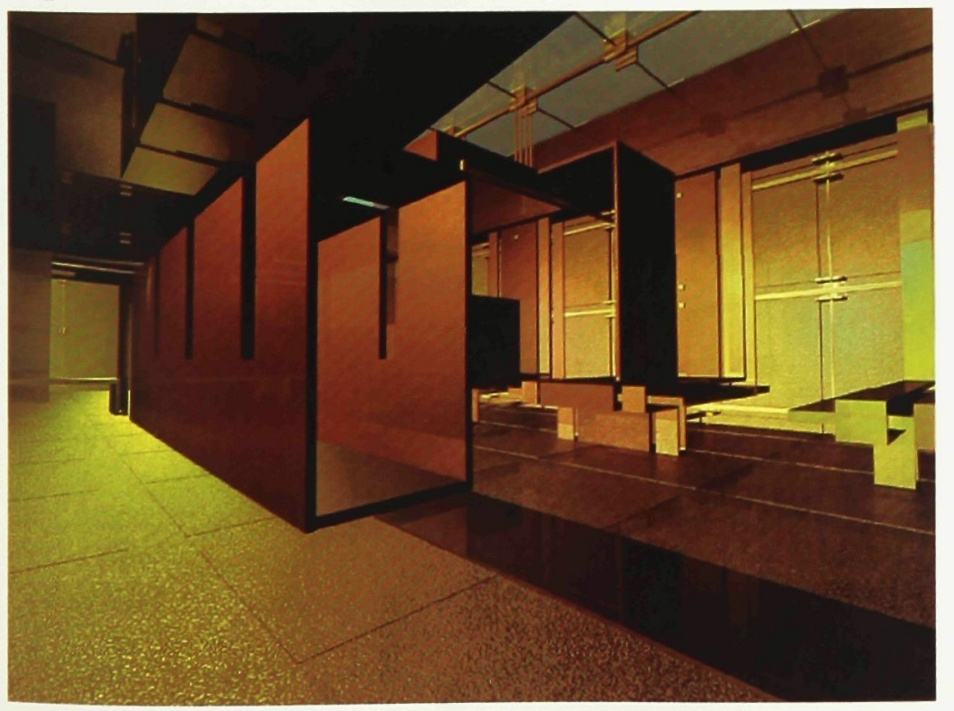

Figure 32. Interior Perspective

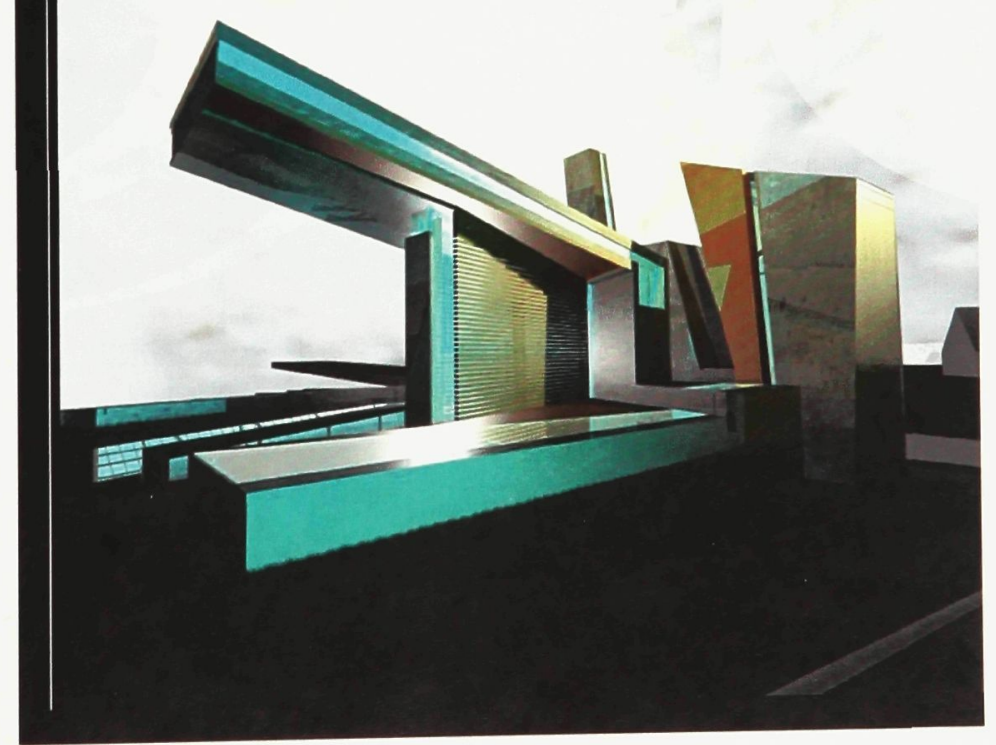

Figure 35. Exterior Perspective 


\section{APPENDIX-7.RESEARCH PAVILLION}

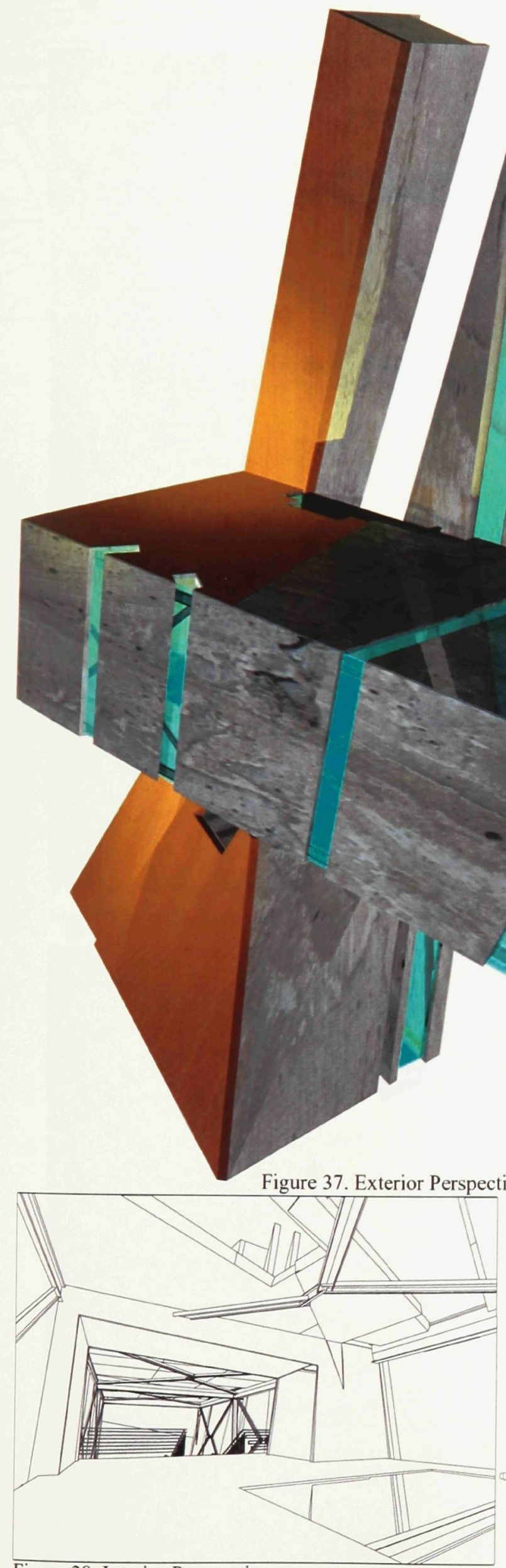

Figure 38. Interior Perspective

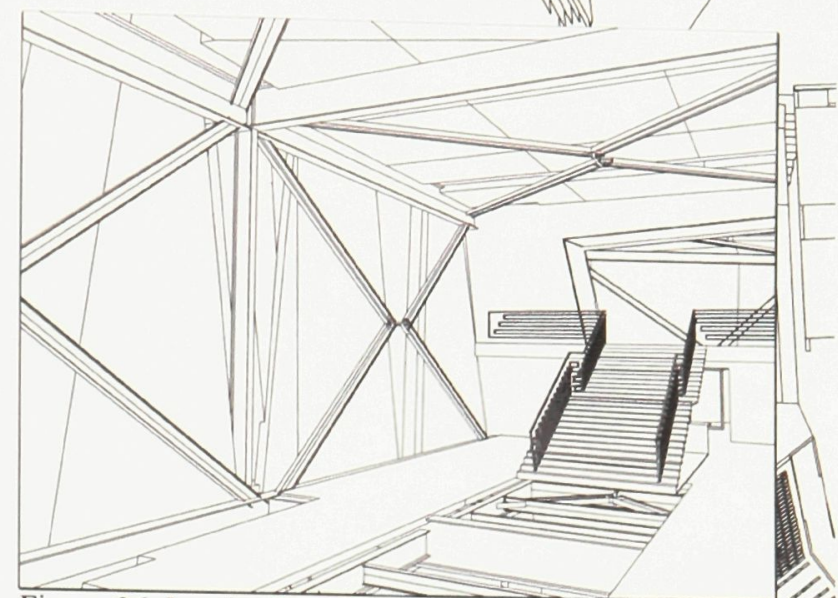

Figure 36. Interior Perspective of Research Space
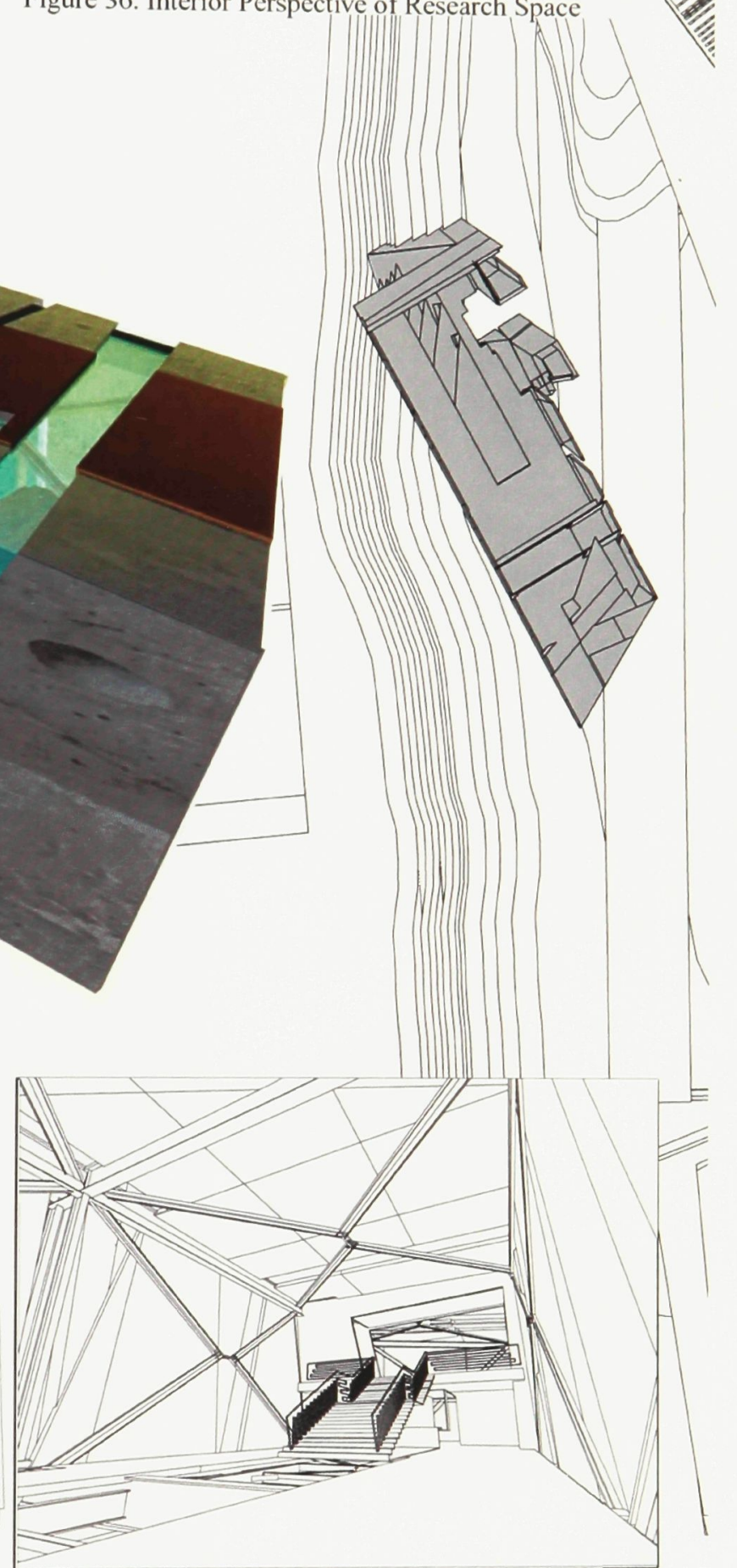

Figure 39. Interior Perspective 


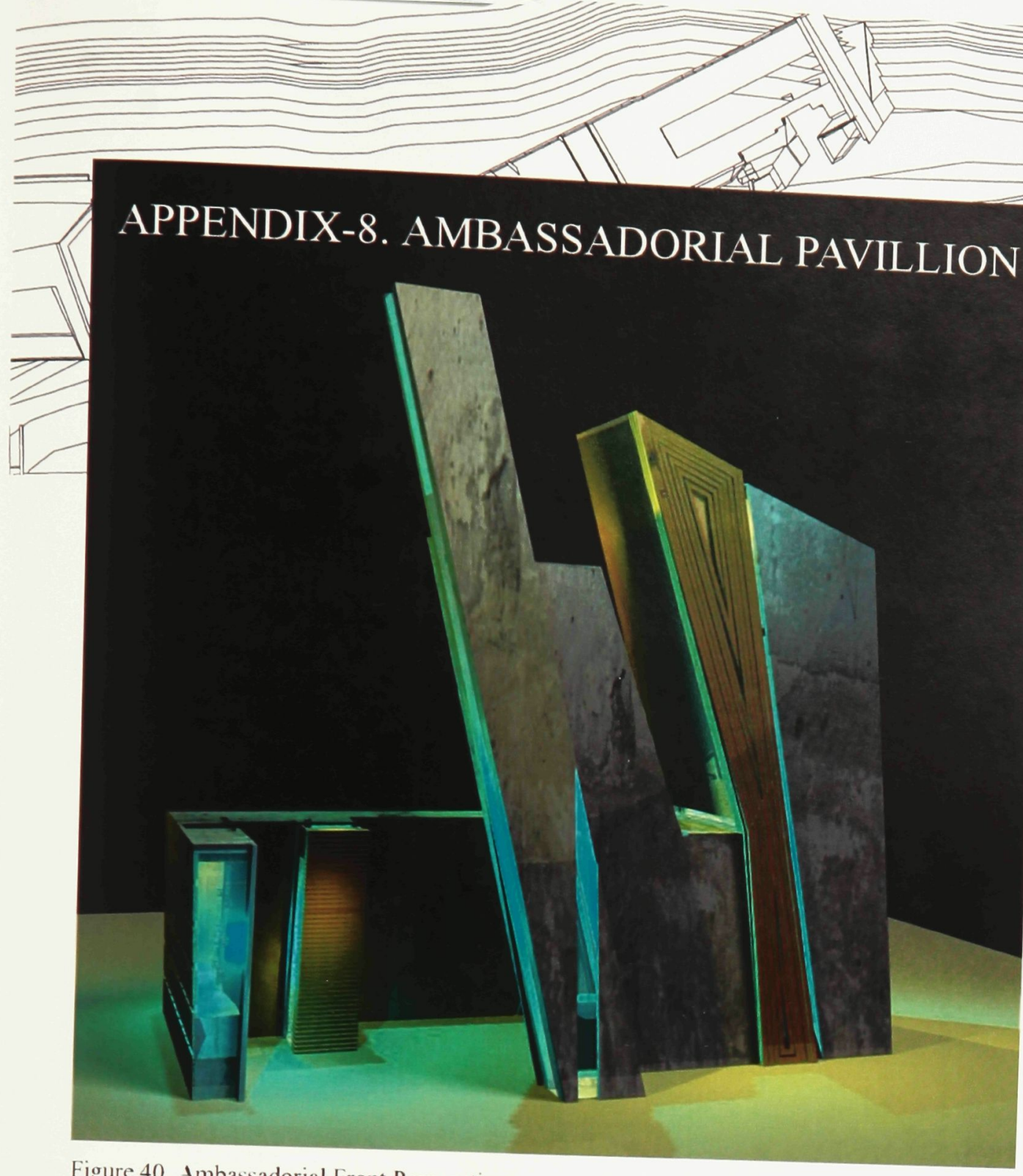

Figure 40. Ambassadorial Front Perpsective

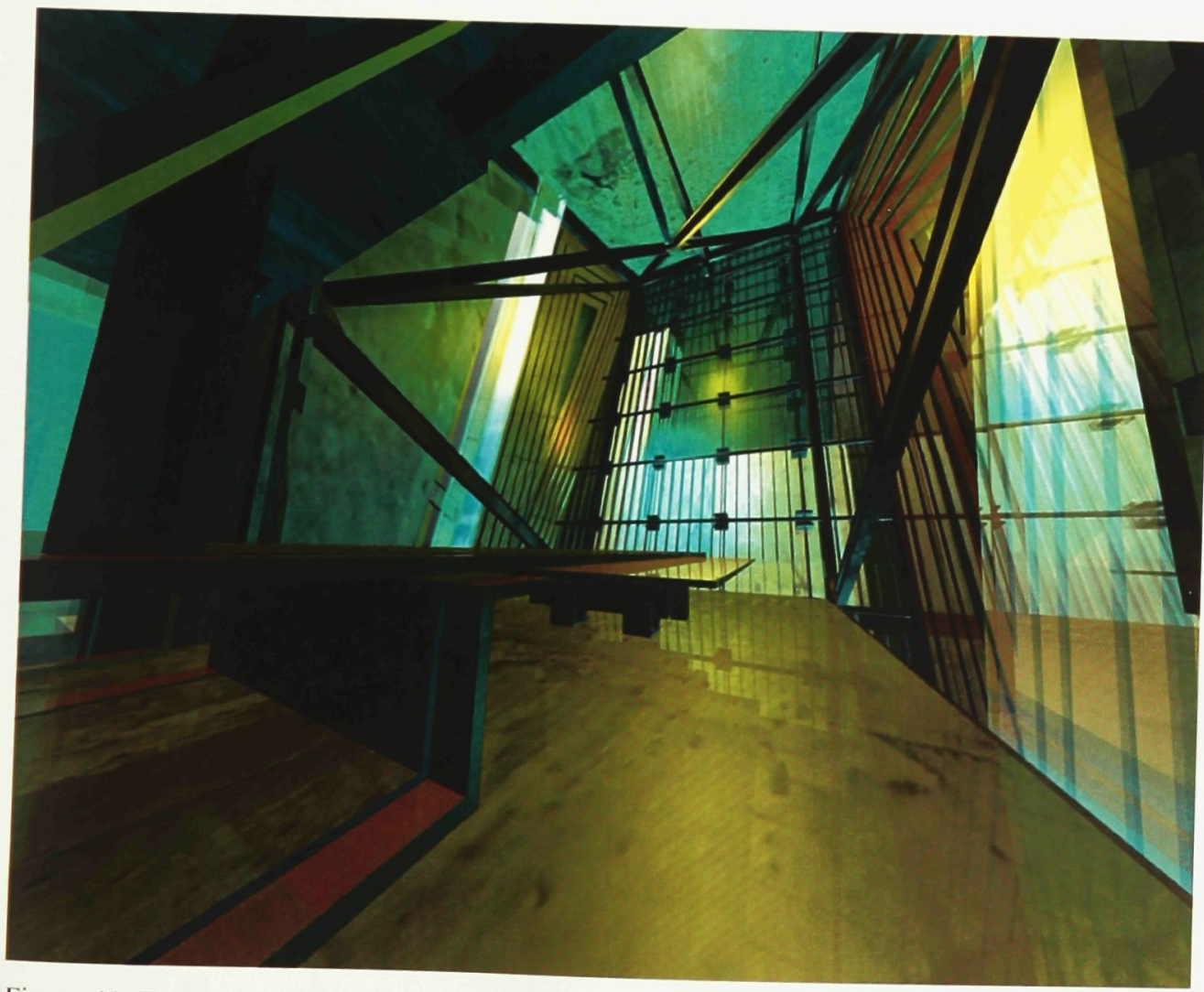




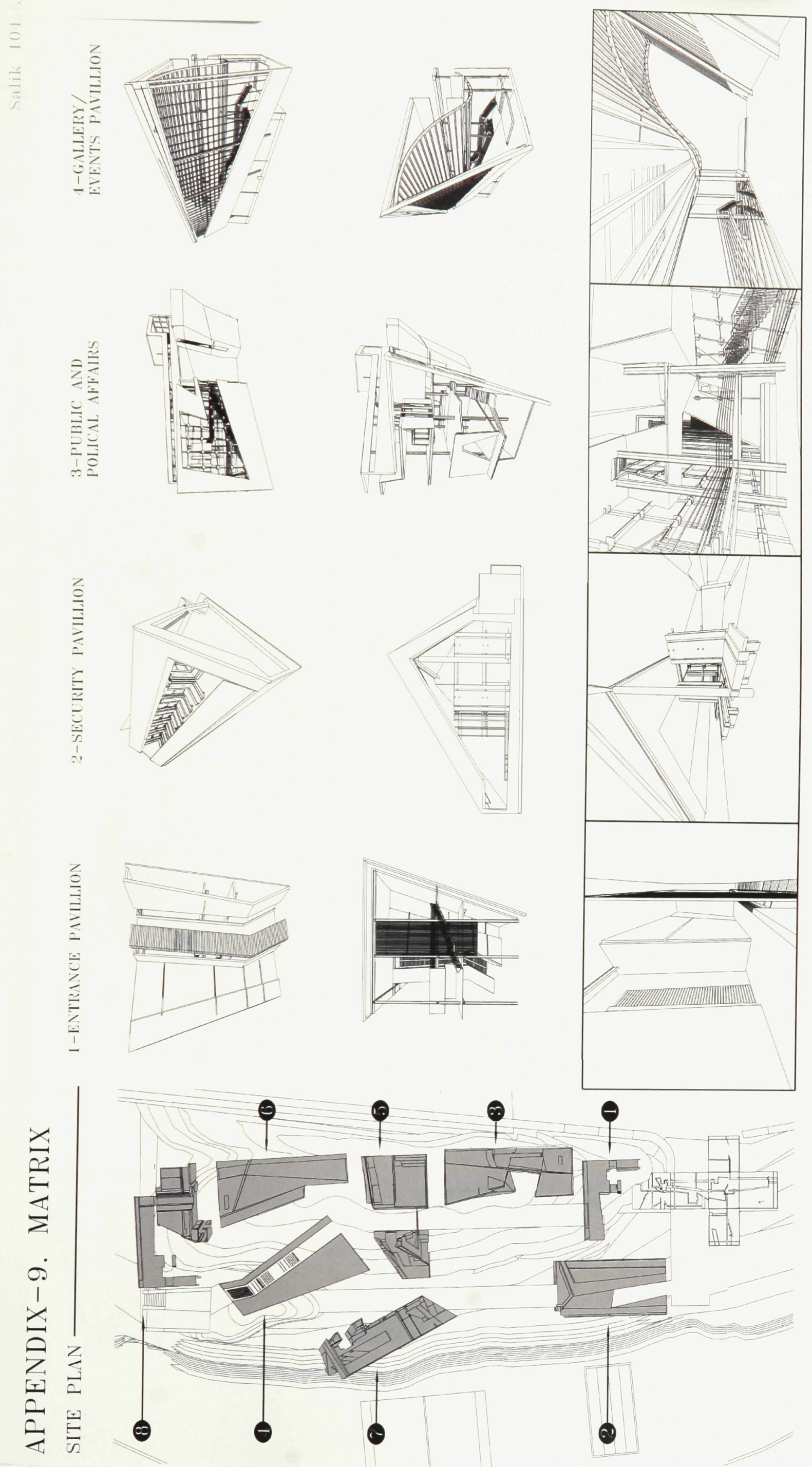



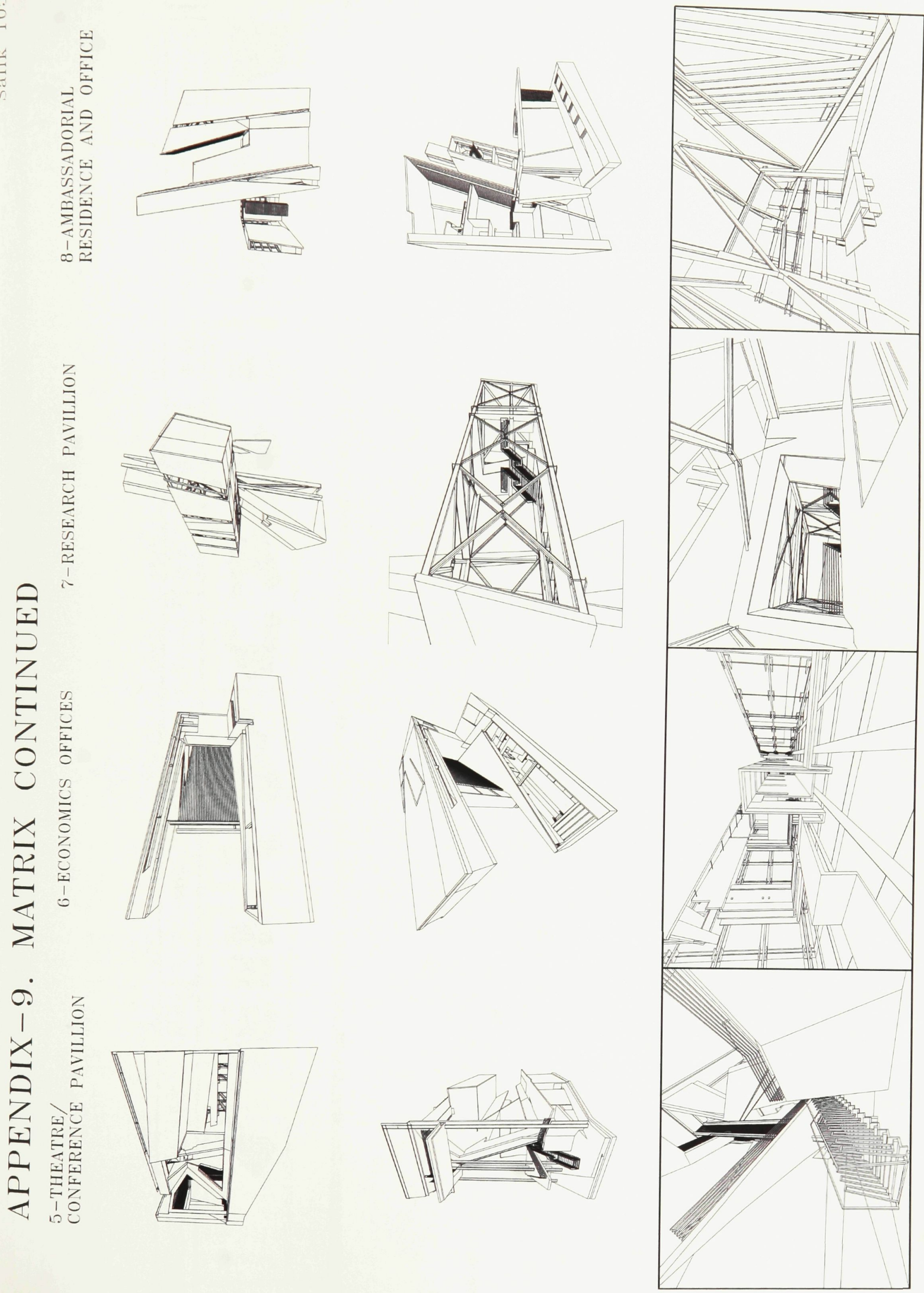

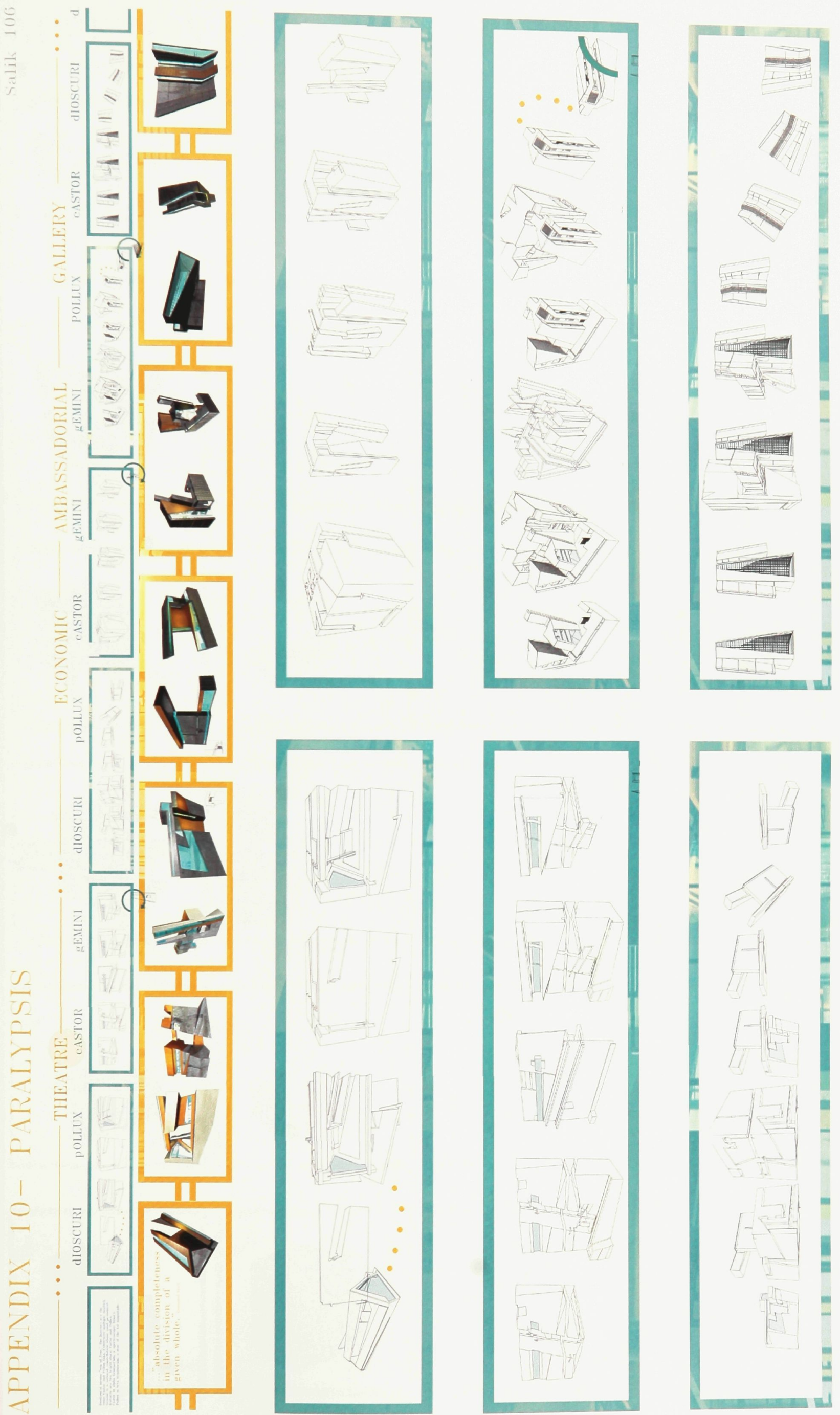
APPENDIX $11-$ CHIASM
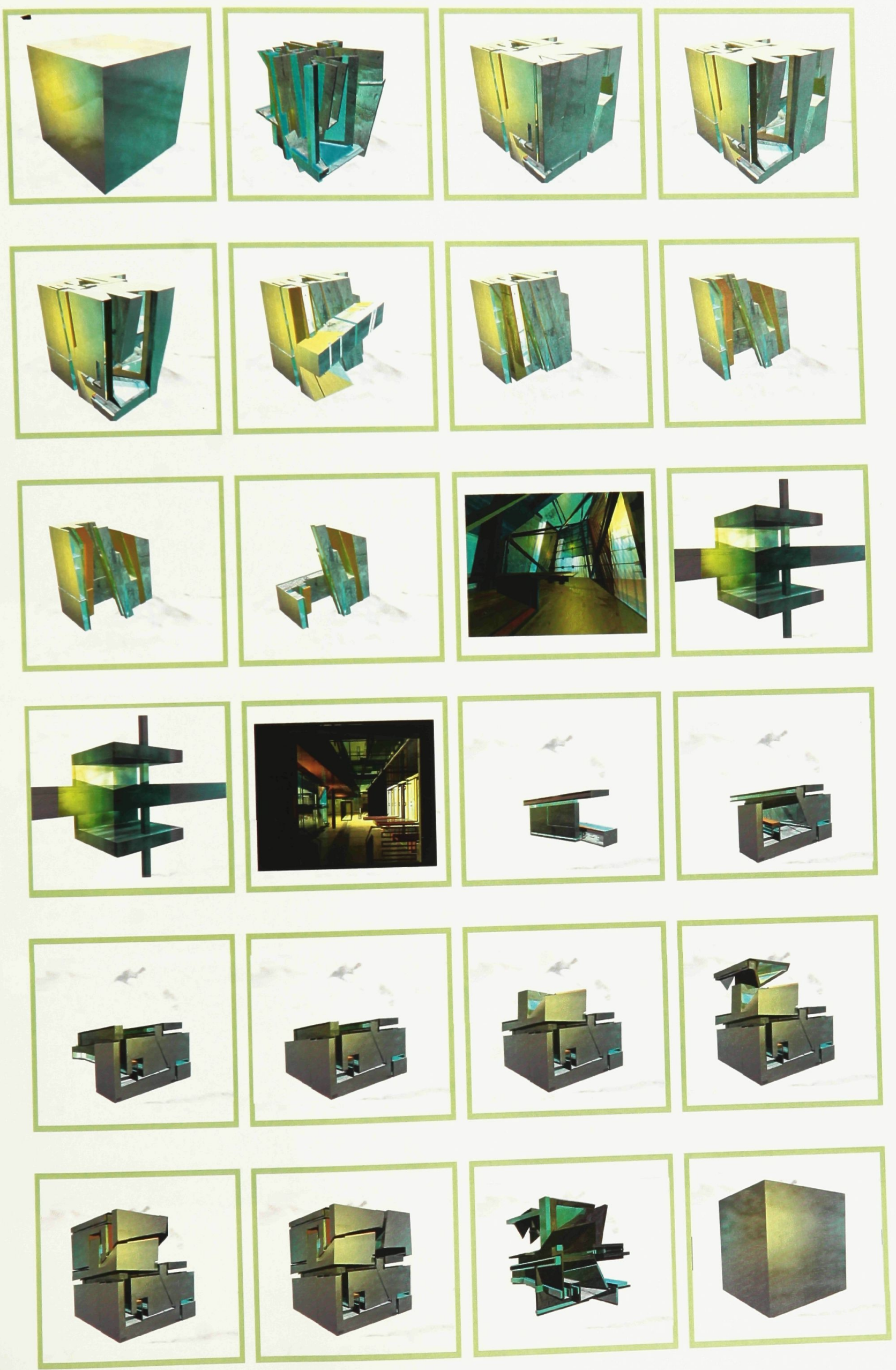
APPENDIX-13. PROCESS WORK
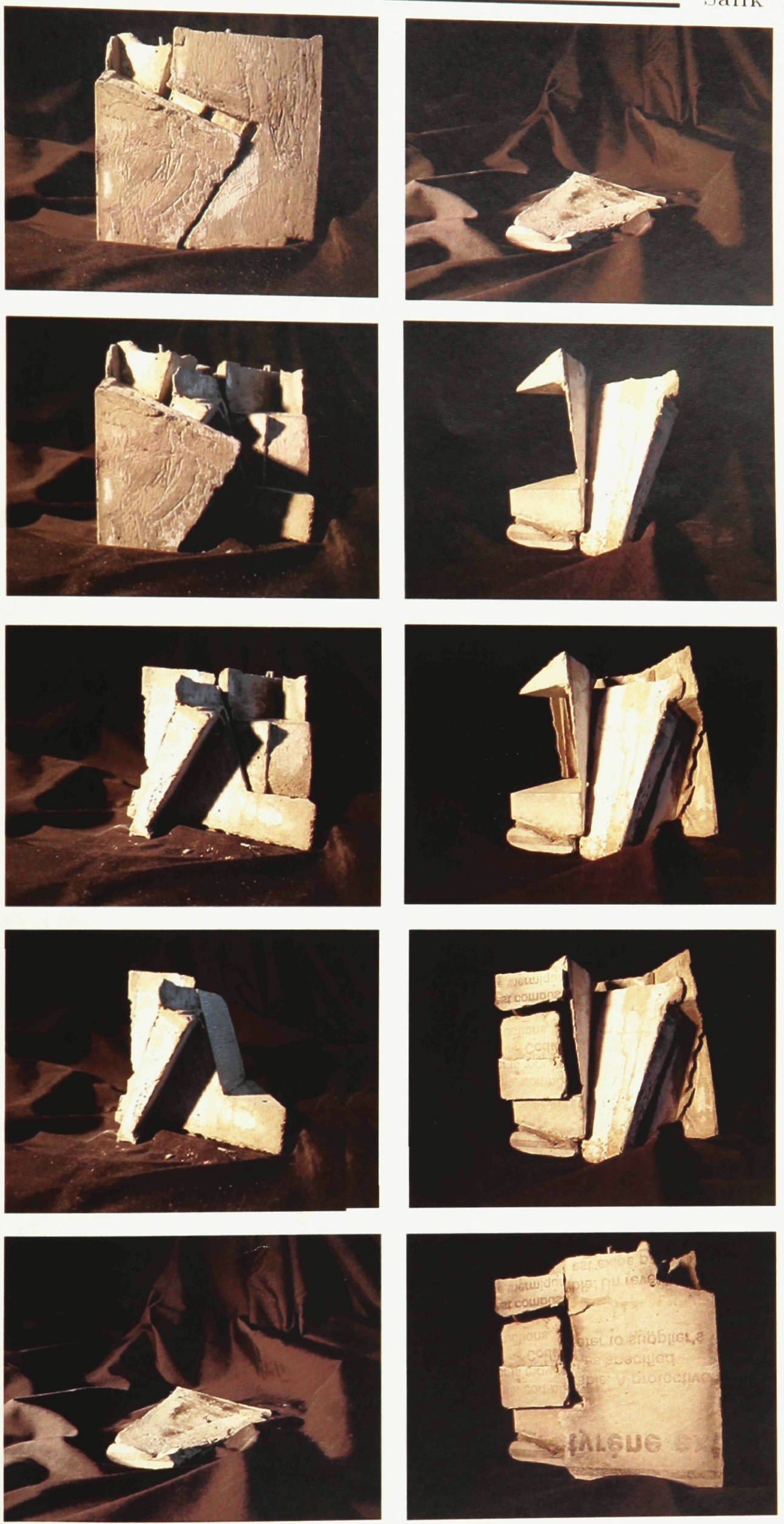


\section{APPENIDIX-14. CIIELEPIIANT CONSTRUCTION}
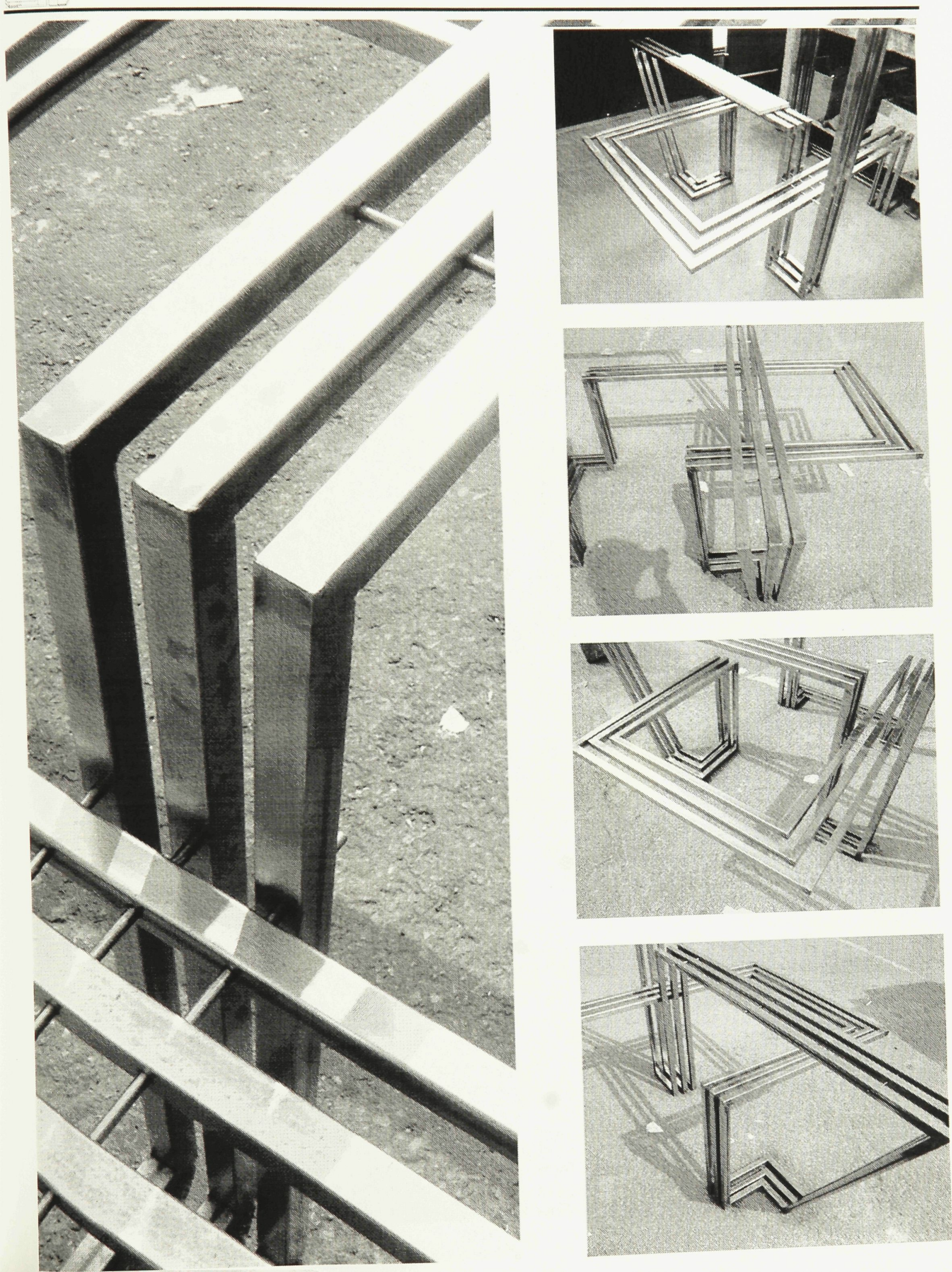


\section{APYENUIX-16. GEMINI CONSTRUCTION}
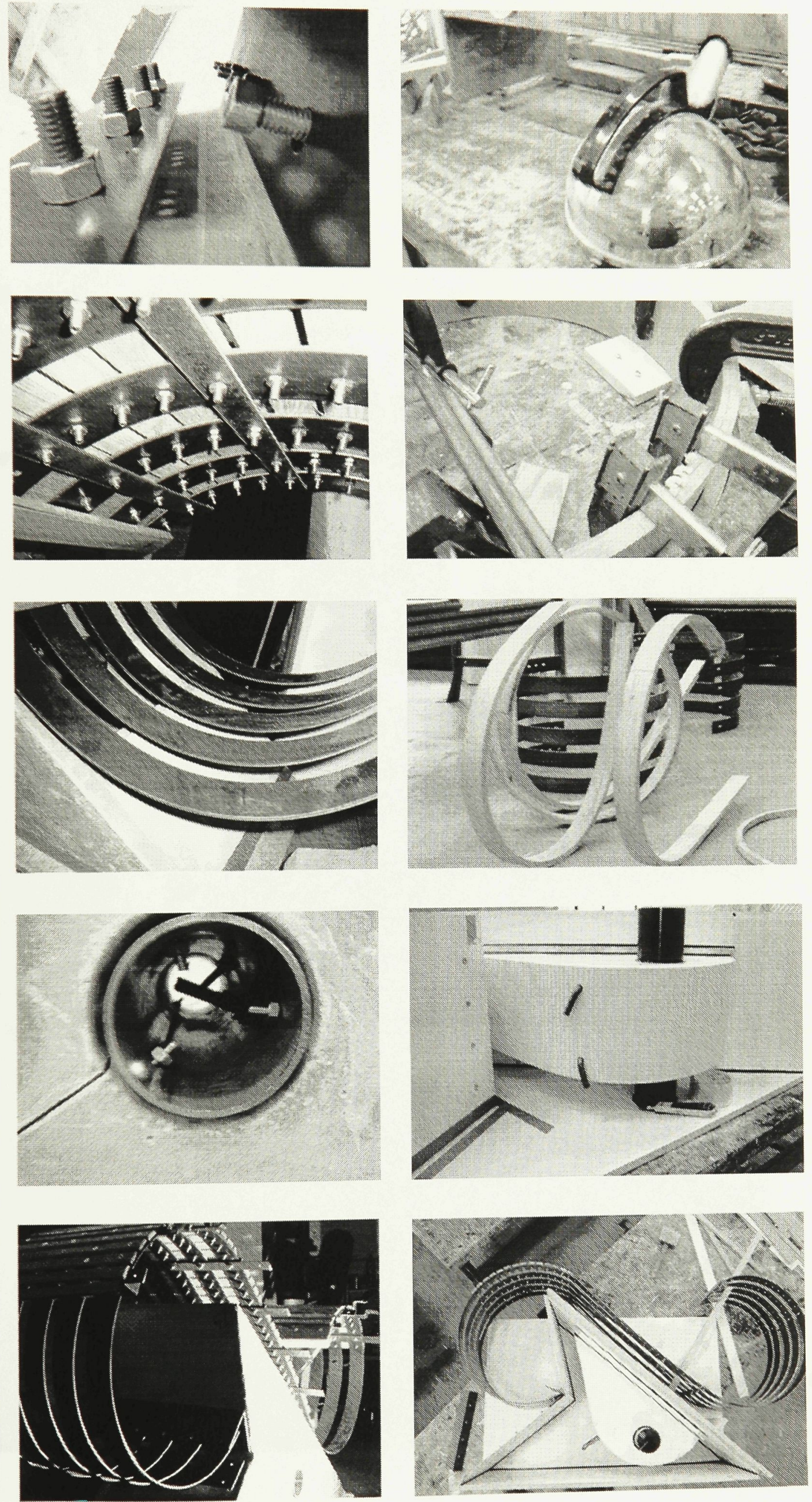


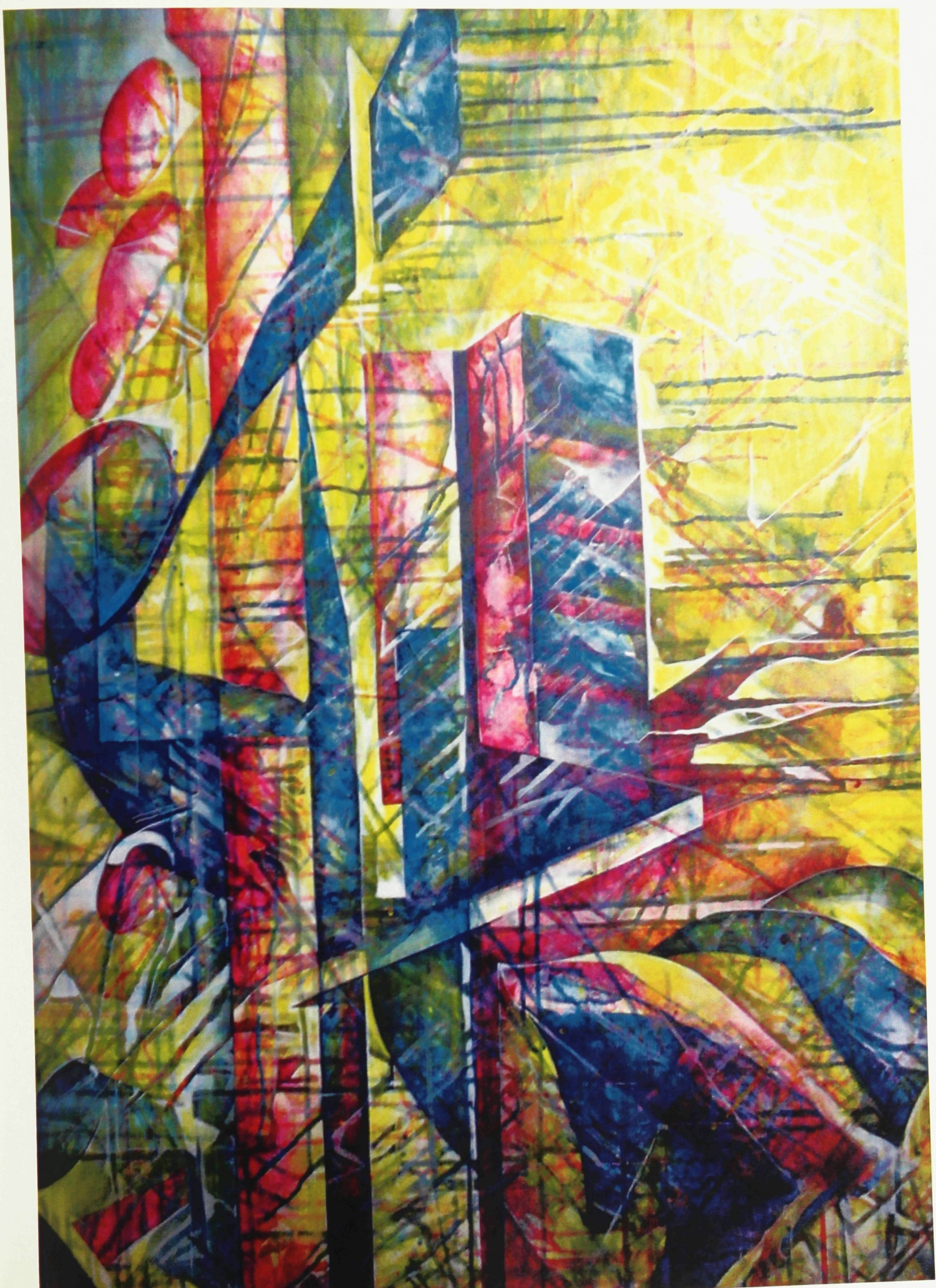



\PPE\DIX-18. MEDEA COLLAGE

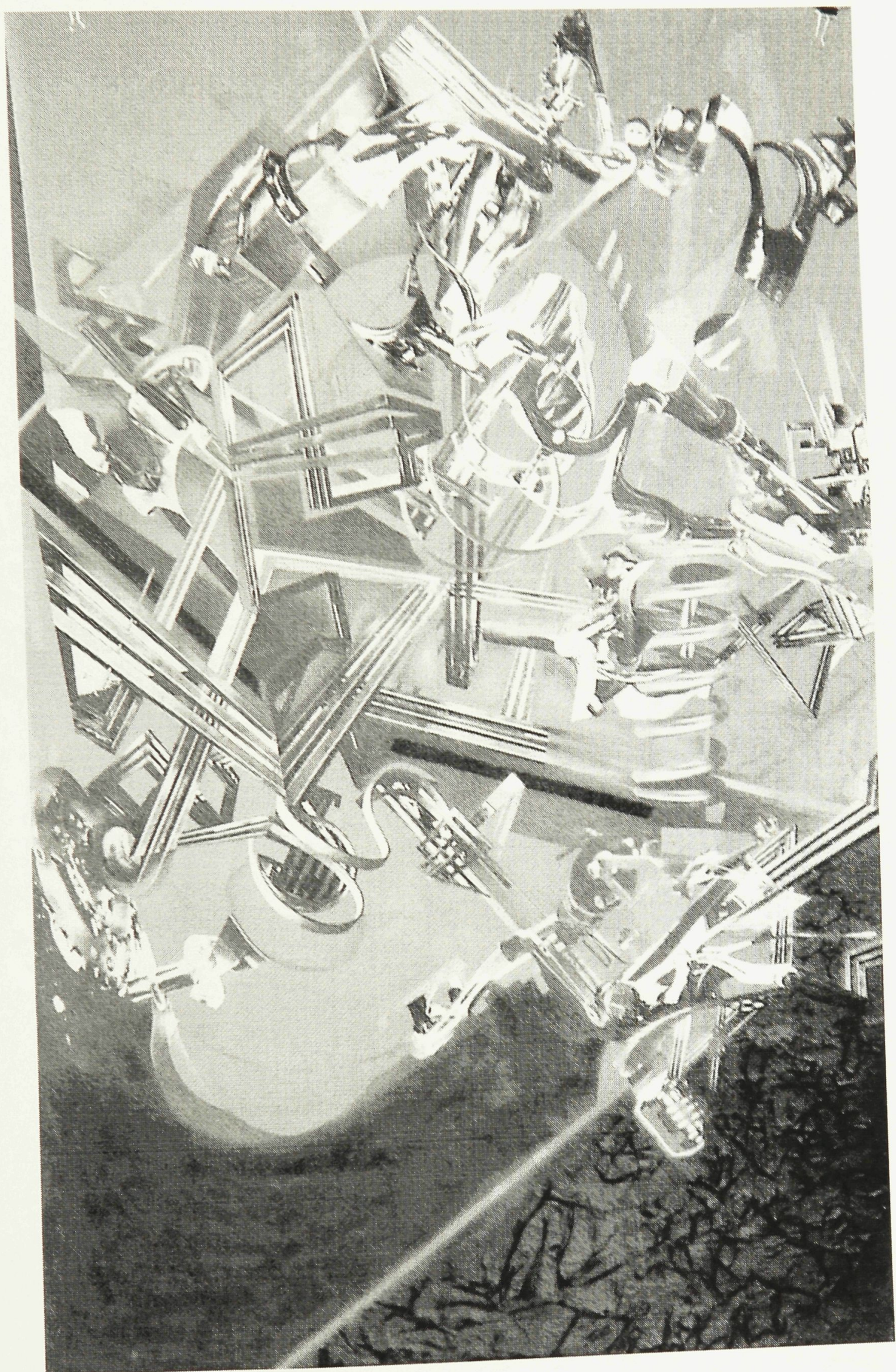




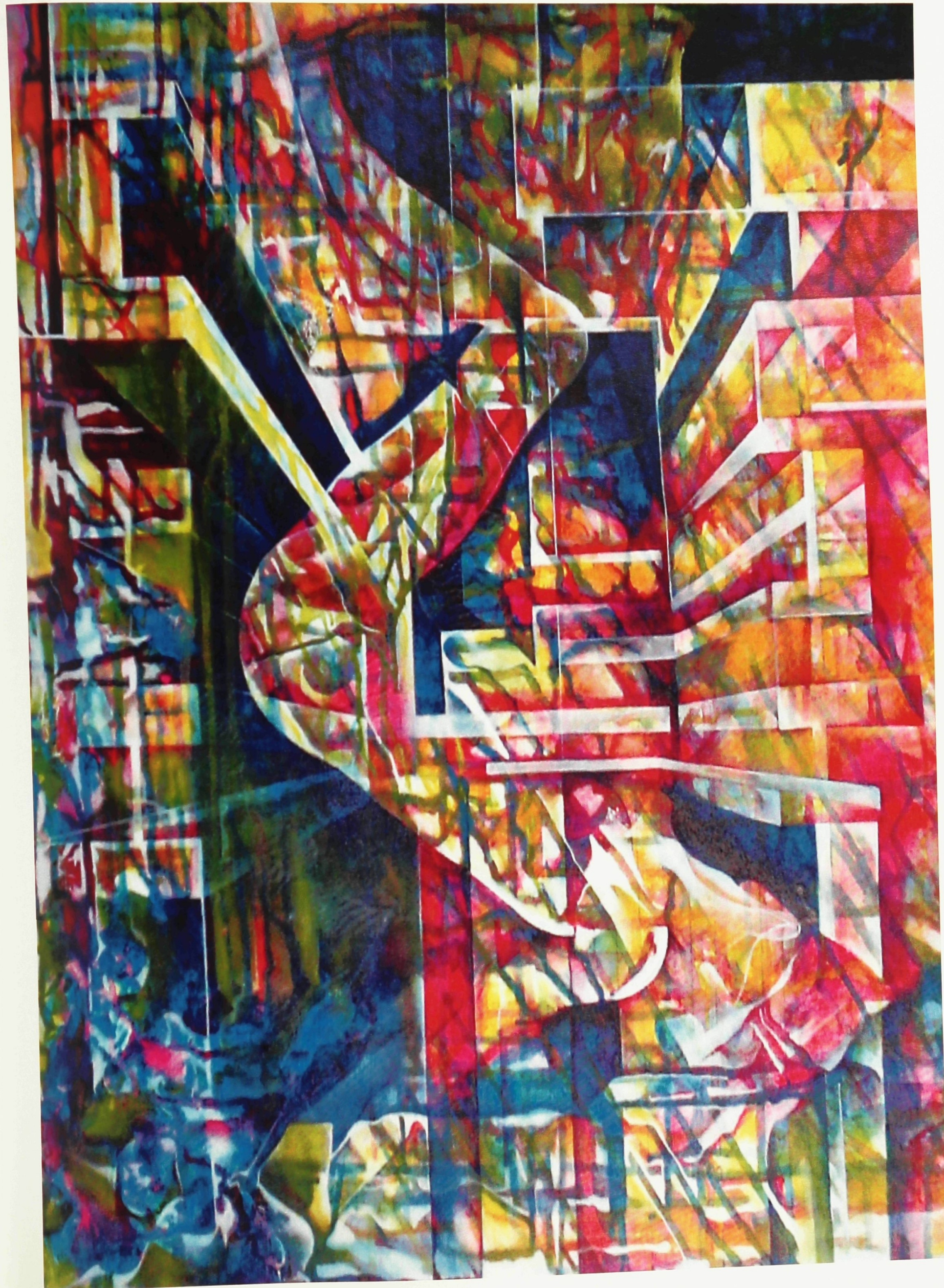


IPPENDIX-20. CANNIBAL COLLAGE

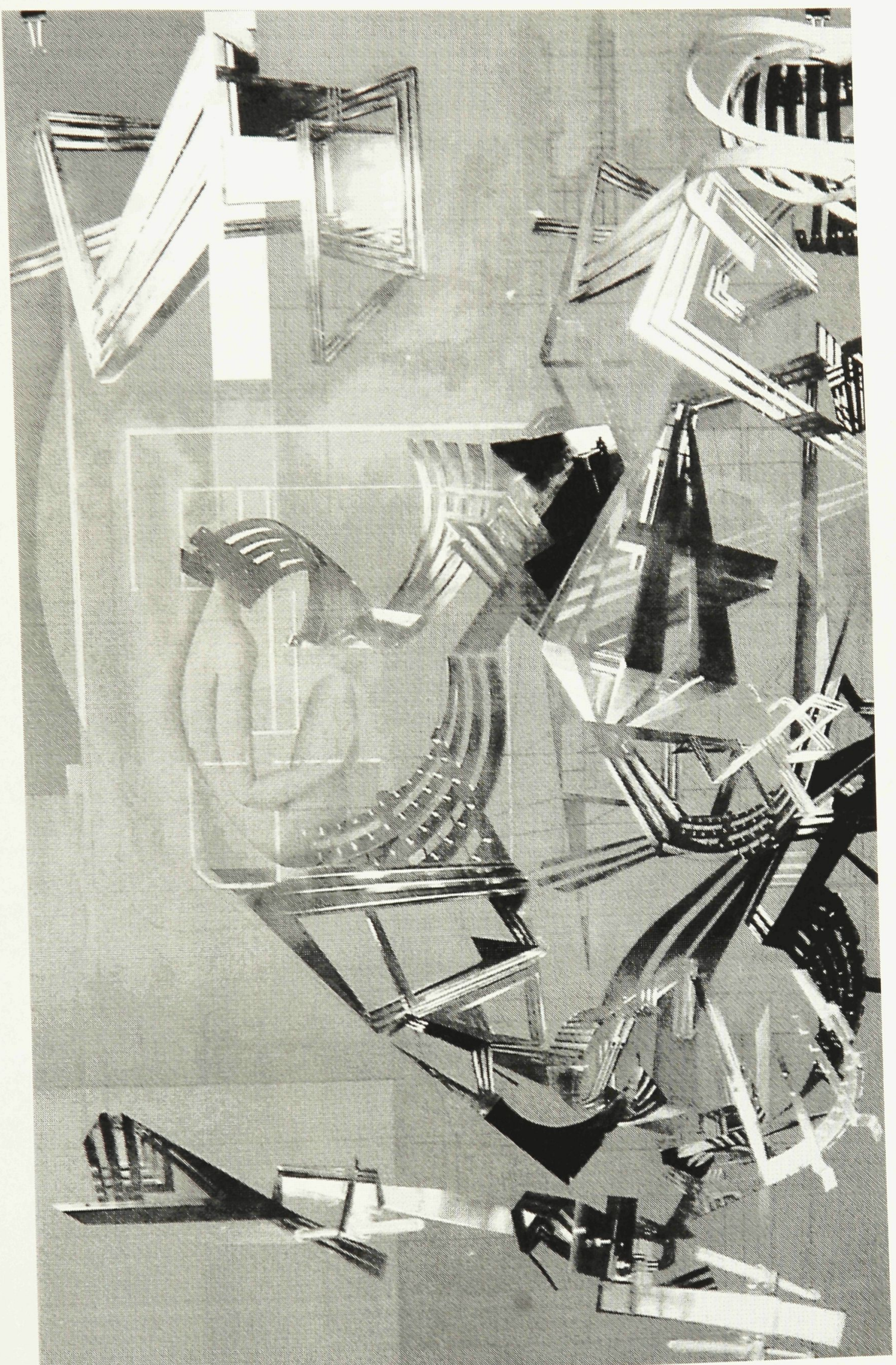




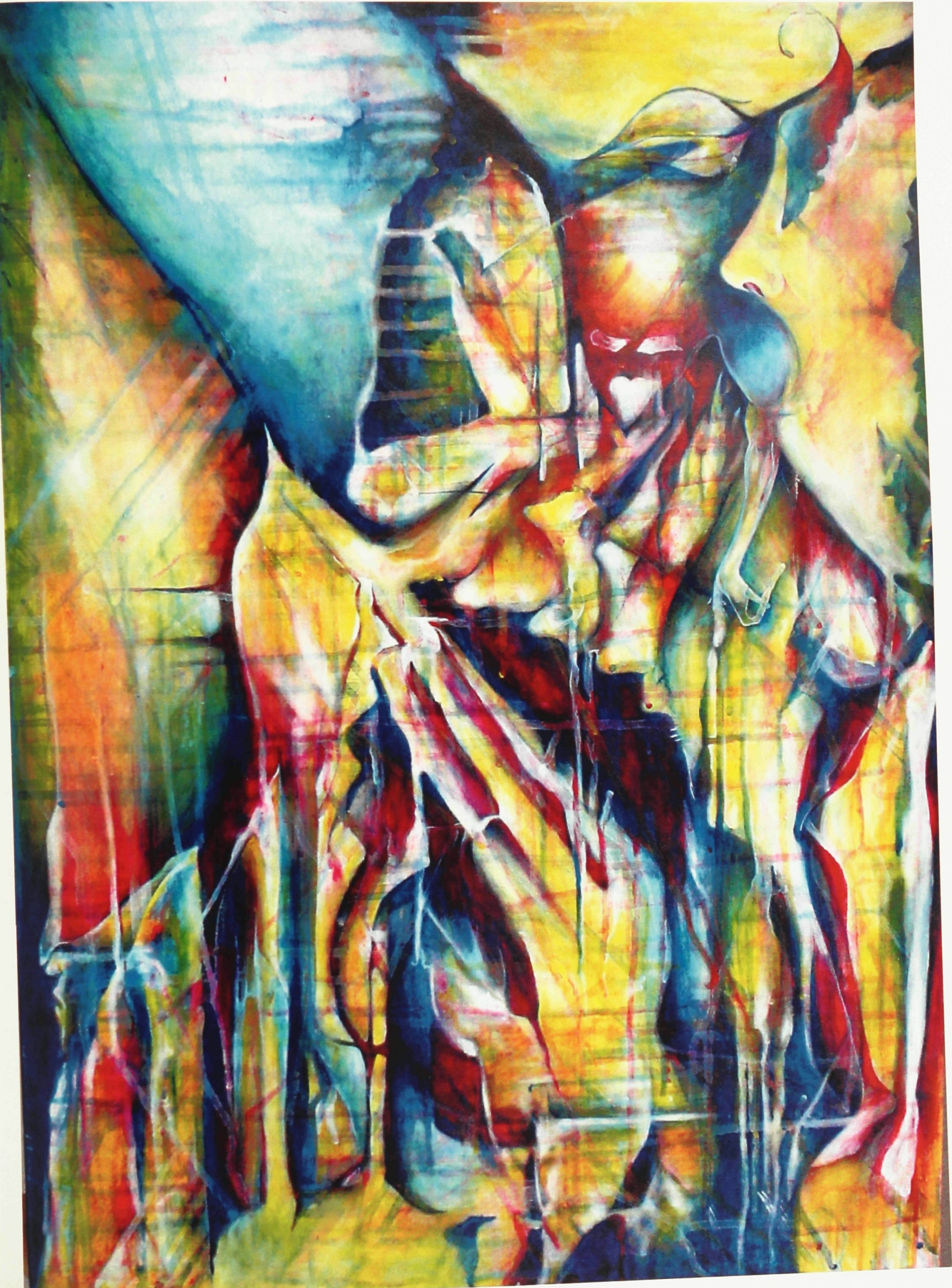




\section{Works Cited}

Alazracki, Jamie. Architecture as Outlook in Borges's Fiction. VIA 8 (1986) : 47-53.

---. $\quad$ Borges and the Kabbalah: And Other Essays on his Fiction and Poetry.

Cambridge: Cambridge UP, 1998.

Baulch, David, M. "Time, Narrative, and the Muliverse: Post-Newtonian Narrative in Borges's "The Garden of Forking Paths" and Blake's Vala or the Four Zoas." Comparatist 27 (2003) : 56-78.

Bering, Henrik. "Denmark, the Euro, And Fear of the Foreign." Policy Review 104 (2000). 7 May $2005<$ http://www.policyreview.org/dec00/Bering.html>.

Borges, Jorge Luis. El Aleph. Emecé Editores, 1968.

---. $\quad$ Ficciones. Buenos Aires, Emecé Editores, 1968.

Burgin, Richard. Conversations with Jorge Luis Borges. New York: Avon, 1969)

Casey, Lee, A and David B. Rivkin Jr. "Europe in the Balance." Policy Review 107

(2001). 7 May $2005<$ http://www.policyreview.org/jun01/casey.html .

Chibka, Robert, L. "The Library of Forking Paths.” Representations 56 (1996) : 106-122.

Cirlot, J.E. A Dictionary of Symbols. 2nd ed. Trans. Jack Sage. London: Routledge, 1993.

Cooksey, Thomas, L. "The Labyrinth in the Monad: Possible Worlds in Borges and Leibniz." The Comparatist 17 (1993) : 51-58.

Danow, David, K. "Toward a Theory of Transformation in Narrative (Borges and Cortazar)." American Journal of Semiotics 11. 3/4 (1994) : 87-101.

Davis, Stuart. "Rereading and Rewriting Traditions: The Case of Borges's "La Casa De Asterión." Romance Studies 22.2 (2004) : 139-148. 
De Behar, Lisa, Block. "Rereading Borges's “The Aleph.” CR 4.1 (2004) : 169-187.

De Marval-McNair, Nora. "Of Echos and Clones: Mirror Images in Borges's "The Approach to Al-Mutasim." Contributions to the Study of World Literature 122 (2003) : 303-309.

di Giovanni, Norman Thomas, ed. and trans. The Aleph and Other Stories. London:

Picador, 1973.

---. The Aleph and Other Stories. New York: E.P. Dutton, 1970.

Diamond, Larry. “Universal Democracy?” Policy Review 119 (2003). 7 May 2005 $<\mathrm{http}$ ://www.policyreview.org/jun03/diamond.html>.

Eisenman, Peter. "The End of the Classical: The End of the Beginning, the End of the End." Architecture Theory Since 1968. Ed. K. Michael Hayes. Cambridge/London: MIT P, 1998.

Elliot, T.S. Collected Poems 1909-1962. London: Faber and Faber, 1963.

Fóti, Véronique. "Turning at the Limits of Closure." Philosophy Today. Winter 1996: 306-316.

Frascari, Marco. Monsters of Architecture: Anthropomorphism in Architectural Theory. Savage, MD.: Rowman \& Littlefield, 1990.

Giskin, Howard. "Mystical Phenomenology of the Book in Borges." Revista Canadiense De Estudios Hispanicos. 14.2 (1990) : 235-47.

Grimal, Pierre. The Dictionary of Classical Mythology. Trans. A.R. Maxwell-Hyslop. Oxford: Blackwell, 1996.

Howse, Robert. “Kojeve’s Latin Empire.” Policy Review 126 (2004). 7 May 2005 $<$ http://www.policyreview.org/aug04/howse.html $>$. 
Hurley, Andrew, ed. Jorge Luis Borges: Collected Fictions. New York: Putnam, 1998.

Kant, Immanuel. Critique of Pure Reason. Ed. Vasilis Poltits. London: Everyman, 1993.

Kojeve, Alexandre. "Outline of a Doctrine of French Policy (August 27, 1945)." Trans. Erik De Vries. Policy Review 126 (2004). 7 May 2005 $<\mathrm{http}: / /$ www.policyreview.org/aug04/kojeve.html $>$.

Kenton, Warren. Adam and the Kabbalistic Tree. London: Rider, 1974.

Kunze, Donald and Wesley Wei. "The Vanity of Architecture: Topical Thinking and the Practice of Discontinuity." VIA 8 (1986) : 54-69.

Lingis, Alphonso. The Community of those who have Nothing in Common. Bloomington: Indiana UP, 1994.

---. The Imperative. Bloomington: Indiana UP, 1998.

Levi, Eliphas. The History of Magic. Trans. A.E. Waite. Boston: Weiser, 2001.

Mauss, Marcel. A General Theory of Magic. Trans. Robert Brain. London: Routledge, 1972.

“Meiosis." Dictionary of Literary Terms, (Toronto: Coles, 2005), 116.

Merleau-Ponty, Maurice. "Eye and Mind." The Primacy of Perception. ed. James M. Eddie. Evanston: Northwestern University Press, 1964. Pg. 159-190.

---. "The Chiasm" The Visible and Invisible. Ed. Alphonso Lingis. Evanston: Northwester University Press, 1968.

Paasi, Anssi. "Europe as a Social Process and Discourse: Considerations of Place, Boundaries and Identity." European Urban and Regional Studies 8.1 (2001) : 7 28.

Riley, Patrick. "Introduction to the Reading of Alexander Kojeve." Political Theory 9.1 
(1981) : 5-48.

Rivkin, Jeremy. The European Dream. New York: Tarcher, 2004.

Roth, Michael, S. "A Note on Kojeve's Phenomenology of Right." Political Theory 11.3 (1983) : 447-450.

---. "A Problem of Recognition: Alexandre Kojeve and the End of History." History and Theory 24.3 (1985) : 293-306.

---. “The Ironist’s Cage.” Political Theory 19.3 (1991) : 419-432.

Seiber, Sharon, Lynn. "Time and the Fantastic: Simultaneity in Borges, Cortázar, Lezama Lima, and Paz." Contributions to the Study of Science Fiction and Fantasy 104 (2003) : 23-28.

---. "Time, Simultaneity, and the Fantastic in the Narrative of Jorge Luis Borges." Romance Quarterly 51.3 (2004) : 200-211.

Sheridan, D. "The End of the World: Closure in the Fantasies of Borges, Calvino, and Millhauser." Contributions to the Study of World Literature. 118 (2003) : 9-24. Smulian, Dan. "Jorge Luis Borges, Author of "Alice Through the Looking Glass." Romance Quarterly 36.1 (1989) : 79-85.

Spivakovsky, Erika. “In Search of Arabic Influences on Borges.” Hispania 51.2 (1968) : 223-231.

Taylor, M. "Carnality: Maurice Merleau-Ponty" Alterity. Chicago: University of Chicago Press, 1987.

Taylor, T. "Cannibalism as a Universal Human Practice." British Archaeology 59 (2001) $: 8-12$.

Vellacott, Philip, trans. Euripides: Medea and Other Plays. London: Penguin, 1963. 
Weinberger, Eliot, ed. Jorge Luis Borges: Selected Non-Fictions. Trans. Allen, Esther, Suzanne Jill Levine and Eliot Weinberger. New York: Putnam, 2000.

Winchell, James. "The Oldest Trick in the Book: Borges and the "Rhetoric Immediacy." Studies in Twentieth Century Literature 17.2 (1993) : 197-221.

Wolin, Judith. "The Rhetorical Question." VIA 8 (1986) : 17-31.

Wyers Weber, Francis. "Borges's Stories: Fiction and Philosophy." Hispanic Review $36.2(1968): 124-141$.

Yates, Donald A. and James E. Irby, eds. and trans. Labyrinths, Selected Stories and Other Writings. New York: New Directions, 1964.

Zubinzarreta, Armando, F. "Borges and I," A Narrative Sleight of Hand." Studies in Twentieth Century Literature 22.2 (1998) : 371-381. 


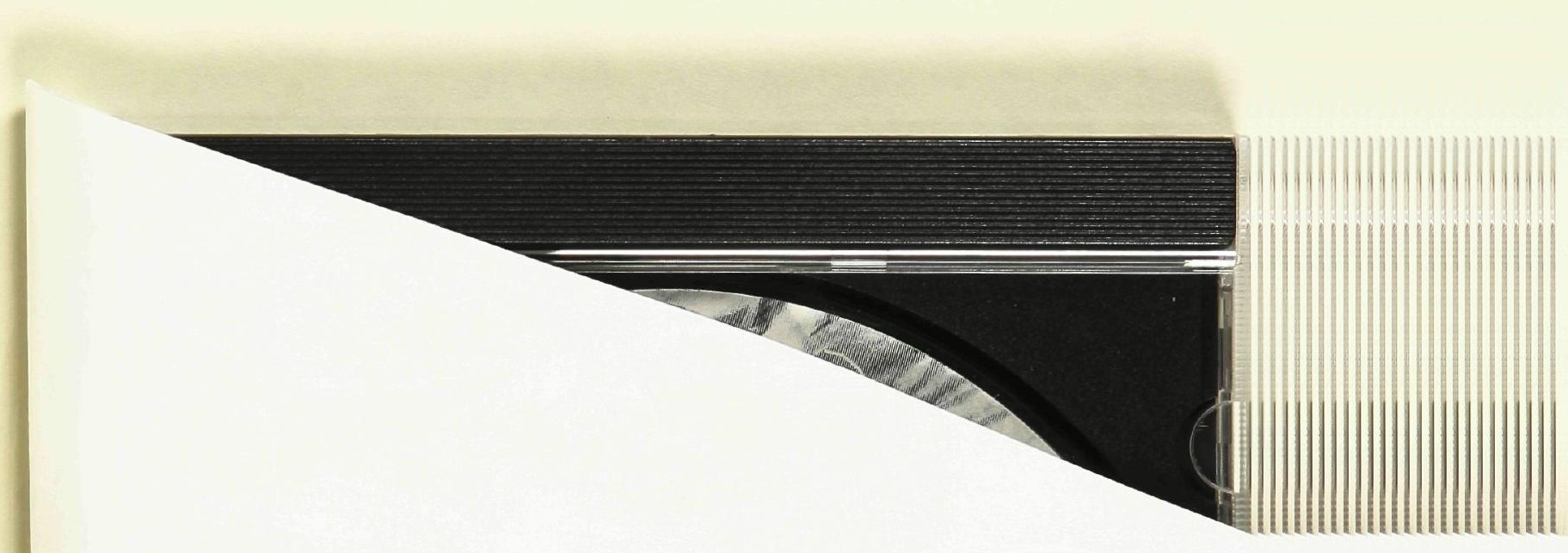

